\title{
A Catalysis Guide Focusing on C-H Activation Processes
}

\author{
Renato L. Carvalho, ${ }^{a}$ Gleiston G. Dias, ${ }^{a}$ Cynthia L. M. Pereira, ${ }^{a}$ Pintu Ghosh, ${ }^{b}$ \\ Debabrata Maiti ${ }^{\circledR} *, b$ and Eufrânio N. da Silva Júnior ${ }^{\circledR} * a$ \\ ${ }^{a}$ Departamento de Química, Instituto de Ciências Exatas, Universidade Federal de Minas Gerais, \\ 31270-901 Belo Horizonte-MG, Brazil \\ ${ }^{b}$ Department of Chemistry, IIT Bombay, Powai, 400076 Mumbai, India
}

\begin{abstract}
From the recent development of catalytically controlled $\mathrm{C}-\mathrm{H}$ activation with amenable synthetic routes obviating many challenges, the demand for this strategy has raised significantly to perform complex organic transformations. The impact of the achieved results in both homogeneous and heterogeneous catalysis reflects its efficacy in modern synthetic chemistry. A consolidated report and guidance of the methodologies involved in the previous and ongoing research in this domain would be very useful for the researchers to focus on more specific and selective $\mathrm{C}-\mathrm{H}$ activation reactions to access desired complex molecular scaffolds. The perspective of this review is to contribute to the scientific community with examples, tips and details of modern development in this field and with a complete illustration of the routes which may be effective for planning of the ubiquitous $\mathrm{C}-\mathrm{H}$ bond activation and its use for synthesis of relevant organic molecules.
\end{abstract}

Keywords: catalysis, $\mathrm{C}-\mathrm{H}$ activation, guidance, characterization

\section{Introduction}

Homogeneous $^{1-7}$ or heterogeneous ${ }^{8-13}$ catalysis are powerful tools in the field of organic synthesis to generate new molecules with potential biological properties. ${ }^{14-16}$ Some of these molecules require several steps to be achieved, ${ }^{17,18}$ sometimes involving complex and expensive catalysts. ${ }^{19-21}$ In this platform, $\mathrm{C}-\mathrm{H}$ activation methods have been showing useful applications, ${ }^{22-26}$ since it can potentially reduce the number of steps and time-span involved in an organic synthesis effectively and with better regio- and stereoselectivities.

It is difficult to predict when the studies on direct $\mathrm{C}-\mathrm{H}$ activation specifically started (Figure 1), but one of the oldest known works was published in 1902 by Otto Dimroth. ${ }^{27}$ In this study, he was able to directly attach a mercury(II) species to the unactivated benzene ring (1), without the need of any halide or other substituent to act as a leaving group. Since then, several efforts had been made throughout the years to develop new catalytic systems and ligands capable of, in a single step, providing structurally complex molecules, simplifying the process of production of any compound. The work published by Janowicz and Bergman ${ }^{28}$ in 1982 was a remarkable example

*e-mail: dmaiti@iitb.ac.in; eufranio@ufmg.br that introduced the possibility of deploying transition metals as a catalyst for intermolecular $\mathrm{C}-\mathrm{H}$ activation where a least reactive $\mathrm{C}\left(\mathrm{sp}^{3}\right)-\mathrm{H}$ bond from compound $\mathbf{3}$ had been activated using an iridium catalyst. Until the present day, transition metals are the ones that offer the best performances in the field of $\mathrm{C}-\mathrm{H}$ activation reactions. ${ }^{29-33}$ Nowadays, not only the usual ortho-C-H activations ${ }^{34,35}$ can be achieved, but also meta ${ }^{36,37}$ or even para-C-H activations $^{38,39}$ can also be attained.

The $\mathrm{C}-\mathrm{H}$ activation has exponentially enhanced in synthetic chemistry, with thousands of publications per year only in the last few decades (Figure 2). Despite this fact, in Brazil, it is still a very incipient topic (Figure 3). In the last year, only 17 publications ( $1 \%$ of global records) have been contemplated on this subject. When compared to 960 publications from China (38\%), 381 publications from the USA (15\%), or 280 publications from India (11\%), it can be noted that Brazil can better explore this topic and be among the most influential countries on its subject in the future.

The general $\mathrm{C}-\mathrm{H}$ activation mechanism involves the cleavage of $\mathrm{C}-\mathrm{H}$ bond and formation of a $\mathrm{C}-\mathrm{M}$ bond, coordinated by the directing groups or any other coordinating ligands resulting in a cyclometallation process followed by insertion of the functional group. ${ }^{40}$ There are several peculiarities concerning this general 
Dimroth $^{27}$

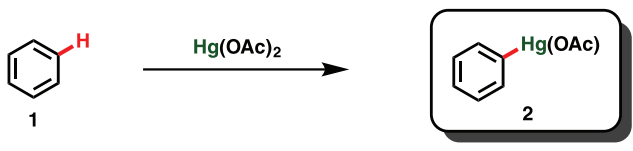

Janowicz and Bergman ${ }^{28}$
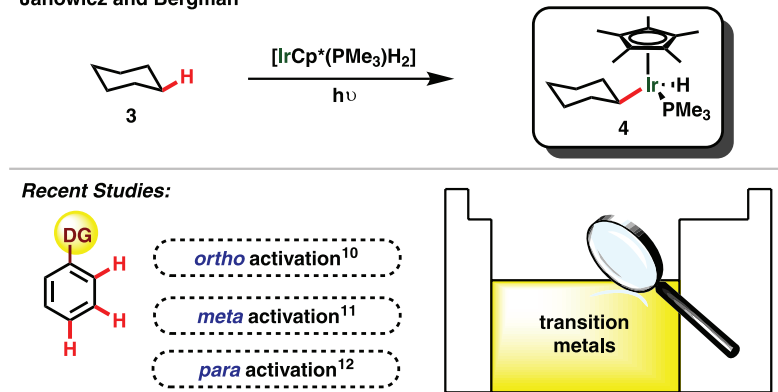

Figure 1. Overview of the historical development of the catalytic C-H activation procedures. ${ }^{10-12,27,28}$

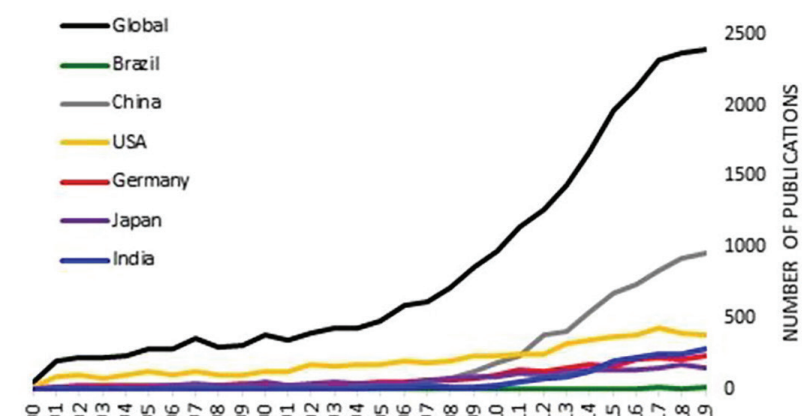

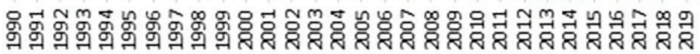
PUBLICATION YEAR

Figure 2. The number of publications covering the topic " $\mathrm{C}-\mathrm{H}$ activation" (Web of Science, data collected on July 10 $10^{\text {th }}, 2020$ ).

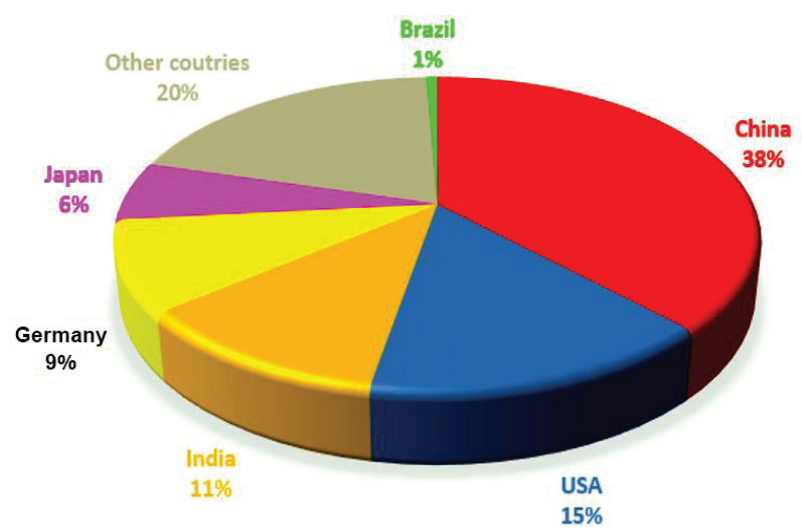

Figure 3. Global contribution to the publications covering the topic " $\mathrm{C}-\mathrm{H}$ activation" from 2019. (Web of Science, data collected on July 10 $10^{\text {th }}, 2020$ ).

mechanism, which depends on the catalyst (metal, the oxidation state of the metal, ligand(s), steric and electronic properties) as well as the substrate involved in the reaction. However, the key step of the reaction is still the (cyclo) metallation.

The interaction of the $\mathrm{C}-\mathrm{H}$ bond with the metal leads to the weakening and breakage of the $\mathrm{C}-\mathrm{H}$ bond. This process occurs via two-path charge transfer (CT): (i) Path 1: from the occupied $\mathrm{d}_{\pi}$ orbital or the metal to the $\sigma^{*}{ }_{\mathrm{C}-\mathrm{H}}$ orbital (reverse CT process), then;

(ii) Path 2: charge transfer from the filled $\sigma_{\mathrm{C}-\mathrm{H}}$ orbital to an empty $d_{\sigma}$ orbital of the metal (forward CT process). ${ }^{41}$

Electron deficient metal species, such as cationic and late transition metals $\left(\mathrm{Pd}^{\mathrm{II}}, \mathrm{Pt}^{\mathrm{II}}, \mathrm{Rh}^{\mathrm{III}}, \mathrm{Ir}^{\mathrm{III}}\right.$ and $\left.\mathrm{Ru}^{\mathrm{II}}\right)$, usually exhibit low-energy $\mathrm{d}_{\pi}$ and $\mathrm{d}_{\sigma}$ electrons. Therefore, metallation occurs via a forward CT process, related to coordination of strong $\sigma$-donation with weak $\pi$-backdonation resulting in electrophilic $\mathrm{C}-\mathrm{H}$ activation, and a heterolytic cleavage followed by deprotonation assisted by external anion. On the other hand, electron-rich transition metal complexes exhibit high-energy $\mathrm{d}_{\pi}$ and $\mathrm{d}_{\sigma}$ electrons promoting the reverse $\mathrm{CT}$, which defines a nucleophilic $\mathrm{C}-\mathrm{H}$ activation. In addition, $\mathrm{C}-\mathrm{H}$ activation mechanism pathways have been widely described in the literature, as it follows:

(i) Oxidative addition: electron-rich late transition metals (i.e., low oxidation states) coordinate via $\mathrm{d}_{\pi}$-back-donation to the $\sigma^{*}{ }_{\mathrm{C}-\mathrm{H}}$ orbital resulting in a strong and synergistic interaction promoting homolytic bond cleavage and oxidation of the metal center in two units (Scheme 1a);

(ii) $\sigma$-bond metathesis: $\sigma$-bond metathesis reactions are facile with early transition metals (electrons deficient metals ${ }^{42}$ via a four-member metallacyclic transition state without oxidation of the metal (Scheme 1b);

(iii) Electrophilic activation: very often feasible with electrondeficient late-stage transition metals (Scheme 1c); ${ }^{43-45}$

(iv) 1,2 Addition: the $\mathrm{M}=\mathrm{X}$ functionality $\left(\mathrm{X}=\mathrm{CR}_{2}, \mathrm{CR}\right.$, $\left.\mathrm{NR}_{2}, \mathrm{NR}, \mathrm{OR}\right)$ adds to a $\mathrm{C}-\mathrm{H}$ bond via formal $[2 \sigma+2 \pi]$ reaction (Scheme 1d); ;6,47

(v) IES (internal electrophilic substitution): mechanisms via electrophilic attack of the metal and deprotonation

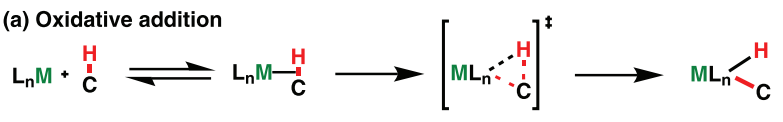

(b) $\sigma$-bond metathesis

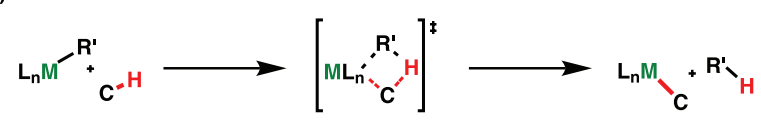

(c) Electrophilic substitution

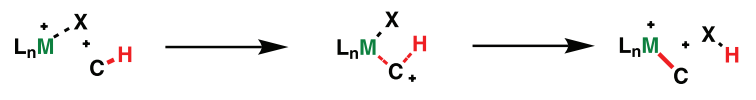

(d) 1,2-addition

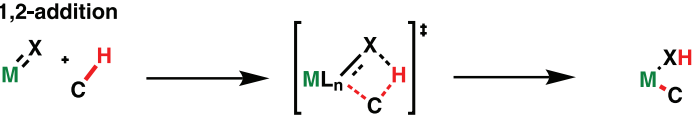

(e) Internal electrophilic substitution (IES)

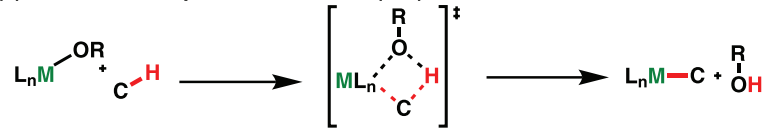

Scheme 1. Most common proposed mechanism pathways. 
by alkoxy ligand via a four-membered transition state (Scheme 1e). ${ }^{48}$

Proposed mechanisms of $\mathrm{C}-\mathrm{H}$ activation reactions carried out using a metal bearing a Lewis-basic ligand, such as oxygen-containing carboxylates, have been investigated by experimental and computational studies. In this sense, Lapointe and Fagnou ${ }^{49}$ proposed a concerted metallation-deprotonation (CMD) (Scheme 2a), whereas MacGregor and co-workers ${ }^{50}$ (Scheme 2b) proposed a CMD with the participation of the hydrogen atom based on an amphiphilic metal-ligand activation (AMLA). The approach of a base-assisted internal electrophilic substitution (BIES) has been pointed out as well (Scheme $2 \mathrm{c})^{51-53}$ in the case of electron-rich arenes with acetate or carboxylate ligands.

(a) CMD

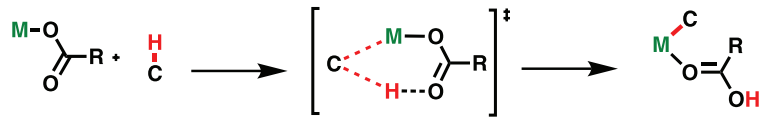

(b) AMLA
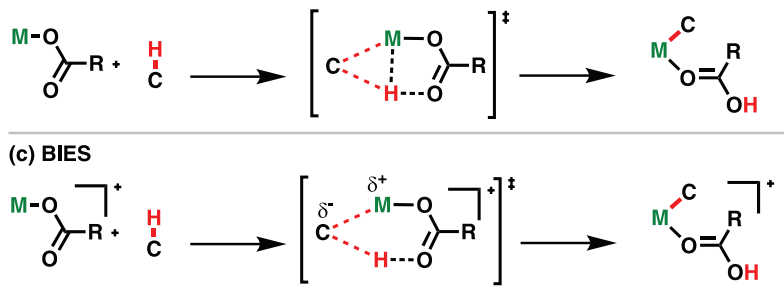

Scheme 2. Base-assisted C-H activation proposed mechanism.

The authors wish this review article will provide a plethora of catalytic guidance to every researcher in this field to carry out the challenging organic synthesis, with excellent selectivities and high yield, starting from the very first idealization until the last experimental procedures of $\mathrm{C}-\mathrm{H}$ functionalization concomitant characterizations, investing least expenses and time.

\section{Innate and Guided Selectivity in $\mathbf{C}-\mathrm{H}$ Bond Activation}

Regioselectivity is one of the key challenges of the reaction planning employing $\mathrm{C}-\mathrm{H}$ activation, which may be achieved via innate selectivity or guided selectivity. ${ }^{54,55}$ In the first case, electronic or steric effects would induce the regioselectivity. For instance, bulky groups can sterically hinder nearby $\mathrm{C}-\mathrm{H}$ bonds, whereas other similar bonds remain available to activate, or $\mathrm{C}-\mathrm{H}$ bonds with relatively higher kinetic acidity will be more susceptible to react (Scheme 3a). In a guided selectivity, Lewis-basic groups, named directing groups (DG), coordinate to the transition metal catalyst followed by $\mathrm{C}-\mathrm{H}$ bond metallation close to the $\mathrm{C}-\mathrm{H}$ bond. One of the most traditional approaches involves ortho-activation via cyclometallation, as shown in Scheme $3 \mathrm{~b}$.

Several groups have been used as DG, such as pyridine,${ }^{56}$ triazole, ${ }^{57}$ pyrazole $(\mathbf{1 8}),{ }^{58}$ amide $(\mathbf{1 1}),{ }^{59}$ ester (10), ${ }^{60}$ carboxylic acid (9) ${ }^{61}$ ketone $\left(\mathbf{1 2}\right.$ and 13) ${ }^{62}$ aldehyde (8) ${ }^{63}$ and others ${ }^{64}$ (Scheme 3c). Modifiable ${ }^{65}$ and removable ${ }^{66}$ DGs have been raised as important strategies when planning different $\mathrm{C}-\mathrm{H}$ activation reactions.
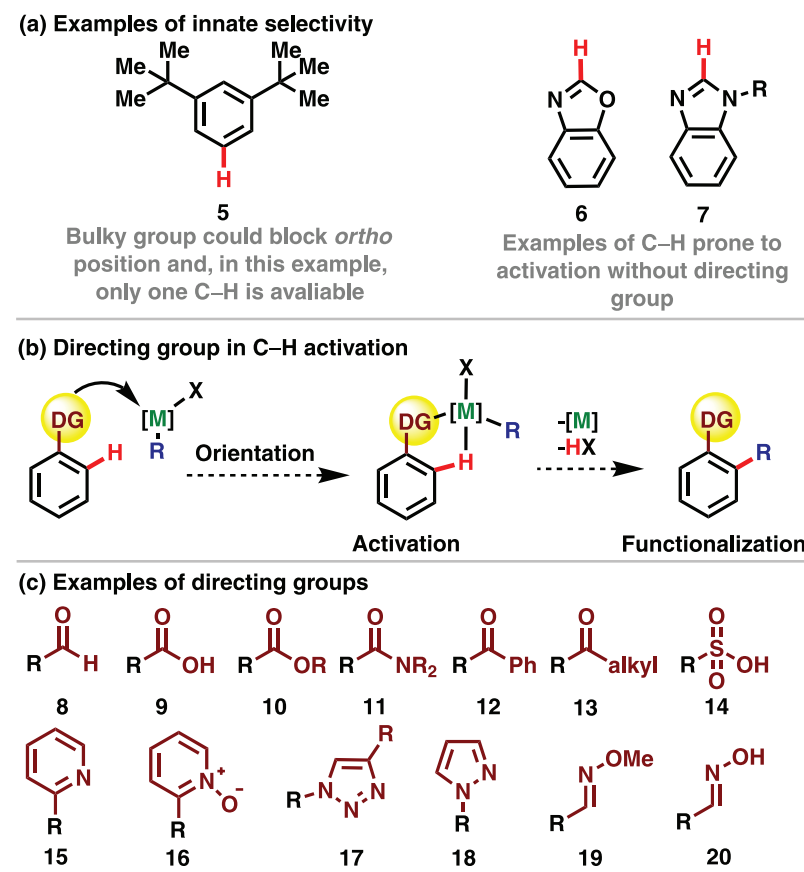

Scheme 3. (a) Innate selectivity via steric and electronic properties, (b) guided selectivity and (c) examples of directing groups.

A work published in 2016 by da Silva Júnior and co-workers, ${ }^{67}$ exemplifies the importance of analyzing the potential orientation that an innate directinggroup may offer (Scheme 4). In this case, an elegant synthetic strategy was performed to transform the highly electrophilic benzoquinone into a nucleophilic substrate under rhodium-catalysis. The challenge of multiple competing sites for $\mathrm{C}-\mathrm{H}$ activation was overcome and the proof-of-concept was established via $\mathrm{C}-\mathrm{H}$ iodination, bromination, and phenylselenation of benzoquinone using a mild and general synthetic method. The products 22-25 and $\mathbf{2 7}$ were achieved in good yields with high selectivity. Biological studies performed later had appointed that those benzoquinones exhibit potent trypanocidal activity. In all transformations, the introduction of an external directinggroup was not necessary since the carbonyl groups present on the quinone itself act as powerful directing groups.

Strategy: observe if the molecule of interest has any group that can act as DG! If not, is it possible to insert a DG, specially a removable one? 
da Silva Júnior and co-workers ${ }^{67}$
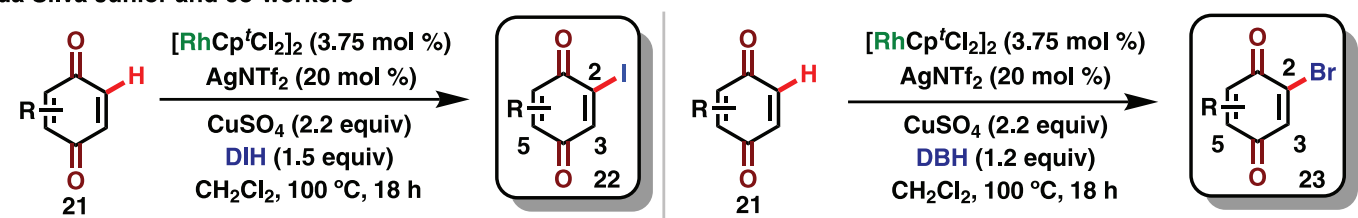<smiles>O=C1C=CC(=O)C(I)=C1</smiles>

$22 \mathrm{a}(95 \%)$<smiles>COC1=C(I)C(=O)C=CC1=O</smiles>

22d (91\%)<smiles>CC1=CC(=O)C=C(I)C1=O</smiles><smiles>[10BH2][14CH3]</smiles><smiles>CC(C)(C)C1=CC(=O)C(I)=CC1=O</smiles>

$22 \mathrm{e}(84 \%)$<smiles>CC1=CC(=O)C(C)=C(C)C1=O</smiles>
22c $(81 \%)$<smiles>CC1=CC(C)C(Cl)=C(Cl)C1=O</smiles>
$22 f(56 \%)$
Scope (examples):<smiles>O=C1C=CC(=O)C(Br)=C1</smiles>

23a $(82 \%)$<smiles>COC1=C(Br)C(=O)C=CC1=O</smiles>

23d $(74 \%)$<smiles>O=C1C=CC(=O)C(Br)=C1</smiles><smiles></smiles><smiles>CC(C)(C)C1=CC(=O)C(Br)C(=O)C1</smiles>

23 e $(57 \%)$ (C2:C3 = 10:1)<smiles>CC1=C(C)C(=O)C(Br)=CC1=O</smiles>

23c (degradation)<smiles>O=C1C=C(Br)C(=O)C(Cl)=C1Cl</smiles>

$23 f(45 \%)$

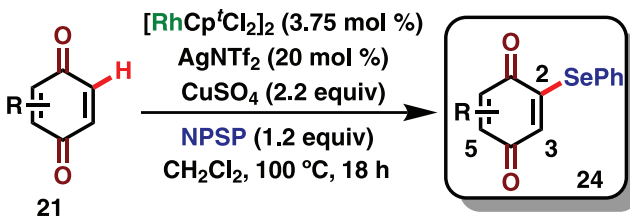

21

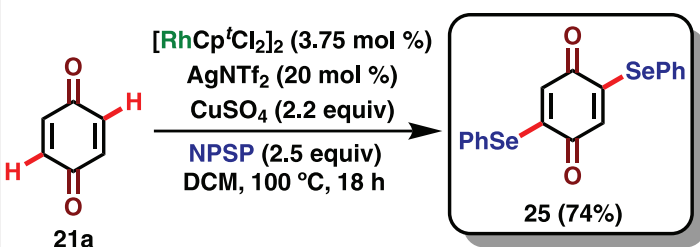

Scope (examples):<smiles>O=C1C=CC(=O)C([Se]c2ccccc2)=C1</smiles>

$24 a(61 \%)$<smiles>C[C@H]1C(=O)C=C([SeH])C(=O)C1=O</smiles>

24b (73\%)<smiles>O=C1C=C(Br)C(=O)C2CCCCC12</smiles>

24c (73\%)

(C2:C3 = 5:2)
$\left[\mathrm{RhCp}^{t} \mathrm{Cl}_{2}\right]_{2}$ (3.75 mol \%) $\operatorname{AgNTf}_{2}(20 \mathrm{~mol} \%)$ $\mathrm{CuSO}_{4}$ (2.2 equiv) NPSP (1.2 equiv) $\mathrm{DCM}, 100^{\circ} \mathrm{C}, 18 \mathrm{~h}$

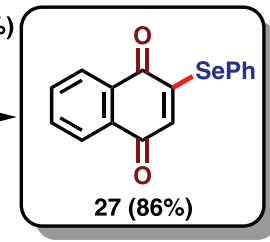

Scheme 4. Example of successful rhodium-catalyzed $\mathrm{C}-\mathrm{H}$ activation processes using quinones as innate directing-groups ${ }^{67}$

Bidentate directing groups (BDG) is a particular case in the rational planning of a $\mathrm{C}-\mathrm{H}$ activation. The strategy involves a fine, tunable, and reversible coordination with the assistance of different structures such as $\mathrm{N}$-dentate, $\mathrm{N}, \mathrm{O}$-dentate, and $\mathrm{N}, \mathrm{S}$-dentate $\mathrm{DG}$, as exemplified in Scheme 5. Basically, BDG must be designed to be stable during the activation step, and besides, BDG should reversibly coordinate to the metal. The key point of using this class of directing groups is the formation of thermodynamically stable chelate intermediates, which could facilitate the metallation process. Chatani and co-workers ${ }^{68}$ recently reviewed the chemistry involving bidentate directing groups.

\section{Remote $\mathbf{C}-\mathbf{H}$ Bond Activation Assisted by Template}

Although ortho- $\mathrm{C}-\mathrm{H}$ bond activation has been widely investigated, several studies involving distal metaand para- $\mathrm{C}-\mathrm{H}$ activation have been described in the literature. ${ }^{69,70}$ This approach is possible by using molecular templates, which could act as directing groups (DG) to access remote functionalization via macrocyclic transition state, as illustrated in Scheme 6.<smiles>[R]/C=C(/[R])C(=O)Nc1cccc2cccnc12</smiles>

28<smiles>C=C(/C=C\C)NS(=O)(=O)c1ccccn1</smiles>

32<smiles>[R]C(=CC)C(=O)Nc1ccccc1C1=NC2COC12</smiles><smiles>CC(C)C(C)C(=O)NC(=O)c1ccccn1</smiles><smiles>O=C(NC1CCCCC1)c1nnn(Cc2ccccc2)c1-c1ccccc1</smiles>

30 31 R.<smiles>O=C([Hg])/C=C\C(=O)Nc1cccc[n+]1[O-]</smiles>
$R$.<smiles>C/C=C\CNC(=O)C(C)=O</smiles><smiles>[R]/C=C(/[R])CNC(C)(C)C(=O)O/C(C)=C(\C)C(=O)NC(C)(C)c1ccccn1</smiles>

Scheme 5. Examples of bidentate directing groups (BDG). 


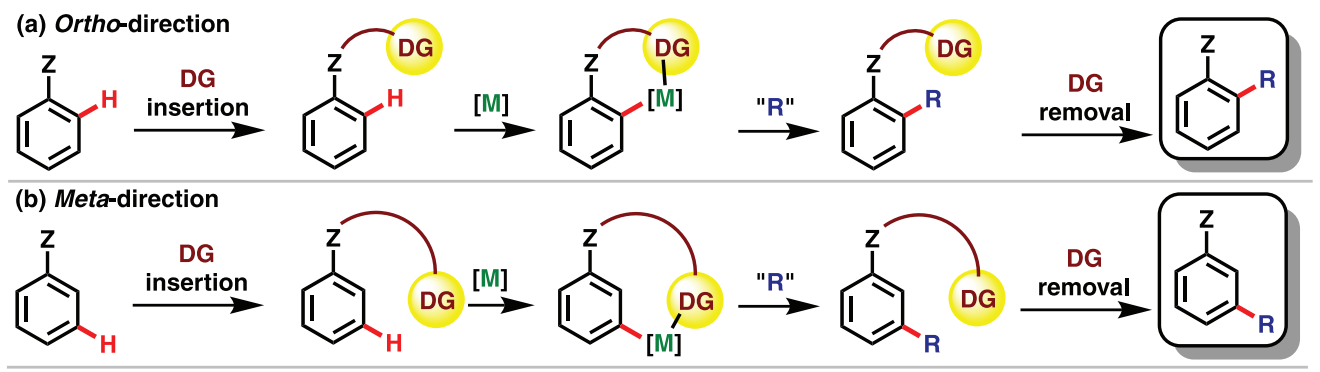

(c) Para-direction

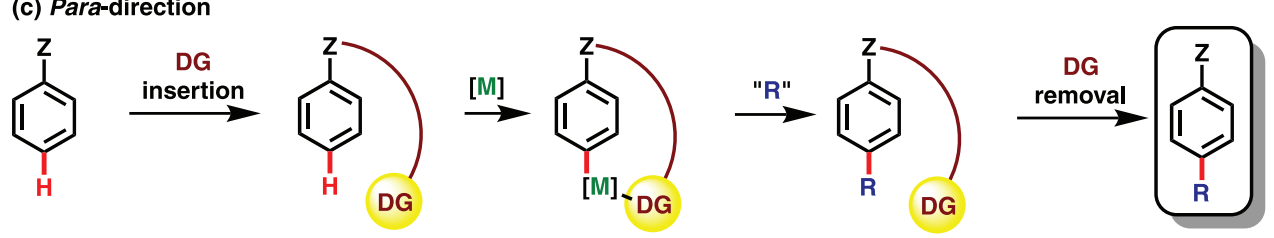

Scheme 6. Schematic representation of template assistance in remote $\mathrm{C}-\mathrm{H}$ activation.

Template groups for distal $\mathrm{C}-\mathrm{H}$ activation are based on long-chain groups bearing a coordinative site, usually nitrile, capable of binding to the metal to activate the distal meta- or para-C-H bond, often followed by the removal of this template. For example, in a pioneering work, $\mathrm{Yu}$ and co-workers ${ }^{69}$ have designed a DG template for selective $\mathrm{C}-\mathrm{H}$ alkenylation of benzylic alcohol derivative 37 , followed by removal of DG and reduction of the alkenyl moiety to provide the desired product 39 (Scheme 7).

The distal para-C- $\mathrm{H}$ activation represents a challenge due to the formation of a large macrocyclic transition state, which is associated with a significant entropy barrier, and should be selective over innately reactive $\mathrm{C}-\mathrm{H}$ bonds. To overcome this synthetic limitation, Maiti and co-workers ${ }^{70}$ had designed the biphenyl-based ligand via an ether linkage to an alkyl-substituted silicon center bearing a nitrile to activate the distal para-C-H bond. This template exhibits the required feature related to the nature and length of the linker. An example of the use of this template was applied to para-C-H bond acetoxylation. Furthermore, similar reaction conditions were applied on para-C-H bond alkenylation reaction, followed by the removal of this template (Scheme 8).

Several other molecular groups toward meta- and para-C-H activation have been addressed to overcome the limitation on accessing distal $\mathrm{C}-\mathrm{H}$ bonds. Some examples of other templates are depicted in Scheme 9. Further information about this class of reaction can be found in the literature..$^{71,72}$

Based on these examples, it is possible to conclude that a directing group can be modulated to achieve specific activation of ortho-, meta- or para-C-H bonds. Although, the latter still represents a more significant challenge.

Lewis-base groups, such as nitrile (Scheme 9) can be located on a strategic position of the directing group to provide the remote para-C- $\mathrm{H}$ activation overriding the ortho or meta position, typically accessible by the other directing groups previously described. In other words, to establish high regioselectivity in $\mathrm{C}-\mathrm{H}$ activation processes, the directing group can be designed to activate one specific desired position. The diisopropyl substituted silyl groups as implemented for the para-directing group in Scheme 8, for instance, leads to a highly strained moiety with a larger silicon-carbon and silicon-oxygen bond distance, inducing a 'Thorpe-Ingold effect' that results in a steric hindrance of ortho position. In contrast, the flexible phenyl-nitrile group promotes para-C- $\mathrm{H}$ activation. ${ }^{73}$

\section{Substrate Selection}

The target molecule of a $\mathrm{C}-\mathrm{H}$ activation study represents a key point in the development or application of this catalytic approach. Several reports ${ }^{53,58}$ had described the

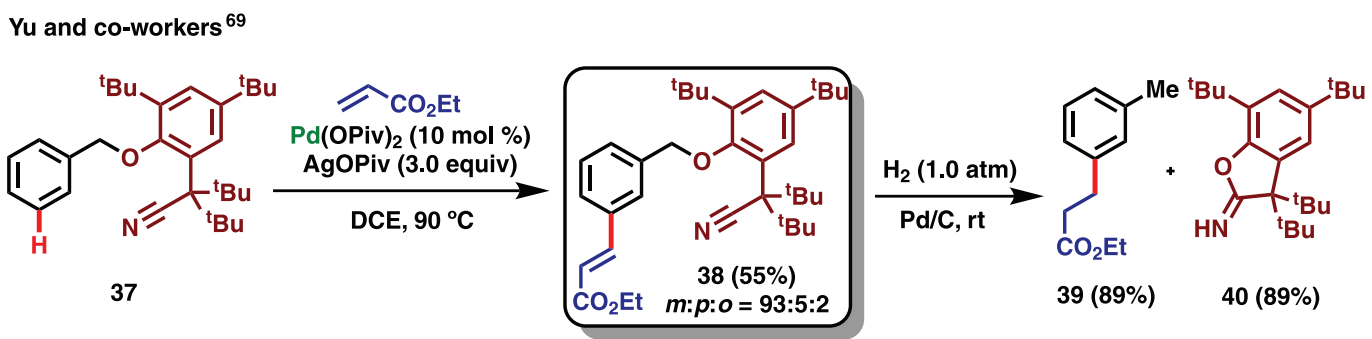

Scheme 7. Template DG designed to selective C-H alkenylation of benzylic alcohol derivatives, followed by DG removal reported by Yu and co-workers. ${ }^{69}$ 


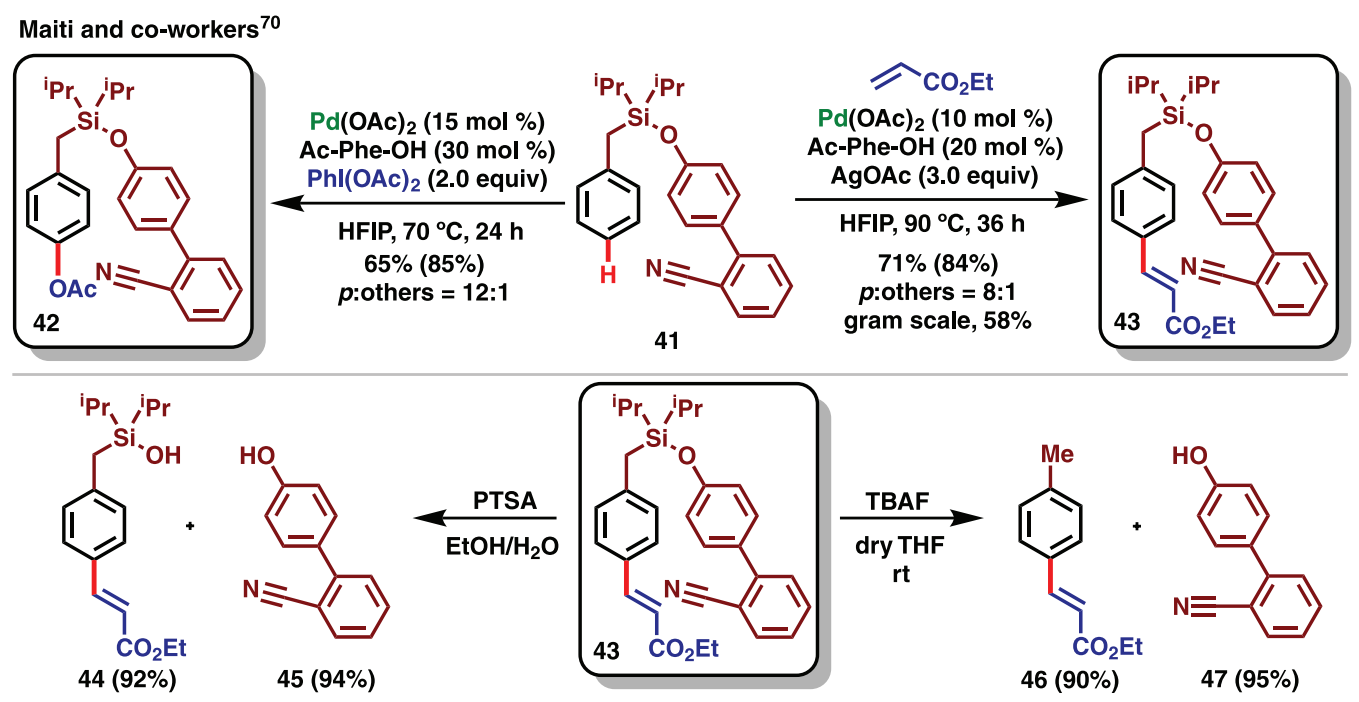

Scheme 8. Distal para-C-H activation of arenes assisted by biphenyl template-based assembly reported by Maiti and co-workers. ${ }^{70}$

(a) Examples of templates for meta-C-H activation<smiles>[R]N(c1ccccc1C)c1ccccc1C#N</smiles>

48<smiles>[2H]C(=O)C(F)Oc1ccccc1C#N</smiles>

49<smiles>[R]Oc1ccc(OC)cc1C#N</smiles>

50

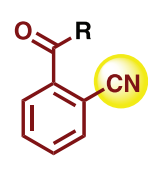

51

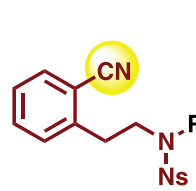

52

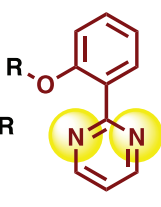

53

(b) Examples of templates for para-C-H activation
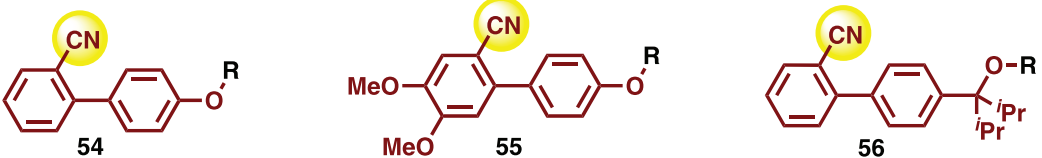

Scheme 9. Examples of template for distal meta- and para-selective $\mathrm{C}-\mathrm{H}$ activation.

use of small molecules as a platform to forge this protocol in organic synthesis with an emphasis on catalysis.

The choice of these substrates is based on the simplicity to obtain (either by synthetic or commercial means), purification and characterization, mainly when respective products have already been described in the literature. Besides that, it is crucial to prove the applicability of the developed reaction toward similar substrates, which requires a small library of similar starting material substrates with electron-withdrawing groups (EWGs) or electron-donating groups (EDGs). If those starting materials demand several synthetic steps or they are expensive, the scope will be reduced, which will affect its respective applicability. Substituted arenes are the simplest examples of substrate used for $\mathrm{C}-\mathrm{H}$ activation studies due to the features previously described: accessible derivatization and characterization.

The position of substituents relative to the directing group is an important feature to be observed. Meta-substituents in relation to the directing group (asymmetrically disubstituted molecules) can lead to the formation of two products from the two available ortho-C-H bonds (Scheme 10a).
Although in some cases, even this asymmetry can lead to a regioselective product.

Considering an ortho-orientating directing group, substrates with one blocked ortho-position usually leads to a single product, even in the presence of other substituents (Scheme 10b). It is noteworthy that substrates with a blocked ortho-position offer an important strategy in the development of selective $\mathrm{C}-\mathrm{H}$ bond activation protocols. On the other hand, para-substituents related to the directing group do not influence the regioselectivity of the reaction since both ortho-C-H bonds are equivalent (Scheme 10c).

For instance, Ackermann and co-workers ${ }^{53}$ developed a $\mathrm{C}-\mathrm{H}$ alkenylation strategy using 2,5-dimethylbenzenesulfonic acid $\mathbf{5 7}$ as a substrate with the orthoposition blocked with a methyl group and a single product was observed (Scheme 11). Dixneuf and co-workers ${ }^{58}$ reported a similar reaction using pyrazole as directing group in substrate $\mathbf{5 9}$, with the ortho position blocked by a methoxy group, leading to a single product $(\mathbf{6 0})$ as well (Scheme 11). However, when both ortho-positions were available (61), mono and di-alkenylated products 
(a)

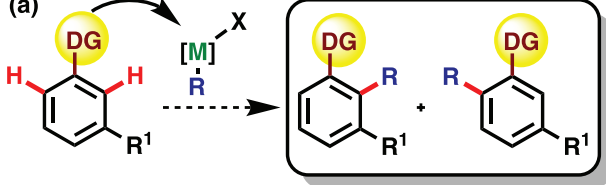

Possible mixture of products resulting in two ortho-C-H functionalized products.

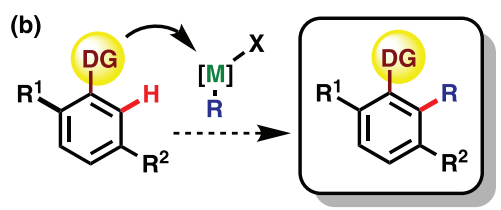

Only one produt is expected since one ortho-position of the substrate is blocked.

(c)

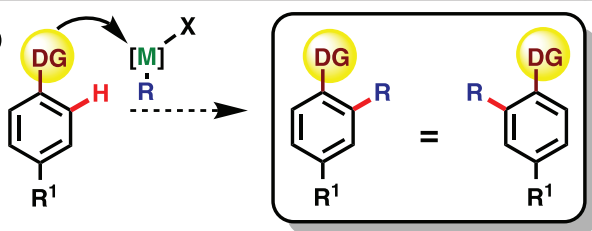

Only one product is expected in the case of symetric substrates, for example, substrates with a para-positioned substituent relative to the DG.

Scheme 10. Isomeric effect of substituents on the substrate (starting materials).

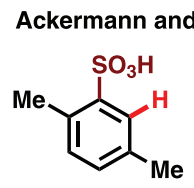

57

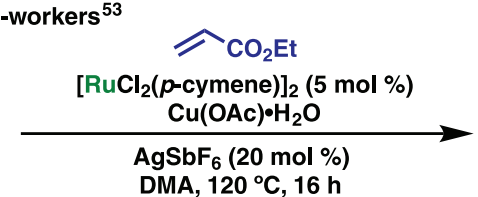

DMA, $120^{\circ} \mathrm{C}, 16 \mathrm{~h}$

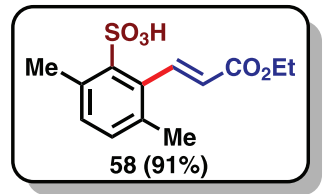

$58(91 \%)$<smiles>COc1ccccc1-n1cccn1</smiles>

59

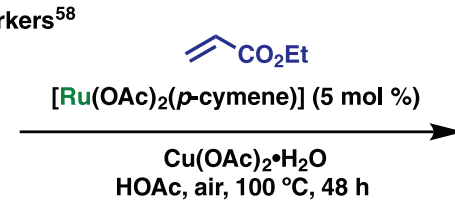

HOAc, air, $100^{\circ} \mathrm{C}, 48 \mathrm{~h}$
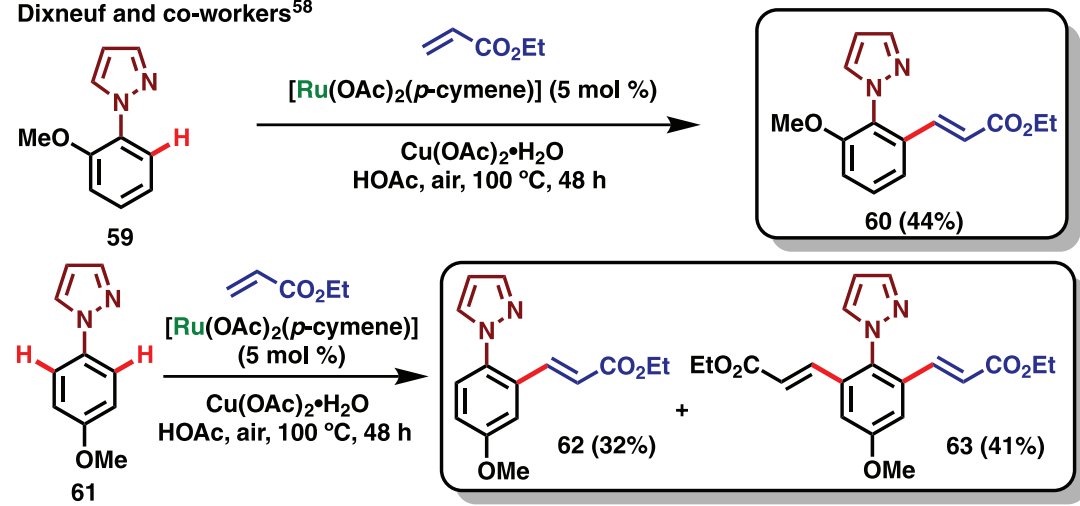

Scheme 11. Example of the isomeric effect of substituents reported by Ackermann and co-workers ${ }^{53}$ and Dixneuf and co-workers..$^{58}$

(62 and 63, respectively) were isolated, resulting in low selectivity.

Strategy: pay attention how laborious is to prepare the substrate and its derivatives! Could the $\mathrm{C}-\mathrm{H}$ activation lead to isomers and how to avoid them? Is it important to block one ortho-position?

\section{5. "Functionalizing Group"}

Substrates have been functionalized with several different groups via $\mathrm{C}-\mathrm{H}$ activation reactions such as arylation, ${ }^{74,75}$ halogenation, ${ }^{76}$ amination, ${ }^{77}$ alkylation, ${ }^{78}$ amongst many others. In order to illustrate different examples of functionalizing groups, 2-phenylpyridine (64) was taken into consideration (Scheme 12) as a classical platform towards diverse $\mathrm{C}-\mathrm{H}$ activation for coupling with different functionalizing groups. Those examples involve oxygenation, ${ }^{79}$ chlorination, ${ }^{80}$ cyanation, ${ }^{81}$ olefination, ${ }^{82}$ acetylation, ${ }^{83}$ arylation, ${ }^{84}$ among others, for the same substrate..$^{85-90}$

The choice of which one to perform relays on specific purposes such as overcoming a limited synthetic approach, access to specific modifications, insertion of a key group in total synthesis, structural modifications toward a biological application, insertion of a precursor for further transformation, amongst others.

Strategy: which group to insert: aryl, halogen, amine, alkyl, alkenyl...!? Which goal will be achieved with this insertion?

\section{First Steps}

Once the substrate of interest is selected, considering a directing group, selectivity issues, and "coupling partner"; optimization studies must be carried out. A careful search in the literature for similar reactions is the first step to develop a synthetic approach; once for now, it is not necessary to 


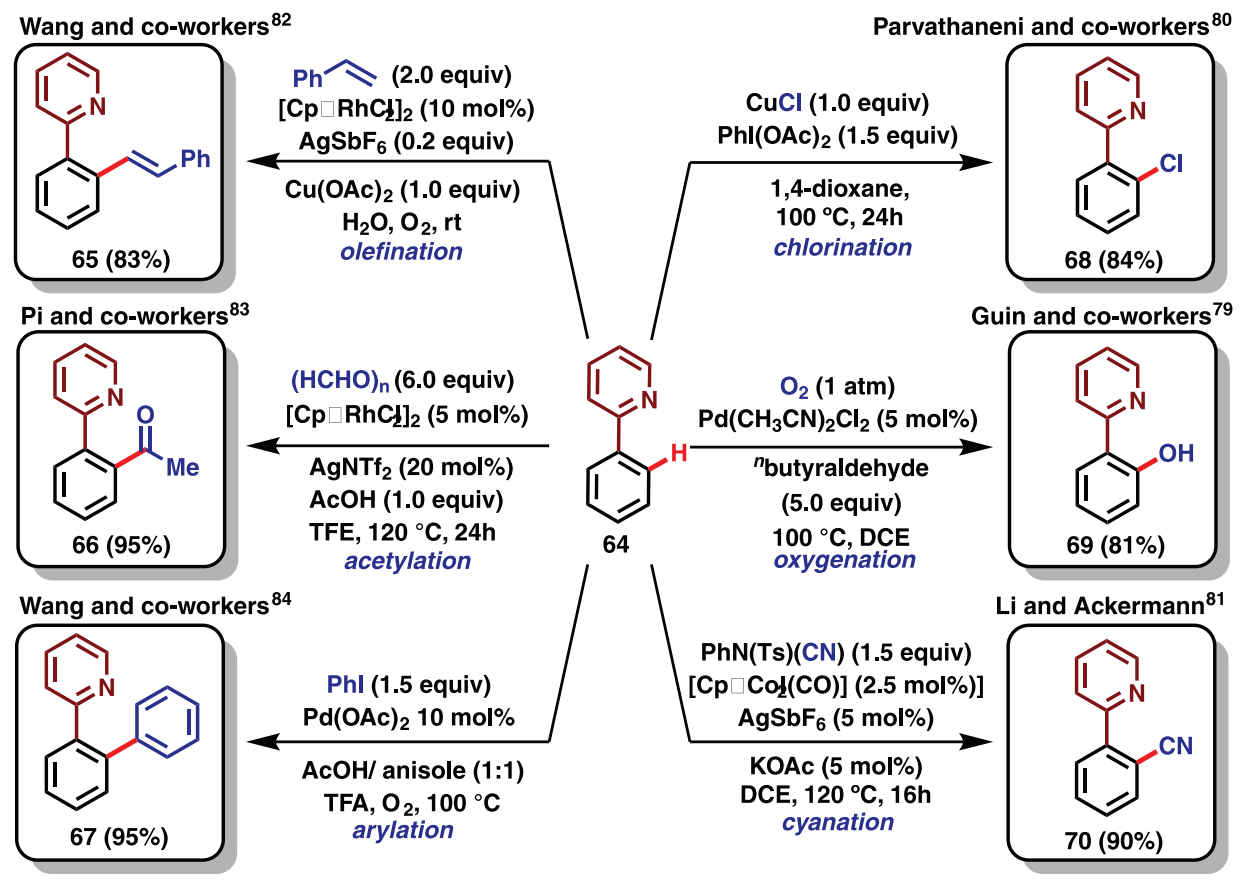

Scheme 12. Some examples of C-H activation using 2-phenylpyridine (64) with the insertion of different functional groups. ${ }^{79-84}$

reinvent the methodology. Reassessing similarly published works allows a broader view of the reaction under study. The search for patterns in these reactions can address the first reactional attempts. For instance, $\mathrm{C}-\mathrm{H}$ oxygenation has been usually performed employing hypervalent iodine or peroxides via catalysis with ruthenium. Alkenylation reactions have been conducted in the presence of copper acetate as an oxidant. In other words, there are synthetic patterns in this methodology, which is a good tip in which direction to follow.

The first attempts must resemble optimized reactions from literature, using the starting material of interest. This preliminary result will lead to insights about how the reaction works, applying a similar approach already described. Furthermore, this first attempt may lead to the desired product, even in low yield, which is important for the characterization of the product, especially when the formation of isomers is possible.

After the first attempt, it is worth checking if the desired product was obtained, and for that purpose, there are some powerful techniques that can help in the analysis of the crude reaction. This procedure will help to save solvent, time waste and helps in the planning of the next steps. Experiments such as gas chromatography-mass spectrometry (GC-MS), ${ }^{91}$ crude nuclear magnetic resonance (NMR, in this case, the molecular structure and its ${ }^{1} \mathrm{H}$ NMR spectrum must be well known), ${ }^{92}$ direct infusion at a mass spectrometer ${ }^{93}$ or even a simple thin layer chromatography (TLC) ${ }^{94}$ can help to check what was obtained from the reaction. If the target compound is not observed but a different product, it is crucial to perform its characterization. In some cases, the resultant product can represent a new method that can arise a significant scientific contribution. Otherwise, it is essential to consider whether the final product has already been published. If it is the case, and the method does not represent an innovative methodology, then it is not worthy of moving forward on that project. Now, if no product was observed at all, additional experiments can be performed to increase the possibility of the reaction occurs, such as a change in the substrate and/or catalyst or some adjustments on the reaction conditions (varying the temperature, solvent, time of reaction, etc.).

Strategy: a careful research in the literature for similar reaction is crucial! Take a look in common reactional conditions (patterns)!

\section{Purification Processes}

In the first attempt, after the crude product is obtained from the work-up process, either by simple extraction or from filtration in celite, and after it is primarily characterized using one of the above-cited techniques, it must be submitted to a more elaborated chromatography process. Some experiments make it possible to obtain the purified desired product directly from the reaction, ${ }^{95,96}$ when it is not soluble in the solvent system applied in the reaction, but this is a rare situation when it comes to $\mathrm{C}-\mathrm{H}$ activation reactions in homogeneous conditions. ${ }^{97}$ In some other cases, other purification processes are also 
appliable, mainly if the desired product cannot have contact with silica, such as recrystallization, ${ }^{98}$ distillation ${ }^{99}$ or sublimation. ${ }^{100}$ To correctly pick the purification process to be used, the reaction must be thoroughly planned, studied and understood. Still, in most of the cases, the first attempt is typical column chromatography. Every method presents an advantage and a disadvantage to be carefully considered when choosing the right one for the process that is under development (Table 1).

Most of the reactions require a chromatographic process to purify a product. ${ }^{101,102}$ In some cases, it is hard to fully know what else, other than the product and starting materials that we have in hands, are in the mixture, but among all the by-products, only the ones obtained in a considerable high quantity are worthy of characterizing. For example, in 2017, Li and co-workers ${ }^{103}$ present a cobaltcatalyzed $\mathrm{C}-\mathrm{H}$ alkenylation that leads to a possible mixture of two compounds (73-A and 73-B), structural isomers. One species is always less present than the other but still worthy of characterizing it. It represents a clarification of the mechanism on which the reaction happens, which can be either a 1,2-insertion or a 2,1-insertion (Scheme 13).

The authors ${ }^{103}$ proposed mechanism starts from an initial $\mathrm{C}-\mathrm{H}$ bond cleavage of the substrate 71a, which generates

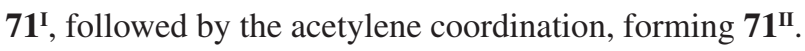
At this point, the carbon adjacent to the pyrimidine group is already activated enough to interact with the $\pi$-system of the alkyne. This is the point that this insertion can happen in two different ways: 1,2- or 2,1-insertion, resulting in the intermediates $\mathbf{7 1} 1^{\mathrm{II}}-\mathbf{A}$ or $\mathbf{7 1} \mathbf{1}^{\mathrm{II}}-\mathbf{B}$, respectively. In both cases, the intermediates lead to the formation of their respective final products 73-A or 73-B upon protonation with pivalic acid, from which the active catalyst species is recovered.

Before performing a chromatographic procedure, it is vital to choose the right system to be used here. Thin-layer chromatography can help a lot to decide this, but it is a mistake to believe that the performance seen in the TLC is precisely what is going to be seen in the column itself
(Figure 4). The TLC resembles the column's layout, but consider that, in the TLC, the optimum space is smaller, the flux is ascendant, and the compaction is way better than the one applied in the column will offer a better resolution. ${ }^{104} \mathrm{~A}$ well-done and optimized TLC analysis is enough to indicate the best eluent and stationary phase to be tried in the column chromatography. Remember to always have a comparison parameter in the TLC. Do not try to compare two different TLC templates only visually without a standard. For this, always use the starting materials or even a purified sample of the product as well.

Strategy: when analyzing the TLC pattern, try to observe if it is worthy moving forward to a column chromatography. How many spots are there and how separated are them?

In some cases, the TLC analysis can be done in the naked eye, when all substances involved are colorful on silica. But in most cases, visualization methods are necessary to check the purity and the retention-factor of the spots correctly. For that purpose, some methods can be applied, such as ultraviolet light, iodine, vanillin, permanganate, Dragendorff's solution, etc. The right approach to be used will depend on what is present in the mixture. ${ }^{105}$ In addition, if the desired product cannot be seen in the TLC, some options must be considered: if the reaction happened, if there is a good separation between the remaining starting material and the product, or if the visualization method employed is the right one to be used.

It is necessary to consider that some products can chemically interact with the silica, ${ }^{106-108}$ from which by-products can be obtained in the middle of the chromatography. It is tricky to know it in advance and understand your reaction to perceive that this phenomenon might be happening. To verify it, a bidimensional TLC ${ }^{109}$ run will indicate if a side-reaction is happening on the silica or not (Figure 5). For this procedure, take a square-shaped TLC plate, apply the crude product on the bottom-left and

Table 1. Advantages and disadvantages of the most used purification methods

\begin{tabular}{lcc}
\hline Method & Advantages & Disadvantages \\
\hline $\begin{array}{l}\text { Column chromatography } \\
\text { it is easier to be controlled and to be set up }\end{array}$ & $\begin{array}{c}\text { require large amounts of silica and solvent; it also } \\
\text { needs the help of TLC as a side analysis to identify } \\
\text { pure samples }\end{array}$ \\
\hline $\begin{array}{l}\text { Recrystallization } \\
\text { Distillation }\end{array}$ & $\begin{array}{c}\text { it is speedy in most of the cases in which it is used as } \\
\text { the main purification method; is easier to achieve } \\
\text { high purity }\end{array}$ & $\begin{array}{c}\text { not every product is possible to be recrystallized, and it } \\
\text { is tricky to be controlled }\end{array}$ \\
\hline $\begin{array}{l}\text { Sublimation } \\
\text { it is the best option in the case of a mixture of liquids }\end{array}$ & $\begin{array}{c}\text { requires previous knowledge of what is being purified } \\
\text { usually well purified }\end{array}$ \\
\hline
\end{tabular}

TLC: thin-layer chromatography. 

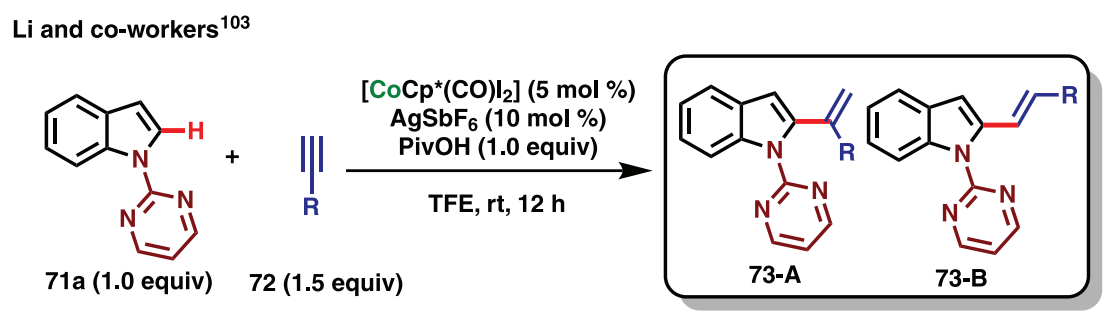

Scope (examples):
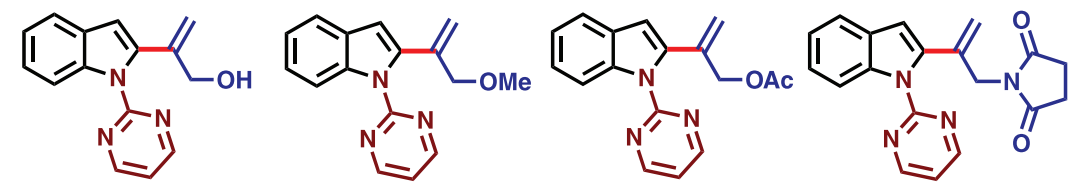

$73 a(82 \%, A: B>20: 1) \quad 73 b(79 \%, A: B=4.5: 1) \quad 73 c(80 \%, A: B=3.6: 1) \quad 73 d(60 \%, A: B=5.6: 1)$

\section{Proposed mechanism:}

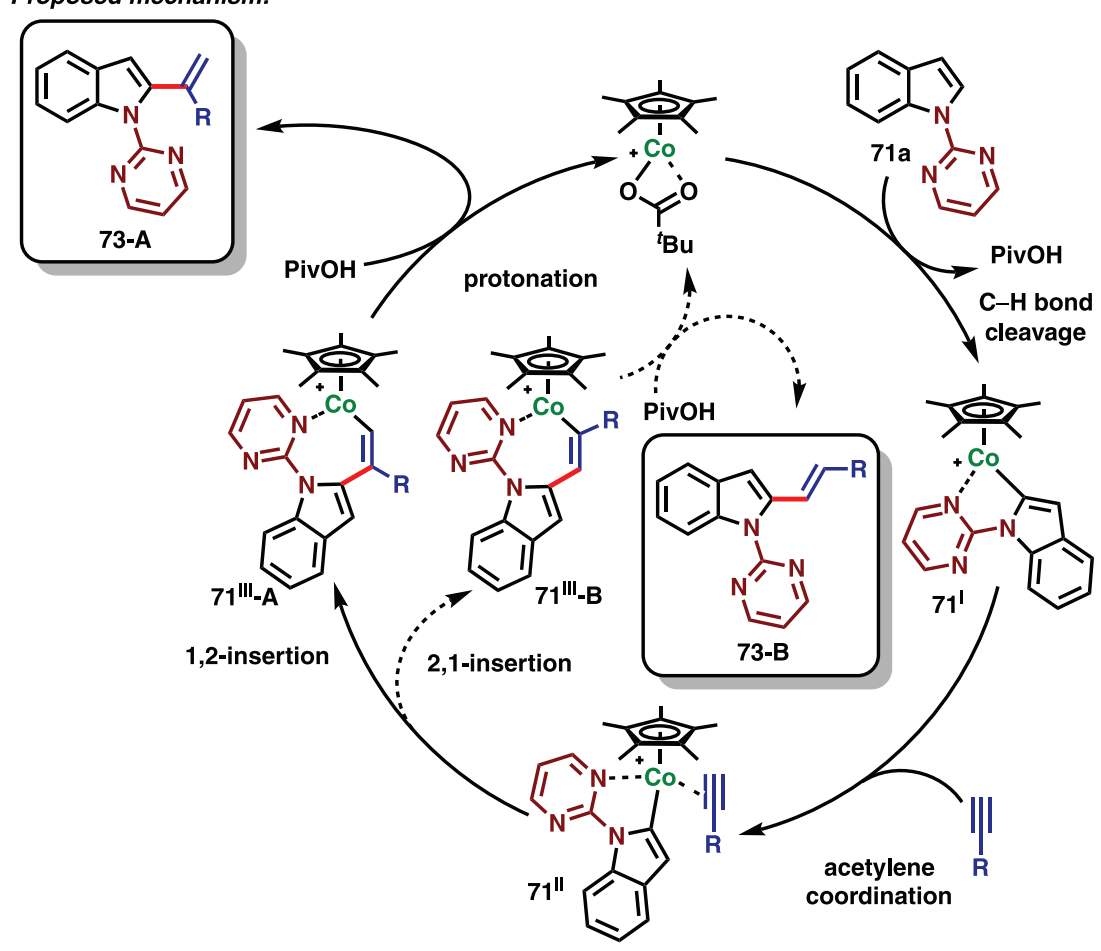

Scheme 13. Cobalt-catalyzed C-H alkenylation. ${ }^{103}$

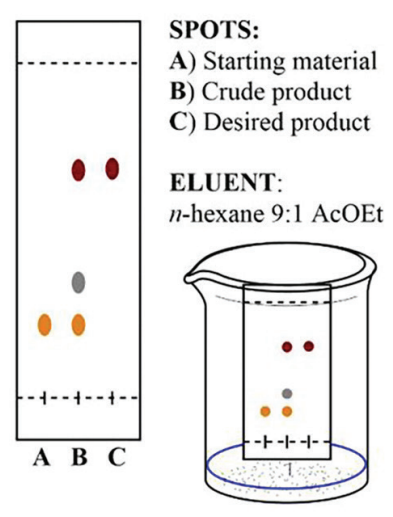

TLC template

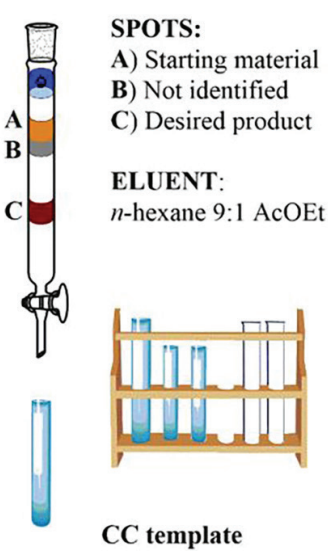

Figure 4. Comparison of the usual visual profile seen between a TLC and a column chromatography $(\mathrm{CC})$ template. run on the respective eluent. Take the TLC plate out, let it dry, rotate it $90^{\circ}$ counterclockwise and run it again, now sideway. If the product spot $\mathrm{C}$ presents a single spot after the second running, then the unidentified spot $B$ is only an impurity. But if the product spot $\mathrm{C}$ divides into a new spot $\mathrm{B}$ and a new spot $\mathrm{C}$, it means that a side-reaction on the silica must be happening. If this is the case, another stationary phase must be tried; usually, alumina or reversed-phase silica are good ideas.

After the TLC analysis is fully understood and it is clear on which column chromatography system the purification must be performed, it is time to prepare the crude product to be submitted to its purification process. Some hints can help the column to be performed in high quality and efficiency: 

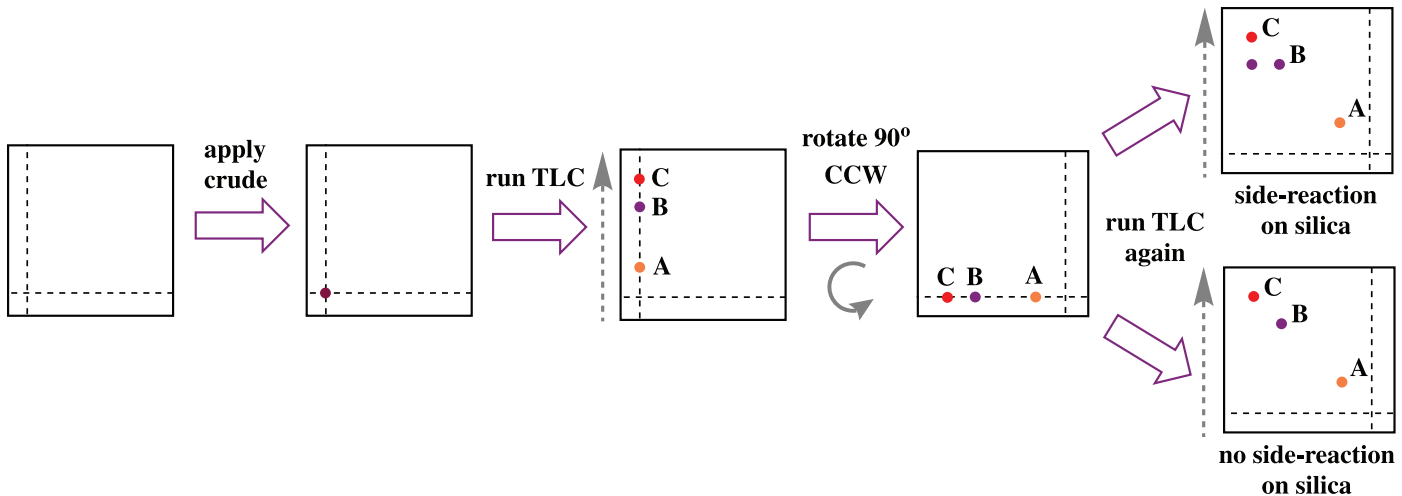

Figure 5. Procedure to perform a bidimensional TLC.

(i) Prior to the column chromatography, consider performing a quick but effective pre-purification of the crude material to remove the catalyst and other impurities that may interfere with the column performance. For that, a simple filtration using a celite ${ }^{110}$ or florisiil ${ }^{111}$ pad can help. (ii) The thickness of the column to be used depends on the amount of dry-loading, and the height of the stationary phase depends on the separation layout observed on the TLC (Figure 6).

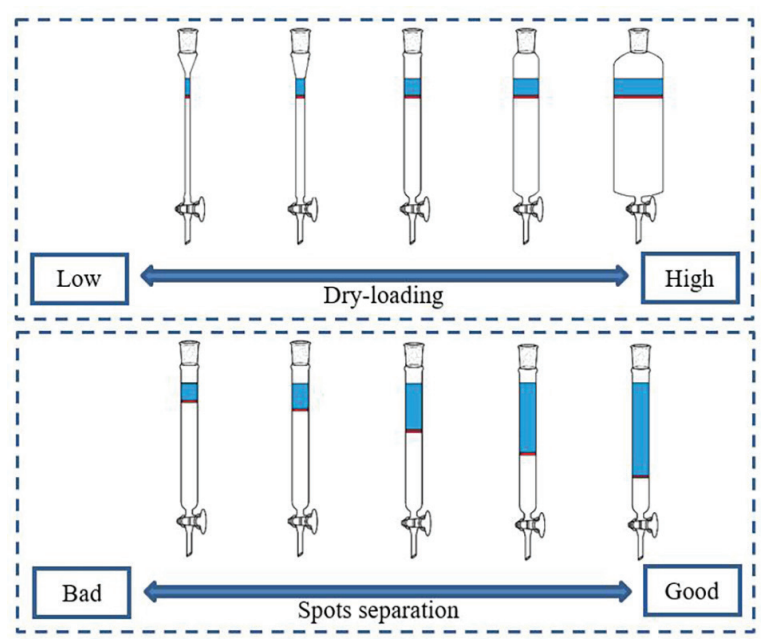

Figure 6. Correlation between the thickness of the column $v s$. dry-loading amount and spot separation $v s$. the height of silica.

(iii) If a normal silica gel is being used, always start the column from a low polarity eluent system, usually 5 to $10 \% \mathrm{v} / \mathrm{v} \mathrm{AcOEt} / n$-hexane and slowly increase the polarity as the column goes, especially when it is the first time a column chromatography is being performed for a specific reaction and when the room temperature is high (during summer, for example). Never increase the polarity abruptly; these solubilizations are usually exothermic and, since in the silica there is an elevated surface contact, this can generate bubbles inside the silica that will damage your system. (iv) Always compact the silica gel in the column with your starting eluent under constant flux. Use a weak pressure from an air pump or by soft, consecutive, and regular hits using a not-hard object (pieces of hoses, usually) on the outside of the column.

(v) The volume of eluted material to be collected depends on how well the separation of the mixture in the column went. If this separation is not visually obvious, consider collecting small volumes instead. This action will guarantee that more vials (or test tubes) will contain the purified product.

(vi) Always run a TLC of the collected material before joining different vials in the same flask to concentrate. Never fully trust a visual skill; always try going for a plausible confirmation that the column chromatography worked.

(vii) Usually, the "head" (first test tubes containing the product) and the "tail" (last test tubes containing the product) have a real low concentration of the desired product and a high probability of containing a non-detected impurity. Therefore, these samples are usually disposed.

\section{Characterization}

After the product is purified, it is strictly essential to characterize them using all available tools. New molecules must have their structures confirmed by infrared spectroscopy, high-resolution mass spectrometry, ${ }^{1} \mathrm{H}$ and ${ }^{13} \mathrm{C}$ NMR spectroscopy. Some cases even require bidimensional NMR analysis as well to help to identify where a specific functional group is located. ${ }^{112-115}$ Some reactions can happen on two different molecule sites, from which two products (usually structural isomers) with maybe two different yields are achieved. A notable example was provided by Tan and co-workers, ${ }^{116}$ in which a palladiumcatalyzed meta-selective alkenylation on modified benzylic alcohols lead to a mixture of two products ( $\mathbf{7 5}$ mono and di-functionalized) of different yields (Scheme 14).

In these examples, it is vital to perform correlated spectroscopy (COSY), heteronuclear single quantum 


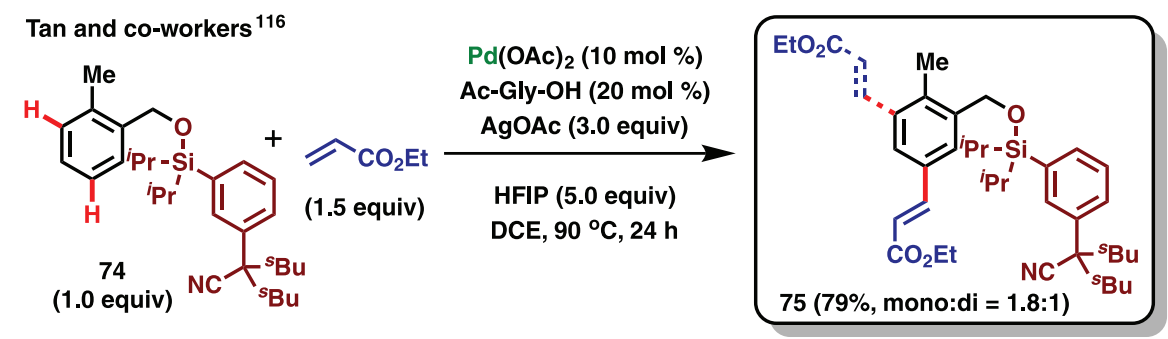

Scheme 14. Example of palladium-catalyzed meta-selective alkenylation. ${ }^{116}$

coherence (HSQC) and heteronuclear multiple bond correlation (HMBC) analysis to ensure that the reaction happened as it is proposed. And in some other cases, the complexity of the compound makes it hard to define the real molecular structure even by bidimensional analysis. In these cases, it is always good to achieve a single crystal of the sample and submit it for crystallographic analysis. With all these analyses, it is possible to attribute a molecular structure that was obtained unequivocally. Our research group, in collaboration with Ackermann and co-workers, ${ }^{117}$ recently reported a good example of this matter, about a ruthenium-catalyzed $\mathrm{C}-\mathrm{H}$ double-annulation of functionalized naphthoquinones (76). In this example, large structures were obtained (77), and this complexity made it impossible to fully characterize the structures of the products only by bidimensional NMR spectroscopy. Some relevant features, such as the exact position of some substituents and the annulation pattern, were only visible on the X-ray analysis (Scheme 15).

\section{Optimization Process}

Once the structure achieved is wholly elucidated, it is time to optimize the applied method. The intention here is to get a methodology that offers:

(i) The best yield (from which the higher amount of product can be obtained);

(ii) The best stoichiometry (in which the lowest extent of reactants is necessary);

(iii) The mildest conditions (which means, the quickest reaction under the lowest temperature);

(iv) Overall, the cheapest methodology.

The best combination of all these aspects will characterize the optimized methodology. For this, all parameters of the reaction can be explored (solvent, temperature, time of reaction, catalyst, the stoichiometry of reactants, additive, atmosphere, or anything else that may be appliable). ${ }^{18-121} \mathrm{~A}$ quick search on the literature looking for similar reactions will help to decide what to try out. Bearing in mind that not all the tried experiments need to be presented in the final work, only the more important ones, which resemble a good improvement of the method. Most of the published works show only half of the attempted reactions.

Synthetic efforts toward a new reactional methodology involve a systematic study, not only to achieve the optimized condition but to do it as soon as possible.

It is recommended to accomplish the methodological study with the assistance of a general table, containing all "entries" with the respective modifications and yields (Table 2). This table provides an overview of the progress of the work, what else needs to be studied and the relation between entries/yields.

\section{Catalyst}

The cornerstone of $\mathrm{C}-\mathrm{H}$ activation methodologies involves ideas for a sustainable approach. However, it is usually necessary to use catalysts based on rare, expensive, and even toxic metals, which may seem contradictory to the idea of methodologies more consistent with green chemistry principles. In this sense, rhodium and iridium catalysts have been less applied than ruthenium and palladium. In the last year, ruthenium catalyst, ${ }^{122}$ such as $\left[\mathrm{RuCl}_{2}(p \text {-cymene })\right]_{2}$, for example, have been the focus of studies of $\mathrm{C}-\mathrm{H}$ activation. There are several examples of rhodium-, ${ }^{123-125}$ iridium-, ${ }^{126-128}$ palladium- ${ }^{129-131}$ and ruthenium-catalysts ${ }^{132-134}$ that can be used on $\mathrm{C}-\mathrm{H}$ activation processes (Figure 7).

Over the years, several efforts had been addressed to use catalysts based on metals considered even cheaper and more accessible than ruthenium. Iron, cobalt, manganese, copper and others ${ }^{135,136}$ consisted of some examples.

For instance, Ding and Yoshikai ${ }^{137}$ reported C2-alkenylation of indoles (71a) with alkynes catalyzed by cobalt-pyphos catalyst (Scheme 16a, left). The same substrate was submitted to a manganese(I)-catalyzed alkynylation, from which the product $\mathbf{7 9}$ was obtained in $86 \%$ yield (Scheme 16a, right). ${ }^{138}$

Kakiuchi and co-workers ${ }^{139}$ described an iron-catalyzed anti-Markovnikov $\mathrm{C}-\mathrm{H}$ alkylation of aromatic ketones (80) using different alkenes in relatively mild conditions and solvent-free reaction (Scheme 16b). Ortho-selective halogenation of 2-arylpyridines (64) using copper(II) acetate under oxygen atmosphere was described by 
da Silva Júnior et al.117<smiles>[R7]c1ccc2c(c1)C(=O)C(NC(C)=O)=CC2=O</smiles>

76

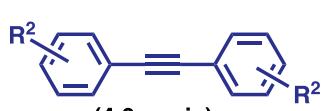

(4.0 equiv) $\left[\mathrm{RuCl}_{2}(\text { p-cymene })\right]_{2}(5 \mathrm{~mol} \%)$ NaOPiv ( 0.5 equiv) $\mathrm{Cu}(\mathrm{OAc})_{2} \bullet \mathrm{H}_{2} \mathrm{O}$ (2.0 equiv) DCE $(0.1 \mathrm{M}), 120^{\circ} \mathrm{C}, 24 \mathrm{~h}$

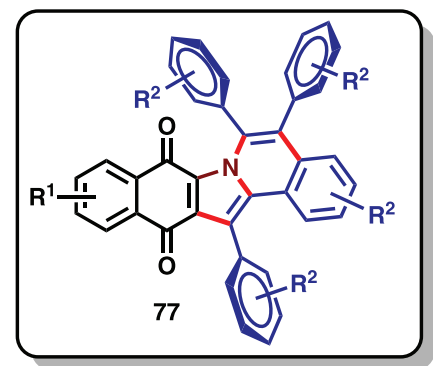

Compounds caractherized by $X$-ray analysis (examples):<smiles>O=C1c2ccccc2C(=O)c2c1c(-c1ccccc1)c1c3ccccc3c(-c3ccccc3)c(-c3ccccc3)n21</smiles>

$77 a(63 \%, 80 \% *)$

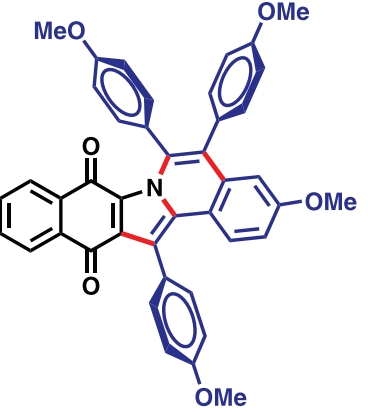

77b $(76 \%, 91 \% *)$

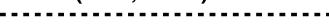

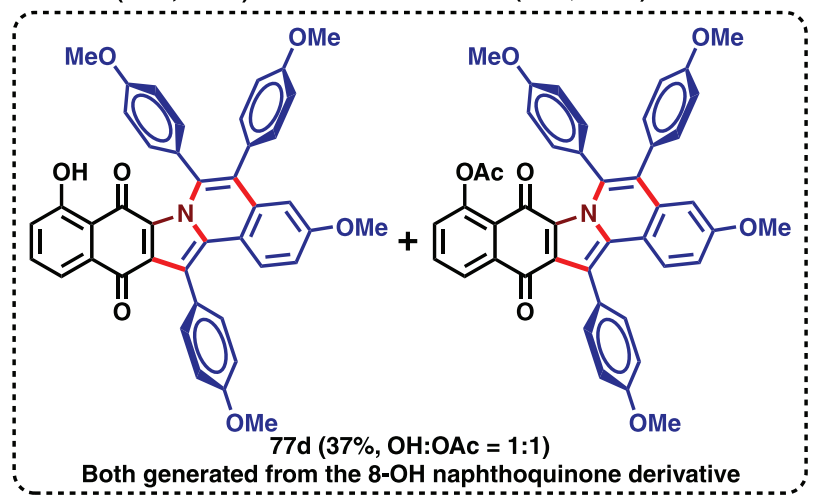

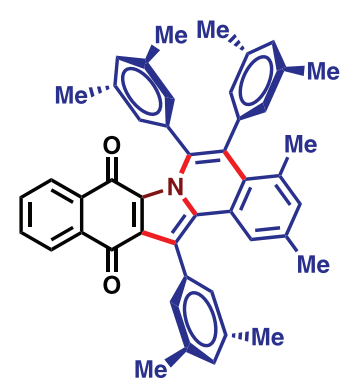

$77 \mathrm{c}\left(25 \%, 64 \%^{*}\right)$<smiles>COc1ccc(-c2c3c(n(C(C)=O)c2-c2ccc(OC)cc2)C(=O)c2cc4ccccc4cc2C3=O)cc1</smiles>

$77 e(13 \%, 44 \% *)$

Scheme 15. Ruthenium-catalyzed double $\mathrm{C}-\mathrm{H}$ annulation. ${ }^{117} *$ An additional $5 \mathrm{~mol} \%$ of the catalyst was added after $12 \mathrm{~h}$.

Yu and co-workers ${ }^{140}$ using 1,1,2,2-tetrabromoethane as bromo source, molecular iodine as iodine source and solvent (Scheme 16c).

Two examples of nickel-catalyzed cycloaddition of aromatic $(O$-benzyl)-ketoximes $(\mathbf{8 4})$ with alkynes were described by Kurahashi and co-workers ${ }^{141}$ (Scheme 16d). In this work, isoquinoline (86) and $N$-oxide isoquinoline derivatives $(\mathbf{8 5})$ were achieved.
The catalyst must be chosen carefully. Once it is selected, its application on the reaction must be optimized, which basically means that the amount to be loaded is an important matter to be evaluated. The study can start with the amount that will be used on the basis-reference, and from there, depending on the results, higher and lower amounts can be explored.

Table 2. Example of suitable reaction screenings for optimization studies

\begin{tabular}{|c|c|c|c|c|c|c|c|}
\hline entry & $\begin{array}{c}\text { Catalyst } \\
\text { (concentration } / \mathrm{mol} \% \text { ) }\end{array}$ & $\mathrm{T} /{ }^{\circ} \mathrm{C}$ & $\mathrm{t} / \mathrm{h}$ & Reagent (equiv) & $\begin{array}{c}\text { Additive } \\
\text { (concentration / } \mathrm{mol} \% \text { ) }\end{array}$ & $\begin{array}{c}\text { Oxidant } \\
\text { (concentration / mol\%) }\end{array}$ & Yield / \% \\
\hline 1 & {$\left[\mathrm{Ru}(p \text {-cymene }) \mathrm{Cl}_{2}\right]_{2}(1.0)$} & 110 & 18 & ethyl acrylate (1.2) & $\mathrm{AgSbF}_{6}(10)$ & $\mathrm{Cu}(\mathrm{OAc})_{2}(50)$ & 11 \\
\hline 2 & {$\left[\mathrm{Ru}(p \text {-cymene }) \mathrm{Cl}_{2}\right]_{2}(2.0)$} & 110 & 18 & ethyl acrylate (1.2) & $\operatorname{AgSbF}_{6}(10)$ & $\mathrm{Cu}(\mathrm{OAc})_{2}(50)$ & 16 \\
\hline 3 & {$\left[\mathrm{Ru}(p \text {-cymene }) \mathrm{Cl}_{2}\right]_{2}(5.0)$} & 110 & 18 & ethyl acrylate (1.2) & $\operatorname{AgSbF}_{6}(10)$ & $\mathrm{Cu}(\mathrm{OAc})_{2}(50)$ & 11 \\
\hline$\cdots$ & $\cdots$ & $\ldots$ & $\cdots$ & $\cdots$ & $\ldots$ & $\ldots$ & $\cdots$ \\
\hline
\end{tabular}

$\mathrm{T}$ : temperature; t: time; equiv: equivalents. 
(a) Rhodium-based catalysts

$\mathrm{RhCl}_{3} \bullet \mathrm{nH}_{2} \mathrm{O}$

Rhodium(III) chloride hydrate

Tris(triphenylphosphine) rhodium(I) chloride

(b) Iridium-based catalysts

$\mathrm{IrCl}_{3} \bullet \mathrm{nH}_{2} \mathrm{O}$

Iridium(III) chloride hydrate<smiles>Cl[Te]1([Al]2CCCCC2)C2CC[Al](CC2)[I-]1(Cl)Cl</smiles>

Chloro(1,5-cyclooctadiene)iridium(I) dimer

(c) Palladium-based catalysts $\mathrm{PdCl}_{2}$

Palladium (II) cloride

$\mathrm{Pd}(\mathrm{OAc})_{2}$

Palladium (II) acetate $\mathrm{Pd}(\mathrm{TFA})_{2}$

Palladium(II) trifluoroacetate

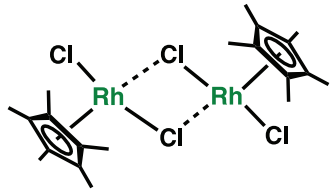

Pentamethylcyclopentadienyl)rhodium(III) dichloride dimer

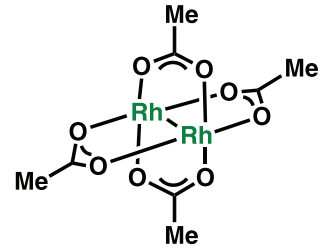

Rhodium(II) acetate dimer

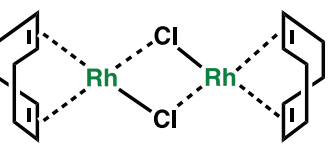

Chloro(1,5-cyclooctadiene)rhodium(I) dimer

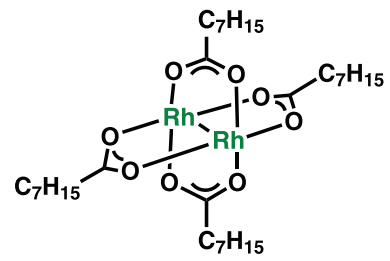

Rhodium(II) octanoate dimer

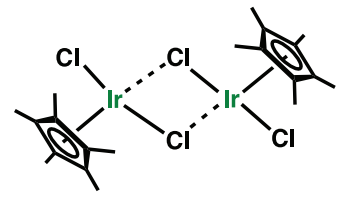

(Pentamethylcyclopentadienyl)iridium(III) Dichloride Dimer

$$
\begin{gathered}
\mathrm{Pd}\left(\mathrm{PPh}_{3}\right)_{2}(\mathrm{OAc})_{2} \\
\begin{array}{l}
\text { Bis(triphenylphosphine)- } \\
\text { palladium(II) Diacetate }
\end{array} \\
\mathrm{Pd}\left(\mathrm{PPh}_{3}\right)_{2} \mathrm{Cl}_{2}
\end{gathered}
$$

Bis(triphenylphosphine)palladium(II) Dichloride

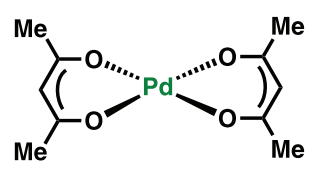

Palladium acetylacetonate

(d) Ruthenium-based catalysts $\mathrm{RuCl}_{3}$

Ruthenium(III) chloride

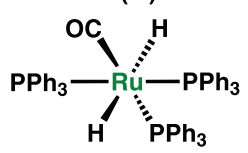

Carbonyl(dihydrido)-

tris(triphenylphosphine) -ruthenium(II)

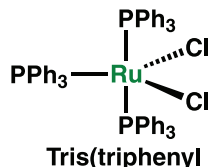

phosphine)-

ruthenium(II)

dichloride

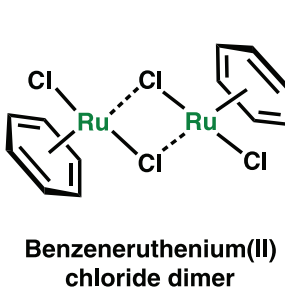

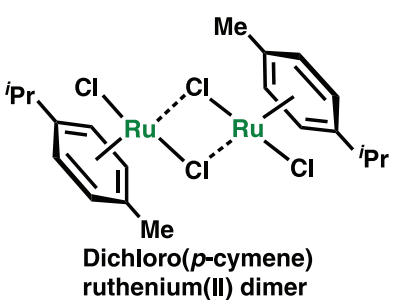

Figure 7. Examples of common palladium, rhodium, iridium and ruthenium catalysts.

Strategy: to use large amounts of the catalyst (higher than $20.0 \mathrm{~mol} \%$ ) is inefficient. In this case, try another catalyst or do separate loadings.

\section{Solvent}

Solvents play an important role in $\mathrm{C}-\mathrm{H}$ activation reaction, although usually, it is not so obvious. Miura and co-workers ${ }^{142}$ had recently described the selective $\mathrm{C}-\mathrm{H}$ alkenylation and alkylation of 2-pyridones (87) with acrylates, leading to different products, according to the employed solvent (Scheme 17). In dimethylformamide (DMF), the C6-alkenylated product $\mathbf{8 9}$ was obtained, whereas in hexafluoroisopropanol (HFIP), at same reactional conditions, alkylation reaction was observed (88), probably due to the capability of HFIP to act as a proton source, according to the authors.

Based on the examples briefly described above, it is possible to observe the importance of solvent in the reaction. Typical solvents for $\mathrm{C}-\mathrm{H}$ activation processes include acetic acid, trifluoroacetic acid (TFA), methanol, trifluoroethanol (TFE), 1,4-dioxane, tetrahydrofuran (THF), dichloromethane (DCM), dichloroethane (DCE), toluene, dimethylformamide (DMF), dimethylacetamide (DMA), and $N$-methyl-2-pyrrolidone (NMP).

Solvents used in catalytic reactions must be previously 
(a) Ding and Yoshikai ${ }^{137}$ [left] and Ackermann and co-workers ${ }^{138}$ [right]

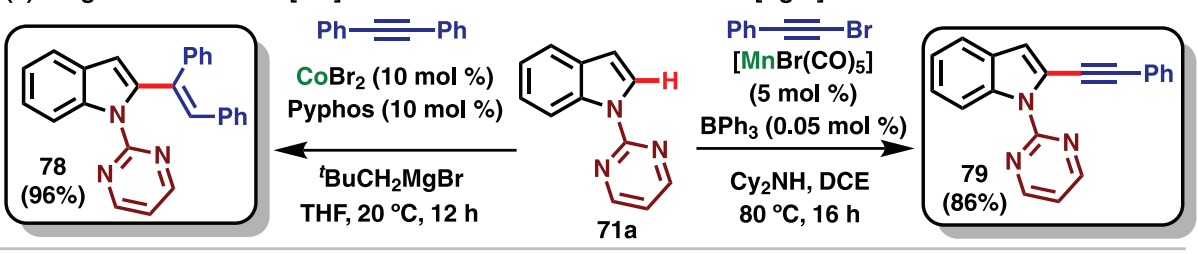

(b) Kakiuchi and co-workers ${ }^{139}$<smiles>O=C(Br)c1ccccc1</smiles>
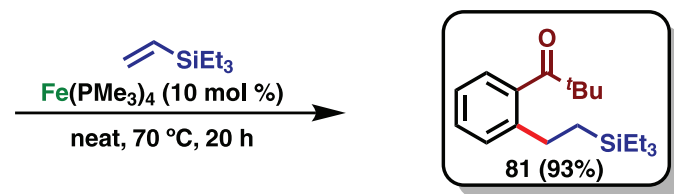

(c) Yu and co-workers ${ }^{140}$
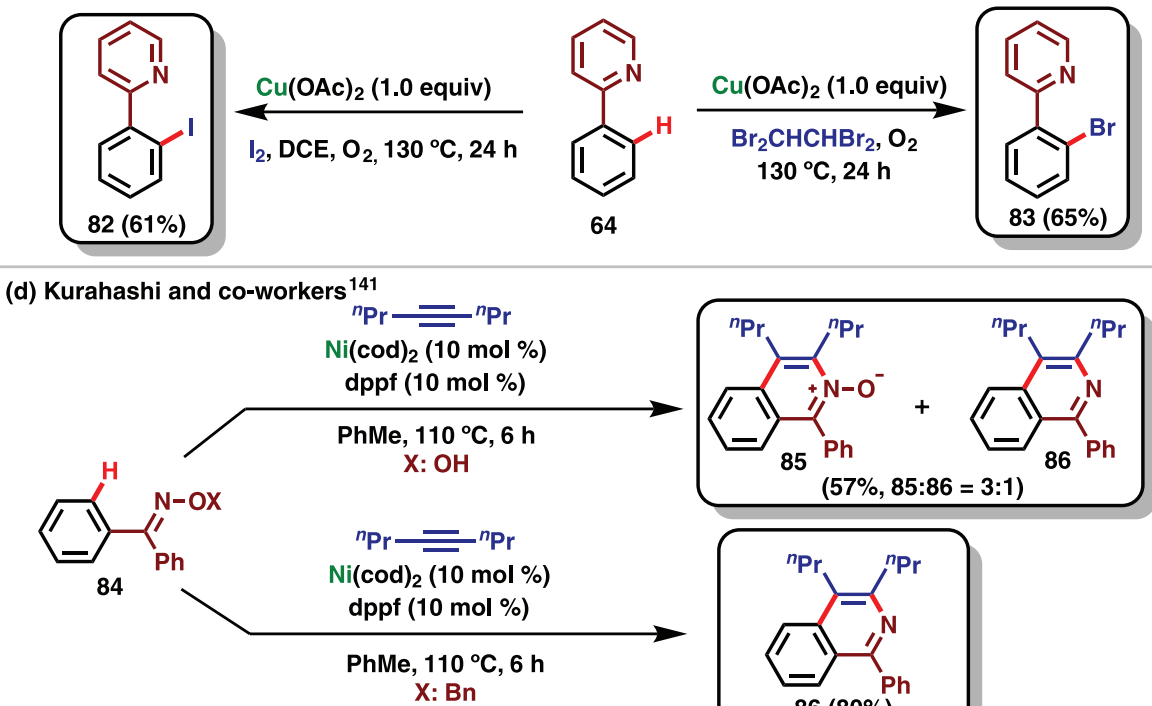

$(57 \%, 85: 86=3: 1)$

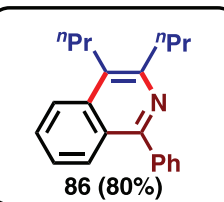

Scheme 16. Examples of C-H activation using a less expensive catalyst. ${ }^{137-141}$

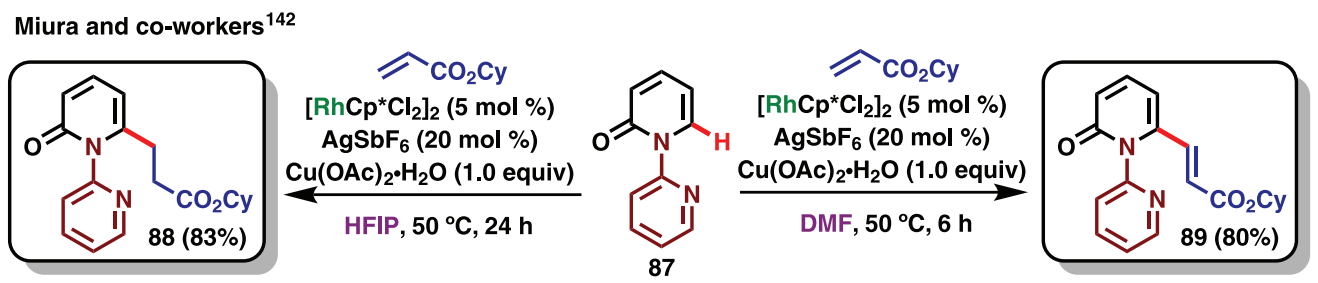

Scheme 17. Solvent effect on C-H activation of 2-pyridones reported by Miura and co-workers. ${ }^{142}$

purified and dried once as impurities and water could interfere significantly in due course. When the reaction is performed in distilled water, it is important to degas it since dissolved oxygen can induce undesirable reactions.

The dried solvent must be stored under an inert atmosphere (Ar or $\mathrm{N}_{2}$ ) and carefully handle to avoid contamination. Some examples of solvent purification processes are briefly described in Table 3, based on standard procedures. ${ }^{143}$

On the first sight, it is not simple to establish a relation between solvent properties (polarity, boiling point, miscibility) and the reaction process. In this sense, the screening of solvent in the $\mathrm{C}-\mathrm{H}$ activation reaction in development usually starts based on solvents that showed success described in the literature for similar reactions, keeping other parameters steady (catalyst, additive, oxidant, temperature).

The reaction must be performed in different solvents, keeping all other parameter, and the yield of each reaction must be recorded, as previously described. Based on those results, a possible relation between solvent and yield may be established, indicating the best solvent for this reaction. In some cases, more than one solvent can lead to a good result, which means both solvents must be studied posteriorly. 
Table 3. Solvents used in $\mathrm{C}-\mathrm{H}$ activation ${ }^{143}$

\begin{tabular}{|c|c|}
\hline Solvent & Process (briefly) \\
\hline $\begin{array}{l}\text { Methanol, } t \text {-amyl alcohol, toluene, } \\
o-, m-, p \text {-xylene, } n \text {-hexane, } \\
\text { 1,4-dioxane }\end{array}$ & $\begin{array}{l}\text { dried and distilled over metallic } \\
\text { sodium using benzophenone as an } \\
\text { indicator }\end{array}$ \\
\hline \multicolumn{2}{|l|}{$\begin{array}{l}\text { Triethylamine, dichloroethane, } \\
\text { dimethylacetamide, } \\
\text { dimethylformamide, dimethyl } \\
\text { sulfoxide, pyridine }\end{array}$} \\
\hline$n$-Butanol, acetonitrile & $\begin{array}{c}\text { dried over a molecular sieve and } \\
\text { degassed by freeze-pump-thaw } \\
\text { cycles }\end{array}$ \\
\hline Dichloromethane & $\begin{array}{l}\text { acid/base wash; pre-dried with } \\
\mathrm{CaCl}_{2} \text {, and distilled from } \mathrm{CaSO}_{4} \text {, } \\
\mathrm{CaH}_{2} \text { or } \mathrm{P}_{2} \mathrm{O}_{5}\end{array}$ \\
\hline Tetrahydrofuran & $\begin{array}{l}\text { dried with sodium until a } \\
\text { characteristic blue color of } \\
\text { benzophenone then, distillate }\end{array}$ \\
\hline
\end{tabular}

It is noteworthy to mention that the boiling point of the solvent and the temperature at which the reaction will be carried out have to be taken into consideration when setting up the reaction. If the solvent exhibits a boiling point considerably lower than the temperature at which the reaction will be conducted, a pressure-resistant reactor, such as a pressure tube, should be used. Also, at the end of the reaction, it is important to wait until the reaction medium cools down to room temperature before opening the flask to avoid accidents.

\section{Oxidant Screening in $\mathrm{C}-\mathrm{H}$ Activation}

External oxidant in $\mathrm{C}-\mathrm{H}$ activation is crucial in several reactions. The role of the oxidant is related to regenerate the active catalyst form, to promote the reductive elimination of organometallic intermediates and to produce the reactive species capable of functionalization leading to the functionalized product. Redox-neutral $\mathrm{C}-\mathrm{H}$ reactions might not require an external oxidant. ${ }^{144}$

The oxidizing ability of a chemical to selectively oxidize organometallic intermediates is more important than the regeneration of catalyst species since the latter is less sensitive to the nature of the oxidant. Therefore, it is required that the oxidant exhibits a redox potential higher than the oxidation potential of the organometallic intermediate. However, at this point, this intermediate has not been determined and is usually only theorized based on literature; for that reason, it is not evident to know its oxidation potential.

For that constraint, the choice of the optimal oxidant is one of the biggest challenges in the development of $\mathrm{C}-\mathrm{H}$ activation methodology. In experimental studies in the development of oxidative $\mathrm{C}-\mathrm{H}$ activation, the oxidant screening represents an essential process towards the optimization of reaction. In this sense, all parameters (catalyst, solvent, additive, temperature) of reaction in the study are maintained. Only the oxidant (species and amount) is altered to understand how it interferes with the reaction yield.

Several oxidants have been used in $\mathrm{C}-\mathrm{H}$ activation reactions, such as metal-based oxidant $\left(\mathrm{Cu}(\mathrm{OAc})_{2}\right.$, ceric ammonium nitrate $(\mathrm{CAN}))$, peroxides $\left(\mathrm{KHSO}_{5}\right.$, $\mathrm{K}_{2} \mathrm{~S}_{2} \mathrm{O}_{8}$, meta-chloroperoxybenzoic acid (m-CPBA), $t$-BuOOH$)$, silver source $\left(\mathrm{Ag}_{2} \mathrm{CO}_{3}, \mathrm{AgOAc}\right)$. However, it is an important approach to replace these chemicals with organic oxidant compounds (benzoquinone, quinoline $N$-oxide, anthraquinone, 2,2,6,6-tetramethylpiperidin1-yl)oxyl (TEMPO), $N$-methylmorpholine $N$-oxide (NMO), $\mathrm{PhI}(\mathrm{OAc})_{2}$ (PIDA), $\mathrm{PhI}\left(\mathrm{CO}_{2} \mathrm{CF}_{3}\right)_{2}$ (PIFA)) in order to reduce the amount of metal in the reaction and consequently reduce the waste. Molecular oxygen, $\mathrm{O}_{2},{ }^{145}$ is a natural, inexpensive, and eco-environmental oxidant strongly recommended instead of other catalysts, once its use produces no waste and it is prominent to scalability. ${ }^{146}$

\section{Additives}

As previously described, catalysts, solvents and oxidants, associated to a suitable choice of substrate and directing group, can lead to the achievement of a new approach in $\mathrm{C}-\mathrm{H}$ activation reaction. However, generally, it is required to use the additives to obtain the product in good yields. Several chemicals have been used to this purpose, such as bases (alkaline acetate, carbonates, bicarbonate, pivalate, fluoride, alkoxide, phosphate), carboxylic acids ( $\mathrm{AcOH}, \mathrm{PivOH}$, TsOH, TFA), inorganic salts (hexafluorophosphate), silver sources $\left(\mathrm{AgNO}_{3}, \mathrm{AgSbF}_{6}, \mathrm{AgOAc}, \mathrm{Ag}_{2} \mathrm{CO}_{3}, \mathrm{AgNTf}_{2}, \mathrm{AgBF}_{4}\right)$, phosphine $\left(\mathrm{PPh}_{3}, \mathrm{PCy}_{3}, \mathrm{X}\right.$-Phos, $\left.\mathrm{P}\left(\mathrm{NMe}_{2}\right)_{3}\right)$ and organic compounds (1,10-phenanthroline, 2,6-di-tert-butylpyridine (2,6-dtbpy), 1,1'-ferrocenediyl-bis(diphenylphosphine) (DPPF), L-proline).

The role of additives in the reaction course is widely discussed in the literature for the researchers to draw some conclusive trends. For example, silver additives are usually used with $\left[\mathrm{RuCl}_{2}(p \text {-cymene })\right]_{2}$ and $\left[\mathrm{RhCp} * \mathrm{Cl}_{2}\right]_{2}$ because it promotes the formation of an active catalytic species by breaking the dimer structure. However, when silver is used with palladium catalysts, it provides the heterodimeric $\mathrm{Pd}-\mathrm{Ag}$ complex. ${ }^{147,148}$ Carboxylate additives can break the arene $\mathrm{C}-\mathrm{H}$ bond via a hydrogenatom-transfer mechanism. ${ }^{149}$

An important example of additive was reported by Sherikar et al. ${ }^{150}$ in which rhodium(III)-catalyzed C-H activation of indole $\mathbf{9 0}$ at the $\mathrm{C} 4$-position is performed. An 
acid additive led to the formation of 1,4-addition products (93), whereas a base additive promotes the formation of Heck-type products (92) (Scheme 18a). Lai et al. ${ }^{151}$ had described the obtention of two different heterocycles (96 or 97) according to the applied additive (NaOAc or $\mathrm{CuF}_{2} / \mathrm{CsOAc}$ ) (Scheme 18b). ${ }^{151}$

The screening of the additive for the development of a $\mathrm{C}-\mathrm{H}$ activation methodology involves the understanding of similar reactions and chemicals previously described in the literature. In this sense, all other reaction parameters must be maintained steady with varying additives until a good one gets disclosed. Once the optimized catalyst is obtained, its amount must be studied towards increasing the yield.

\section{Reaction Performance vs. Optimization}

Interesting optimization studies were observed by Miura et al. ${ }^{119}$ when they performed a rhodium-catalyzed $\mathrm{C}-\mathrm{H}$ borylation. In this work, after screening catalyst, ligand, solvent, temperature and time, the best yield was achieved by applying $2.5 \mathrm{mmol}$ of limiting reagent. This amount was higher than expected, leading to the desired product 98 in $83 \%$ yield (Table 4 , entry 12), against $74 \%$ when applying ten times less of the substrate (Table 4, entry 11). Additionally, only $0.25 \mathrm{mmol}$ of each substrate was used, even though the best yield was achieved using large amounts. This example suggests that the best yield does not always resemble the best-optimized condition. This decision should be taken considering all the aspects of the applicability of the reaction.

The optimization process indeed takes time, but it is possible to save a lot of time by placing simultaneous reactions as much as possible. For example, when optimizing the additive, it is possible to set five different reactions with five other additives simultaneously, on the same day, on the same heating plate, using an oil bath or a heating block (Figure 8). With this in mind, what would require a whole week can be done in a single day. For safety reasons, once the reactions can generate gases in closed vials, it is necessary to place them in a fume hood using an additional transparent shield that will retain glasses pieces in the case of a spontaneous generation of a large amount of gas.

$\mathrm{C}-\mathrm{H}$ activation reactions usually are carried out in a sealed tube under an inert atmosphere resulting in a system under pressure. This experimental condition disables the possibility to follow the course of the reaction taking out samples from the reactional system to accomplished traditional techniques (TLC, GC-MS, extraction, etc.) without compromising the system. For that reason, the time of reaction is an established condition determined during optimization studies and kept for all examples of methodological scope.

When performing the optimization, three aspects are important to be measured (Scheme 19):

(i) Yield: percentage of the product obtained over the expected total amount of product.

(ii) Conversion: percentage of reactant that reacted over the total amount of reactant applied.

(iii) Recovered starting material: percentage of starting material left over the total amount of reactant applied.

These facts will help understand the logistic of the reactions, if it is going the way it was presumed or if a side reaction is starting to take over the optimization process. Although there is no need to measure all the three aspects in every single reaction (which would take a lot of effort and goods, sometimes for no practical reason), it is recommended to measure them at least once every time you are optimizing one parameter of the reaction. And for that, it does not have to be an isolated result. At this point, it is expected that the behavior of the product on the column and

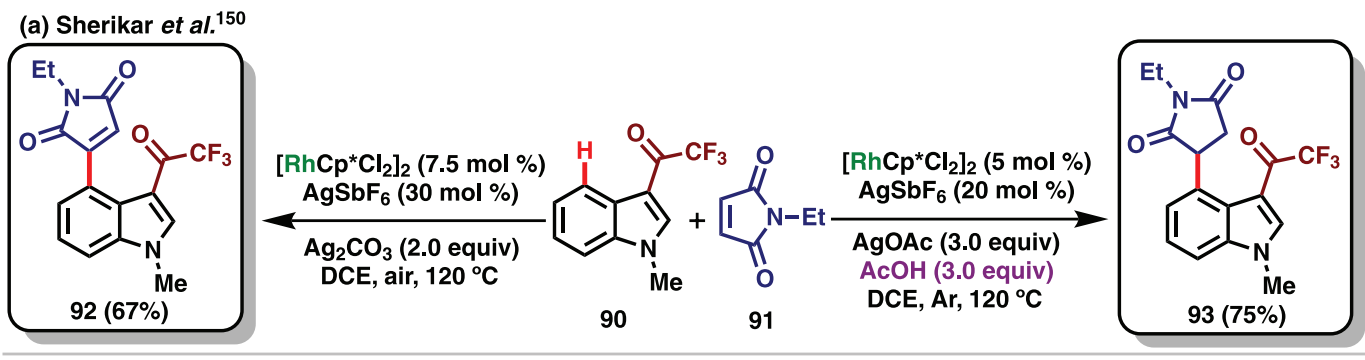

(b) Lai et al.. ${ }^{151}$

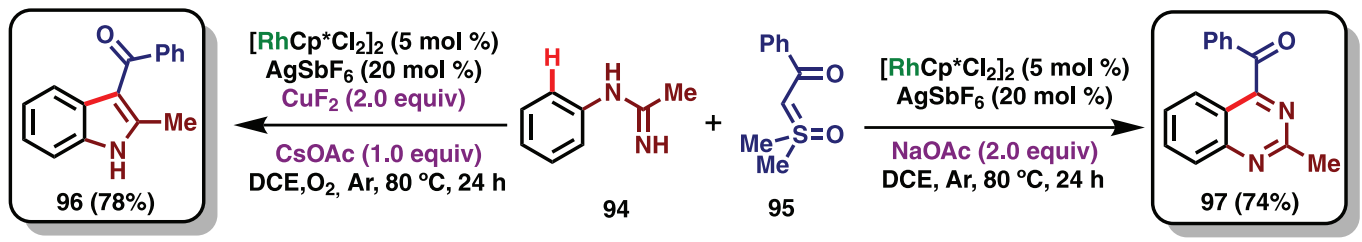

Scheme 18. Examples of the influence of additives on the reaction. ${ }^{150,151}$ 
Table 4. Optimization of a rhodium-catalyzed $\mathrm{C}-\mathrm{H}$ borylation ${ }^{119}$

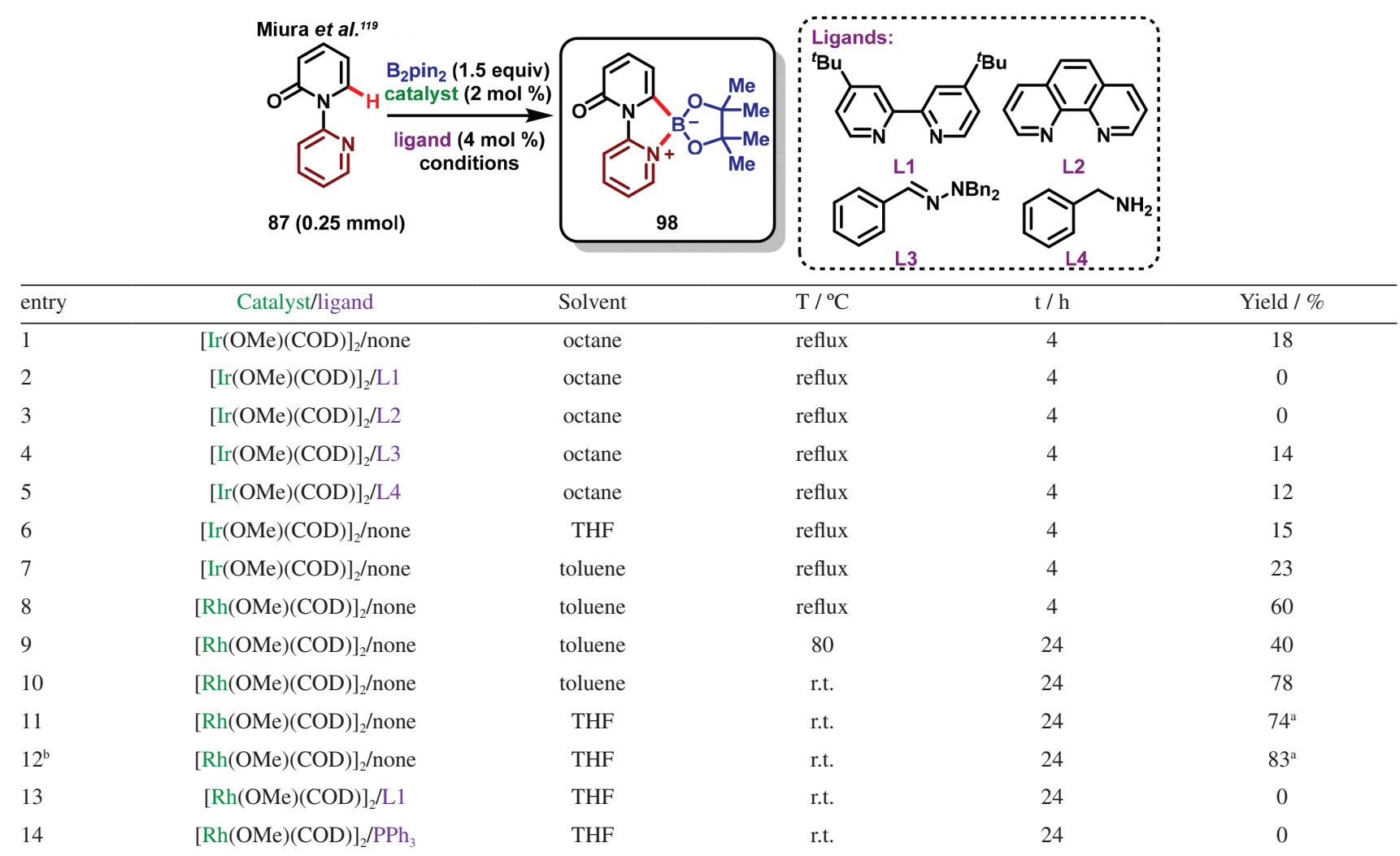

aIsolated yields. ${ }^{\text {b2 }} .5 \mathrm{~mol}$ of substrate. equiv: equivalents; T: temperature; t: time; COD: cycloocta-1,5-diene; THF: tetrahydrofuran; r.t.: room temperature.

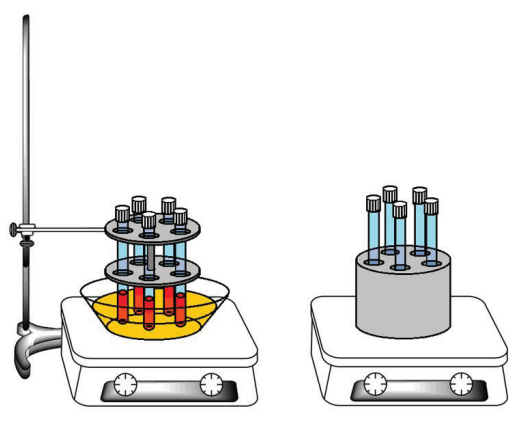

Figure 8. Easy processes to optimize the use of a heating plate.

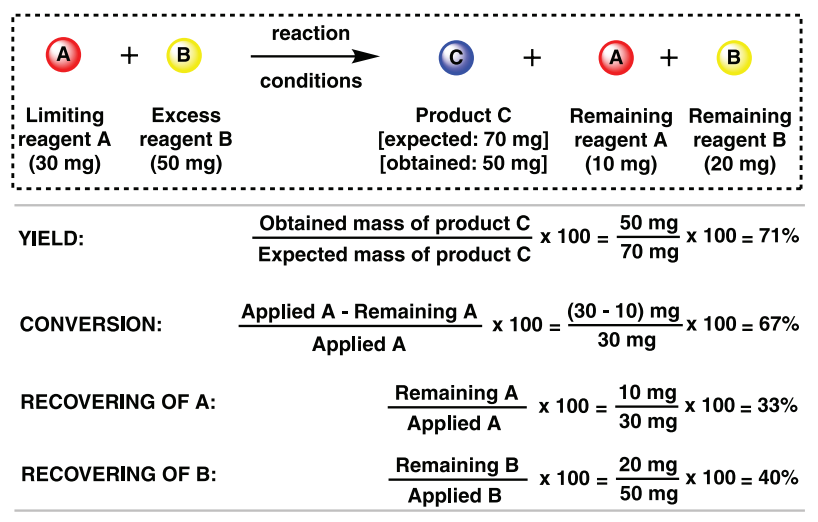

Scheme 19. Clarification of the calculation of yield, conversion and recovering percentages. even under ${ }^{1} \mathrm{H}$ NMR analyses are well-known. It is possible to measure the yield using a standard internal method from the ${ }^{1} \mathrm{H}$ NMR or chromatographic methods (GC-MS or high-performance liquid chromatography (HPLC)). This can save not only chemicals and other materials but also can save time.

\section{Calculation of Yield in situ Using ${ }^{1} \mathrm{H}$ NMR}

To calculate yields in situ by ${ }^{1} \mathrm{H}$ NMR it is always necessary to use an internal standard with a well-known concentration that presents one or maximum two signals (Figure 9). ${ }^{152,153}$ Among all used internal standards, 1,4-dinitrobenzene $(\mathbf{9 9})$ is the most indicated one, ${ }^{154,155}$

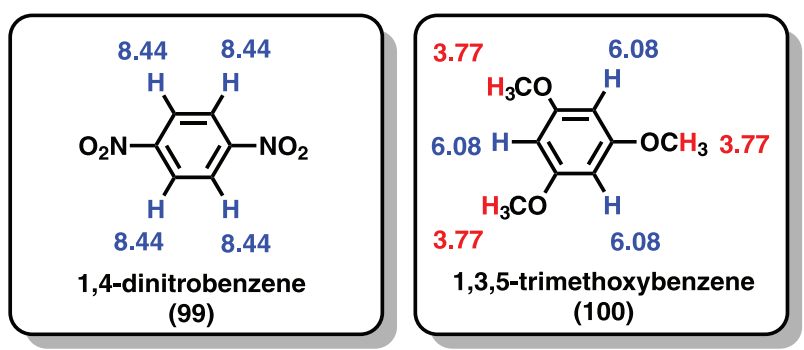

Figure 9. Chemical shift $(\delta)$ of the hydrogen atoms of the compounds 1,4-dinitrobenzene (99) and 1,3,5-trimethoxybenzene (100). 
because it presents only an isolated singlet signal at $\delta 8.43(4 \mathrm{H}) .{ }^{156}$ The most used internal standard is 1,3,5-trymethoxybenzene (100), ${ }^{157,158}$ which shows two singlets, one at $\delta 6.08(3 \mathrm{H})$ and one at $\delta 3.77(9 \mathrm{H}) .{ }^{159}$ However, since this species is rich in electrons, it may react with any residual iodine. ${ }^{160-162}$

The applicability of this method was exemplified by a palladium-catalyzed allylic substitution published by Poli and co-workers, ${ }^{155}$ in which the whole optimization process was studied using ${ }^{1} \mathrm{H}$ NMR calculated yield, with 1,4-dinitrobenzene (99) as internal standard (Table 5). In this specific work, a maximum yield of $88 \%$ was observed using $5.0 \mathrm{~mol} \%$ of palladium acetate, $15.0 \mathrm{~mol} \%$ of triphenylphosphine, diethyl ether at room temperature for $5 \mathrm{~h}$, and these parameters were adopted as the optimized method for the scope development.

To accurately prepare your sample for this process, these steps must be followed (Figure 10):

(i) Filter the crude product on a sintered glass filter containing a layer of celite or silica.

(ii) Wash up the silica/celite using HPLC grade chloroform.

(iii) Concentrate the solution under reduced pressure to obtain a solid/semi-solid crude product.

(iv) Finalize the concentration under a high-vacuum pump.

(v) Prepare the stock solution of an internal standard by measuring a maximum of $20 \mathrm{mg}$ of 1,4-dinitrobenzene in a $1.00 \mathrm{~mL}$ volumetric flask and complete it with deuterated chloroform (or any other deuterated solvent that you may need). Be aware that 1,4-dinitrobenzene is not readily soluble in chloroform, but one minute under sonication solves this issue.

(vi) Add $50.0 \mu \mathrm{L}$ of the stock solution of the internal standard into the residual crude solid.

(vii) Dilute it with $450.0 \mu \mathrm{L}$ of deuterated solvent and place it into a $5 \mathrm{~mm}$ NMR tube.

(viii) Submit it to a ${ }^{1} \mathrm{H}$ NMR experiment.

(ix) Once the spectrum is obtained, integrate first the signal of the internal standard and calibrate it to $1 \mathrm{H}$. Afterward, integrate any signal of your molecule that is not overlapping any other one. This value obtained in this integration can then be used in the equation shown in Figure 10.

\section{Calculation of the Yield in situ Using GC-MS or HPLC}

In mass-spectrometry, the best internal standards are the most volatile ones, like $n$-dodecane ${ }^{163-166}$ or $n$-decane..$^{167-169}$ The procedure in these cases requires previous knowledge of the target product because each molecule shows a different ionization profile. It is necessary to build a calibration curve for the product in the presence of an internal standard. It is also possible to build this calibration

Table 5. Optimization of a palladium-catalyzed allylic substitution ${ }^{155}$

Poli and co-workers ${ }^{155}$
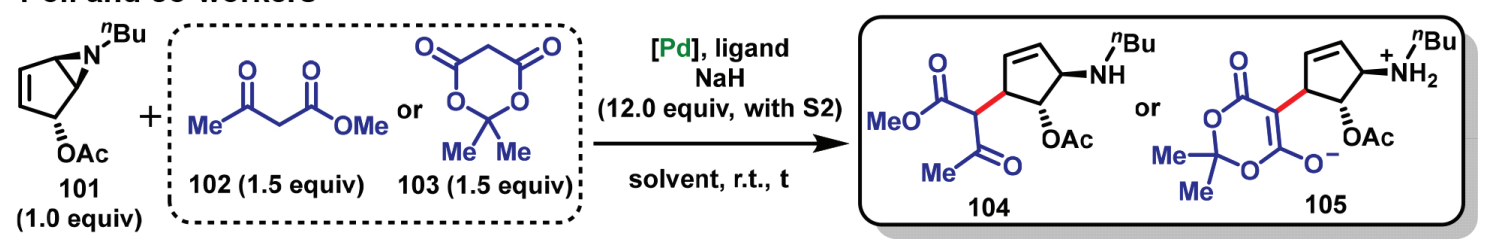

\begin{tabular}{|c|c|c|c|c|c|c|}
\hline entry & Coupling partner & [Pd] (concentration / mol\%) & Ligand (concentration / $\mathrm{mol} \%$ ) & Solvent & time $/ \mathrm{h}$ & Product (yield $\left.{ }^{\mathrm{a}} / \%\right)$ \\
\hline 1 & 102 & $\mathrm{Pd}(\mathrm{OAc})_{2}(10)$ & $\mathrm{PPh}_{3}(30)$ & THF & 4 & $104(50)$ \\
\hline 2 & 102 & $\mathrm{Pd}(\mathrm{OAc})_{2}(10)$ & dppe (20) & THF & 18 & $104(41)$ \\
\hline 3 & 102 & $\mathrm{Pd}(\mathrm{OAc})_{2}(10)$ & $\operatorname{dppf}(20)$ & THF & 18 & $104(32)$ \\
\hline 4 & 102 & $\mathrm{Pd}(\mathrm{OAc})_{2}(10)$ & $\operatorname{MeDCHB}(30)$ & THF & 18 & $104(49)$ \\
\hline 5 & 102 & {$\left[\mathrm{Pd}\left(\mathrm{C}_{3} \mathrm{H}_{5}\right) \mathrm{Cl}\right]_{2}(10)$} & dppe (20) & THF & 18 & $104(8)$ \\
\hline 6 & 102 & $\mathrm{Pd}(\mathrm{OAc})_{2}(10)$ & $\mathrm{PPh}_{3}(30)$ & $\mathrm{Et}_{2} \mathrm{O}$ & 4 & $104(59)$ \\
\hline 7 & 102 & $\mathrm{Pd}(\mathrm{OAc})_{2}(10)$ & $\mathrm{PPh}_{3}(30)$ & 1,4-dioxane & 4 & $104(72)$ \\
\hline 8 & 102 & $\mathrm{Pd}(\mathrm{OAc})_{2}(5)$ & $\mathrm{PPh}_{3}(5)$ & 1,4-dioxane & 18 & $104(74)$ \\
\hline 9 & 103 & $\mathrm{Pd}(\mathrm{OAc})_{2}(10)$ & $\mathrm{PPh}_{3}(30)$ & THF & 3 & $105(63)$ \\
\hline 10 & 103 & $\mathrm{Pd}(\mathrm{OAc})_{2}(10)$ & $\mathrm{PPh}_{3}(30)$ & 1,4-dioxane & 1.5 & $105(73)$ \\
\hline 11 & 103 & $\mathrm{Pd}(\mathrm{OAc})_{2}(10)$ & $\mathrm{PPh}_{3}(30)$ & $\mathrm{Et}_{2} \mathrm{O}$ & 3.5 & $105(84)$ \\
\hline 12 & 103 & $\mathrm{Pd}(\mathrm{OAc})_{2}(5)$ & $\mathrm{PPh}_{3}(15)$ & $\mathrm{Et}_{2} \mathrm{O}$ & 5 & $105(88)$ \\
\hline
\end{tabular}

${ }^{a}{ }^{1} \mathrm{H}$ NMR calculated yields using 1,4-dinitrobenzene as internal standard. equiv: equivalents; r.t.: room temperature; THF: tetrahydrofuran; dppe: 1,2-bis(diphenylphosphino)ethane; dppf: 1,1'-ferrocenediyl-bis(diphenylphosphine); MeDCHB: 2-dicyclohexylphosphino-2'-methylbiphenyl. 

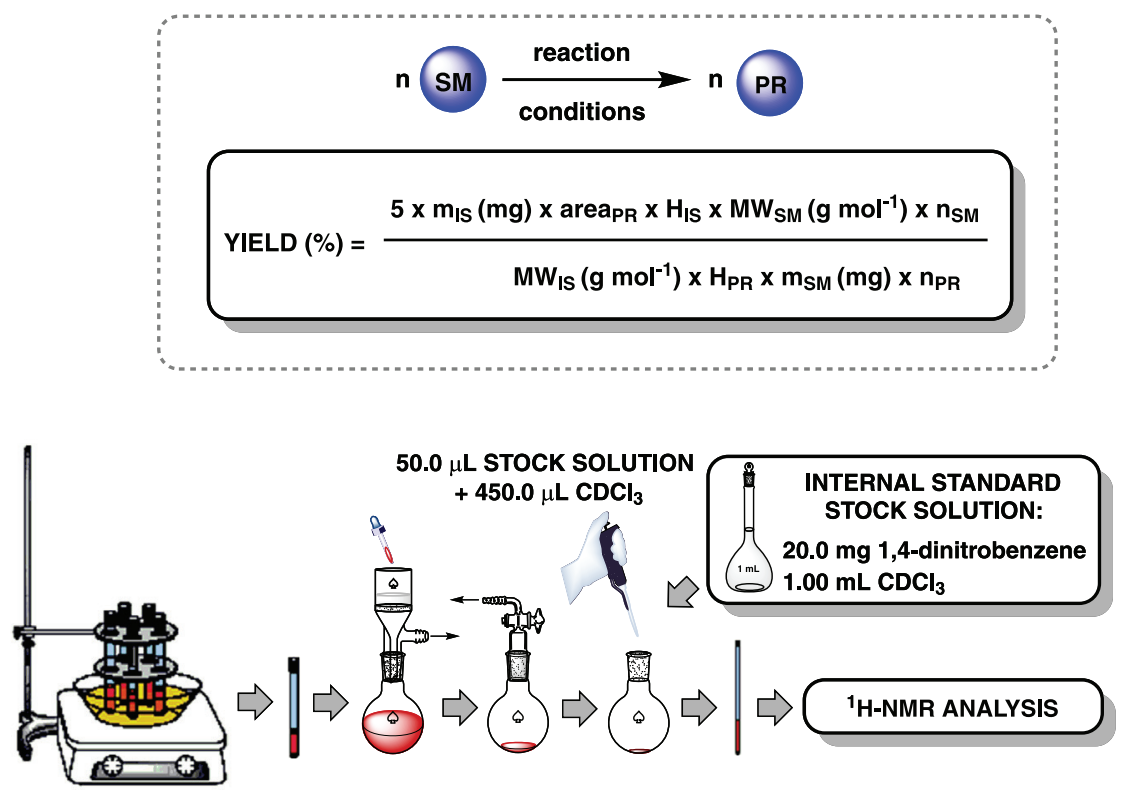

Figure 10. Flowchart to calculate yield in situ using ${ }^{1} \mathrm{H}$ NMR analysis (see text). $\mathrm{m}_{\mathrm{IS}}$ : mass of internal standard; area $\mathrm{PR}_{\mathrm{PR}}$ obtained area of the signal of the

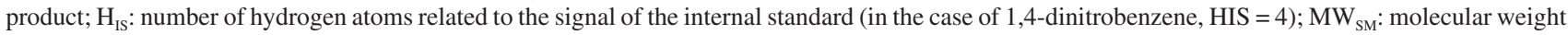
of the starting material; $\mathrm{n}_{\mathrm{SM}}$ : molar equivalence of the starting material from the balanced equation; $\mathrm{MW}_{\mathrm{IS}}$ : molecular weight of the internal standard (in the case of 1,4-dinitrobenzene, $\left.\mathrm{MW}_{\mathrm{IS}}=168.1\right) ; \mathrm{H}_{\mathrm{PR}}$ : number of hydrogen atoms related to the signal of the product; $\mathrm{m}_{\mathrm{SM}}$ : applied mass of starting material; $\mathrm{n}_{\mathrm{PR}}$ : molar equivalence of the product from the balanced equation.

curve and perform the analysis without any internal standard, but this procedure does not protect the collected data from possible measuring mistakes.

Morandi and co-workers ${ }^{163}$ published a notable but straightforward and extremely important work about a palladium-catalyzed chlorocarbonylation in which the optimization was built using GC calculated yield (Table 6). In this case, $n$-dodecane was used as an internal standard. It is worth mentioning that product $\mathbf{1 0 8}$ was not directly analyzed, but its corresponding methyl ester $\mathbf{1 0 9}$

Table 6. Optimization of a palladium-catalyzed chlorocarbonylation ${ }^{163}$

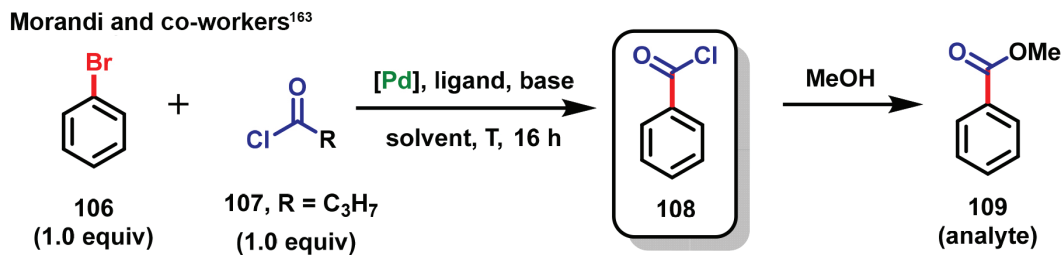

\begin{tabular}{|c|c|c|c|c|c|c|}
\hline entry & {$[\mathrm{Pd}]($ concentration / mol\%) } & Ligand (concentration / mol\%) & Base (equiv.) & Solvent & $\mathrm{T} /{ }^{\circ} \mathrm{C}$ & Yield $^{\mathrm{a}} / \%$ \\
\hline 1 & $\operatorname{Pd}(\mathrm{dba})_{2}(5)$ & Xantphos (10) & DIPEA (2.0) & toluene & 100 & 25 \\
\hline 2 & $\operatorname{Pd}(\mathrm{dba})_{2}(5)$ & $\mathrm{P}^{t} \mathrm{Bu}_{3}(10)$ & DIPEA (2.0) & toluene & 100 & 18 \\
\hline 3 & $\operatorname{Pd}(\mathrm{dba})_{2}(5)$ & BrettPhos (10) & DIPEA (2.0) & toluene & 100 & 2 \\
\hline $4^{\mathrm{b}}$ & $\operatorname{Pd}(\mathrm{dba})_{2}(5)$ & Xantphos (10) & DIPEA (2.0) & toluene & 100 & traces \\
\hline 5 & $\operatorname{Pd}(\mathrm{dba})_{2}(10)$ & Xantphos (10) & DIPEA (2.0) & toluene & 100 & 18 \\
\hline 6 & $\operatorname{Pd}(\mathrm{dba})_{2}(2.5)$ & Xantphos (5) & DIPEA (2.0) & toluene & 100 & 20 \\
\hline 7 & $\operatorname{Pd}(\mathrm{dba})_{2}(5)$ & Xantphos (10) & DIPEA (2.0) & toluene & 80 & 10 \\
\hline 8 & $\operatorname{Pd}(\mathrm{dba})_{2}(5)$ & Xantphos (10) & DIPEA (2.0) & 1,4-dioxane & 100 & 23 \\
\hline 9 & $\operatorname{Pd}(\mathrm{dba})_{2}(5)$ & Xantphos (10) & $\mathrm{NEt}_{3}(2.0)$ & toluene & 100 & 8 \\
\hline 10 & $\operatorname{Pd}(\mathrm{dba})_{2}(5)$ & Xantphos (10) & $\mathrm{K}_{3} \mathrm{PO}_{4}(2.0)$ & toluene & 100 & - \\
\hline 11 & $\operatorname{Pd}(\mathrm{dba})_{2}(5)$ & Xantphos (10) & DIPEA (2.0) & $\mathrm{Et}_{2} \mathrm{O}$ & 100 & 31 \\
\hline $12^{\mathrm{c}}$ & $\operatorname{Pd}(\mathrm{dba})_{2}(5)$ & Xantphos (10) & DIPEA (2.0) & $\mathrm{Et}_{2} \mathrm{O}$ & 100 & 83 \\
\hline
\end{tabular}

${ }^{\mathrm{a}} \mathrm{GC}$ calculated yields related to the in situ derivated methyl ester using $n$-dodecane as internal standard. ${ }^{\mathrm{b}} \mathrm{R}=\mathrm{C}_{4} \mathrm{H}_{9}$ ( 3.0 equiv). ${ }^{\mathrm{c}} \mathrm{PhBr}$ (3.0 equiv). equiv: equivalents; T: temperature; dba: dibenzylideneacetone; DIPEA: $N, N$-diisopropylethylamine. 
was generated in situ by treatment with methanol. This procedure guarantees not only the stability of the product to be purified in the long column of the GC, but also the volatility which is to be high enough for the required vaporization in GC analysis.

Before preparing the mixture, it is important to know the behavior of the product and the internal standard in the adopted method of the chromatographic equipment. It is crucial to find out an optimized way where, on the same screen, it is possible to see the peak of the internal standard and the product separately (hint: usually, the internal bar shows up first since it is usually more volatile). Do not correlate the height of the peaks in a qualitatively fashion, assuming that a higher peak belongs to a more concentrated species. It always depends on the ionization capacity of the compound.

Start preparing a stock solution of the internal standard by solubilizing it in the solvent that will be used in the chromatographic method (usually, dichloromethane for GC-MS and methanol or acetonitrile for HPLC). The final concentration to be analyzed depends on the expected final concentration of the product and the detection limit of the equipment. These chromatographic equipment are usually very sensible, so a low-concentrated final solution must be considered for this matter. It is desirable to inject around $5 \mathrm{ng}$ of the internal standard in the equipment, and considering a volume of injection of $100 \mu \mathrm{L}$, so the following steps must be followed (Figure 11). (i) Place $50.0 \mu \mathrm{L}(37.5 \mathrm{mg}=0.22 \mathrm{mmol})$ of dodecane in a $100.00 \mathrm{~mL}$ volumetric flask and complete it with HPLC grade dichloromethane. This is the stock solution A (2.2 $\mathrm{mM})$ of the internal standard.

(ii) Transfer $66.0 \mu \mathrm{L}$ of the stock solution A into a $5.00 \mathrm{~mL}$ volumetric flask and complete it with HPLC grade dichloromethane. This is the stock solution B $(0.029 \mathrm{mM})$ of the internal standard.

Once the stock solution B is ready, it is time to prepare the samples to build the calibration curve:

(i) Place $0.2 \mathrm{mmol}$ of the target compound into a $100.00 \mathrm{~mL}$ volumetric flask and dissolve it in the complete volume of solvent (the same as the internal standard stock solution, in this example, HPLC grade dichloromethane). This is the stock solution $\mathrm{C}(2.0 \mathrm{mM})$ of your target compound.

(ii) Transfer $100 \mu \mathrm{L}$ of the stock solution C into a $10.00 \mathrm{~mL}$ volumetric flask and complete it with the solvent. This is the solution $\mathrm{D}(0.020 \mathrm{mM})$ of the point I of the curve.

(iii) Transfer $5.00 \mathrm{~mL}$ of the stock solution $\mathrm{D}$ into another $10.00 \mathrm{~mL}$ volumetric flask and complete it with the solvent, generating the stock solution $\mathrm{E}(0.010 \mathrm{mM})$ of the point II of the curve.

(iv) Repeat the previous process consecutively to generate the stock solutions $\mathrm{F}(0.005 \mathrm{mM})$ and $\mathrm{G}(0.002 \mathrm{mM})$ of the points III and IV of the curves, respectively.

The points I $(0.020 \mathrm{mM})$, II $(0.010 \mathrm{mM})$, III $(0.005 \mathrm{mM})$ and IV $(0.002 \mathrm{mM})$ can be generated by placing $100 \mu \mathrm{L}$ of the stock solution B and $900 \mu \mathrm{L}$ of the respective stock

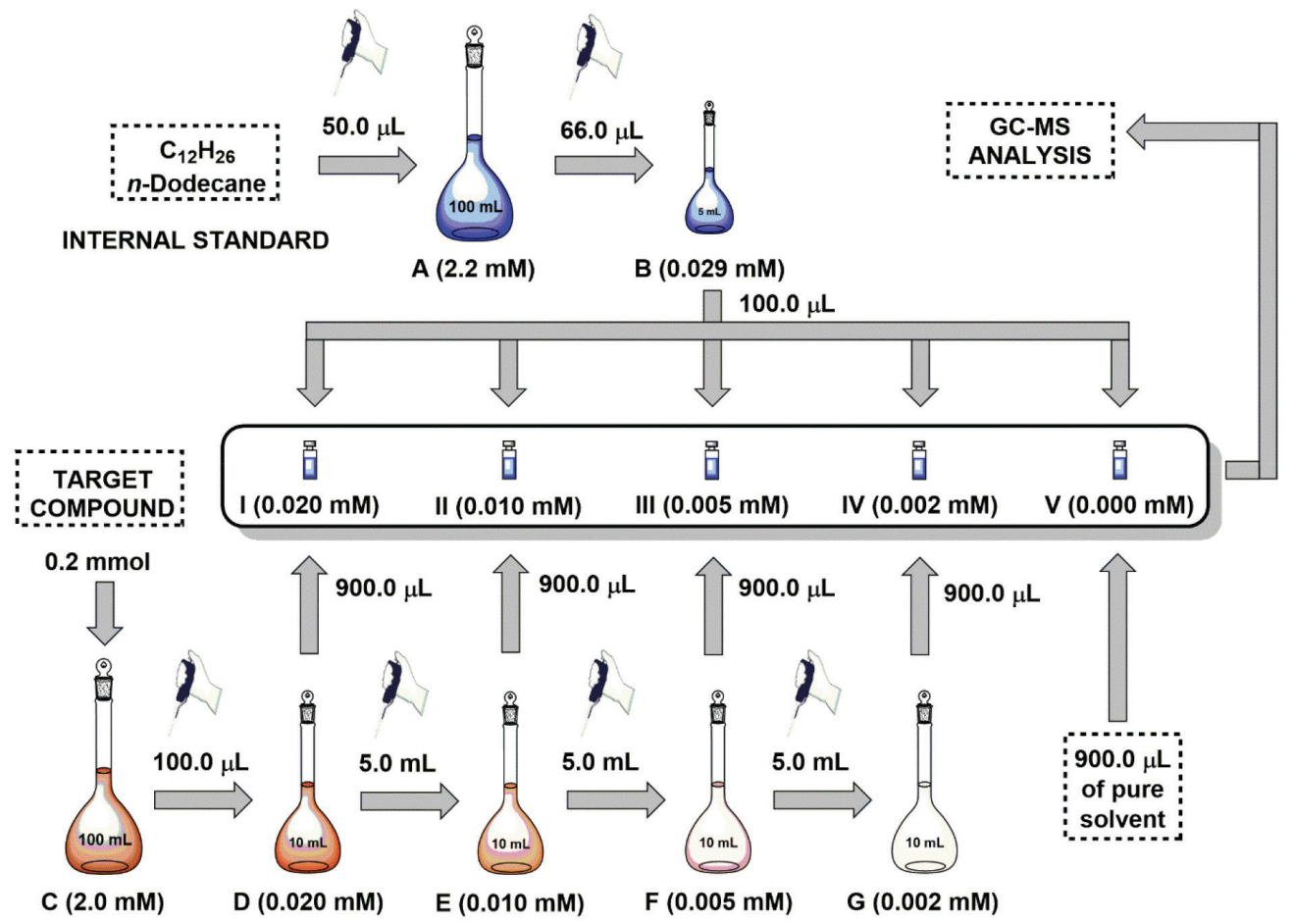

Figure 11. Flowchart to build the calibration curve (see text for further information). 
solution of the target compound in a $1.5 \mathrm{~mL}$ GC-MS vial. The fifth and last vial, point $\mathrm{V}$, as a negative control, only has $100 \mu \mathrm{L}$ of the stock solution $\mathrm{B}$ and $900 \mu \mathrm{L}$ of pure solvent, without any target product in it.

When the measurement is done, it is possible to get the integral of the peaks of the internal standard $\left(\mathrm{A}_{\mathrm{S}-\mathrm{I}}, \mathrm{A}_{\mathrm{S}-\mathrm{II}}, \mathrm{A}_{\mathrm{S}-\mathrm{III}}\right.$, $\mathrm{A}_{\mathrm{S}-\mathrm{IV}}$ and $\mathrm{A}_{\mathrm{S}-\mathrm{V}}$ ), which are expected to be around the same value, and the integral of the peaks of the target compound $\left(\mathrm{A}_{\mathrm{T}-\mathrm{I}}, \mathrm{A}_{\mathrm{T}-\mathrm{II}}, \mathrm{A}_{\mathrm{T}-\mathrm{III}}, \mathrm{A}_{\mathrm{T}-\mathrm{IV}}\right.$ and $\left.\mathrm{A}_{\mathrm{T}-\mathrm{V}}\right)$. These data must be placed on a table (Table 7 ) to facilitate the next steps.

Using the columns "Concentration" and " $\mathrm{A}_{\mathrm{T}} / \mathrm{A}_{\mathrm{S}}$ " of Table 7, it is possible to build a linear graph (Figure 12). The linear regression of this graph will give the correlation between concentration of product and the measured ratio of peak areas $A_{T} / A_{S}$; this is the equation to be used in the experiment. Note that coefficient of determination $\left(\mathrm{R}^{2}\right)$ must be close to 1.000 to validate this method as an appliable one. If it is not so close to 1.000 , it means that this equation will produce wrong values; therefore, it is suggested to try to build the calibration curve again from the beginning.

Now that you have the linear regression in hand, with the correct correlation between the ratio of areas and the concentration, you can perform the reaction and prepare your sample to be analyzed. Assuming a usual reaction, where the stoichiometry between reactant and product is $1: 1$, and $0.2 \mathrm{mmol}$ of reactant is used in $2.0 \mathrm{~mL}$ of solvent, the following process must the followed (Figure 13).

(i) Place $10.0 \mu \mathrm{L}$ of your crude reaction into a $5.00 \mathrm{~mL}$ volumetric flask and complete it with HPLC grade
Table 7. Template for application of collected data

\begin{tabular}{lcccc}
\hline Point & $\begin{array}{c}\text { Concentration } / \\
\mathrm{mM}\end{array}$ & $\mathrm{A}_{\mathrm{S}}{ }^{\mathrm{a}}$ & $\mathrm{A}_{\mathrm{T}}{ }^{\mathrm{b}}$ & $\mathrm{A}_{\mathrm{T}} / \mathrm{A}_{\mathrm{S}}{ }^{\mathrm{c}}$ \\
\hline $\mathrm{I}$ & 0.020 & $\mathrm{~A}_{\mathrm{S}-\mathrm{I}}$ & $\mathrm{A}_{\mathrm{T}-\mathrm{I}}$ & $\mathrm{A}_{\mathrm{T}-\mathrm{I}} / \mathrm{A}_{\mathrm{S}-\mathrm{I}}$ \\
II & 0.010 & $\mathrm{~A}_{\mathrm{S}-\mathrm{II}}$ & $\mathrm{A}_{\mathrm{T}-\mathrm{II}}$ & $\mathrm{A}_{\mathrm{T}-\mathrm{II}} / \mathrm{A}_{\mathrm{S}-\mathrm{II}}$ \\
III & 0.005 & $\mathrm{~A}_{\mathrm{S}-\mathrm{III}}$ & $\mathrm{A}_{\mathrm{T}-\mathrm{III}}$ & $\mathrm{A}_{\mathrm{T}-\mathrm{III}} / \mathrm{A}_{\mathrm{S}-\mathrm{III}}$ \\
IV & 0.002 & $\mathrm{~A}_{\mathrm{S}-\mathrm{IV}}$ & $\mathrm{A}_{\mathrm{T}-\mathrm{IV}}$ & $\mathrm{A}_{\mathrm{T}-\mathrm{IV}} / \mathrm{A}_{\mathrm{S}-\mathrm{IV}}$ \\
$\mathrm{V}$ & 0.000 & $\mathrm{~A}_{\mathrm{S}-\mathrm{V}}$ & $\mathrm{A}_{\mathrm{T}-\mathrm{V}}$ & $\mathrm{A}_{\mathrm{T}-\mathrm{V}} / \mathrm{A}_{\mathrm{S}-\mathrm{V}}$ \\
\hline
\end{tabular}

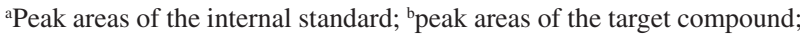
cratio of peak areas of the target compound $\left(\mathrm{A}_{\mathrm{T}}\right)$ and internal standard $\left(\mathrm{A}_{\mathrm{s}}\right)$.

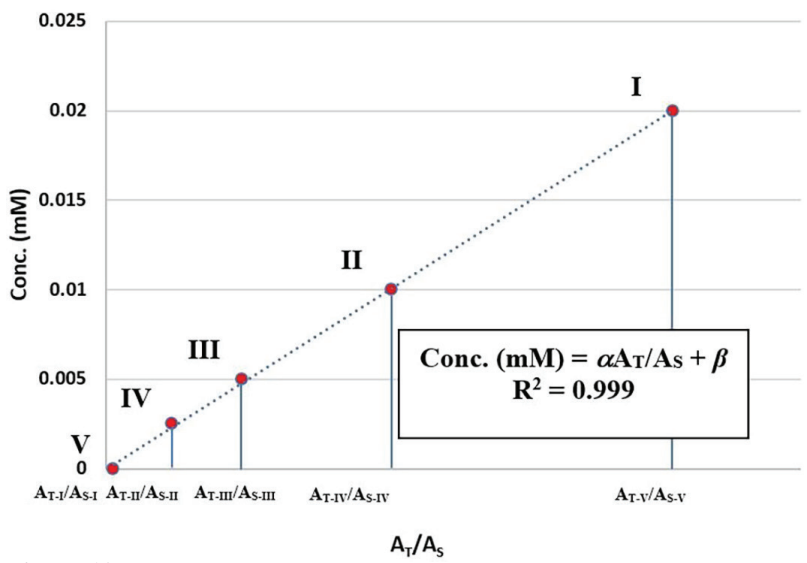

Figure 12. Example of a linear graph between the concentration of product and ratio of areas of chromatogram peaks.

dichloromethane, generating the stock solution $\mathrm{H}$ of your reaction (hint: even if the solvent used in the reaction is not
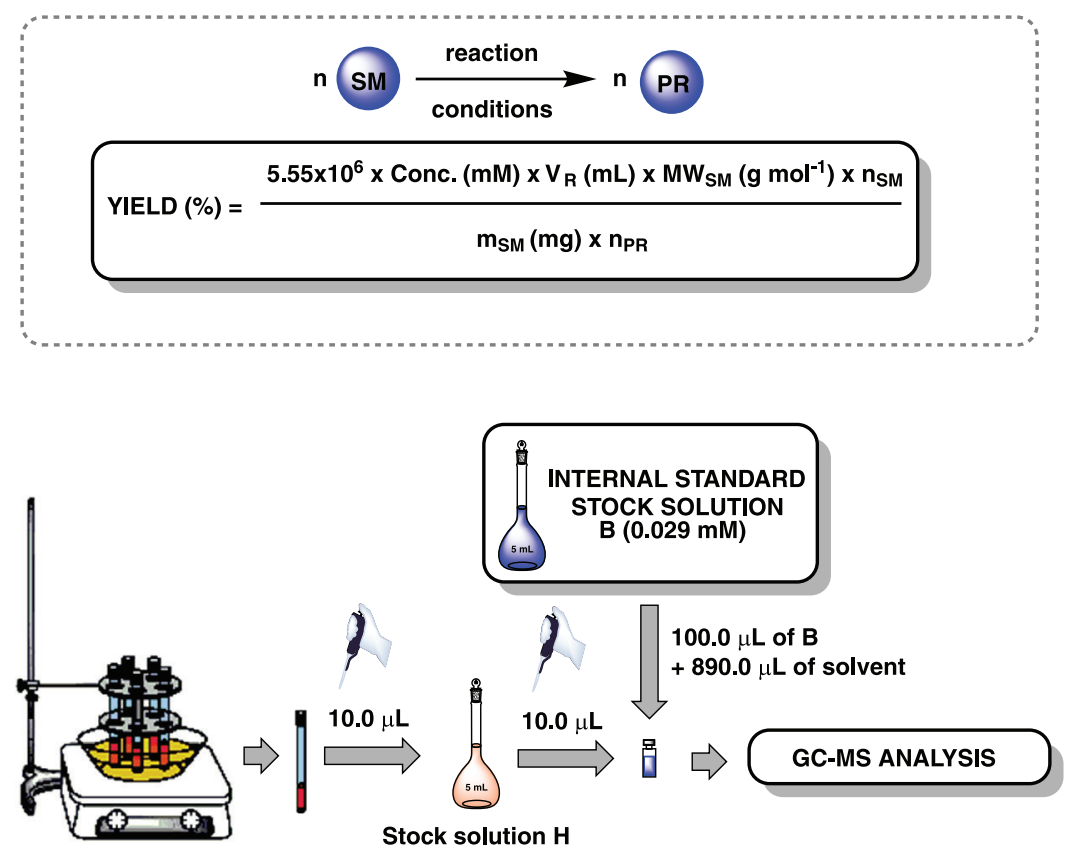

Figure 13. Flowchart to calculate yield in situ using GC-MS analysis. Conc.: concentration of product obtained from the linear equation; $\mathrm{V}_{\mathrm{R}}$ : volume of solvent applied in the reaction; $\mathrm{MW}_{\mathrm{SM}}$ : molecular weight of the starting material; $\mathrm{n}_{\mathrm{SM}}$ : molar equivalence of the starting material from the balanced equation; $\mathrm{m}_{\mathrm{SM}}$ : applied mass of starting material; $\mathrm{n}_{\mathrm{PR}}$ : molar equivalence of the product from the balanced equation. 
dichloromethane, the dilution will be high enough to almost cancel the effect of the solvent to the system).

(ii) Transfer $10.0 \mu \mathrm{L}$ of your stock solution $\mathrm{H}$ into a $1.5 \mathrm{~mL}$ vial, add $100.0 \mu \mathrm{L}$ of the stock solution B of the internal standard and complete it with $890.0 \mu \mathrm{L}$ of solvent.

(iii) Submit the sample to the GC-MS analysis using the same instrumental method used to build the calibration curve and get the ratio $\mathrm{A}_{\mathrm{T}} / \mathrm{A}_{\mathrm{S}}$.

(iv) Place this value in the linear equation and get the concentration that you have on the original vial. From this, it is possible to obtain the calculated yield using the equation shown in Figure 13.

\section{Building Up a Scope}

After the optimized method is achieved, it is necessary to evaluate its behavior when applied to other substrates containing different substituents. The initial idea is to synthesize different substrates with a molecular structure similar to the one used in the optimization process, but with slight variations. ${ }^{170,171}$ der Eycken and co-workers ${ }^{172}$ published a notable work about a $\mathrm{C}-\mathrm{H}$ activation catalyzed by ruthenium, on which two tables were constructed basing on simple variations on both substrates 71a and 110a (Scheme 20). The variations on the main substrate (compound 71) are originated from commercially available indoles 71a-71i containing bromide, fluoride, methyl and methoxy on different positions. The variations on the secondary substrate (compound 110) are more diverse (110b-110o), from simple aryl substituents on different positions to enantiopure alkyl groups. ${ }^{172}$ The synthesis of these substrates must be simple, applying mostly reactants that are commercially available or that were submitted to well-known reactions (like acetylation, nitration or halogenation), so not too much time will be spent in this step. Be aware that, obviously, not every substrate that will be tried will work, so the best strategy is to plan everything, exceeding the expected number of examples.

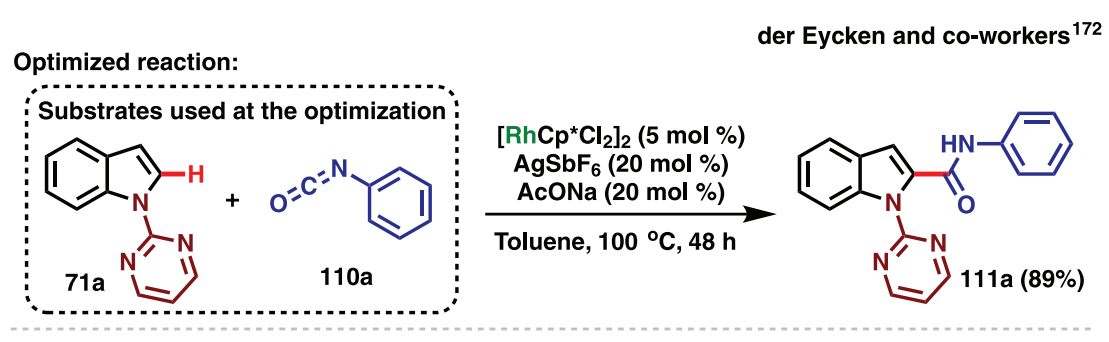

Variations on substrate 1:

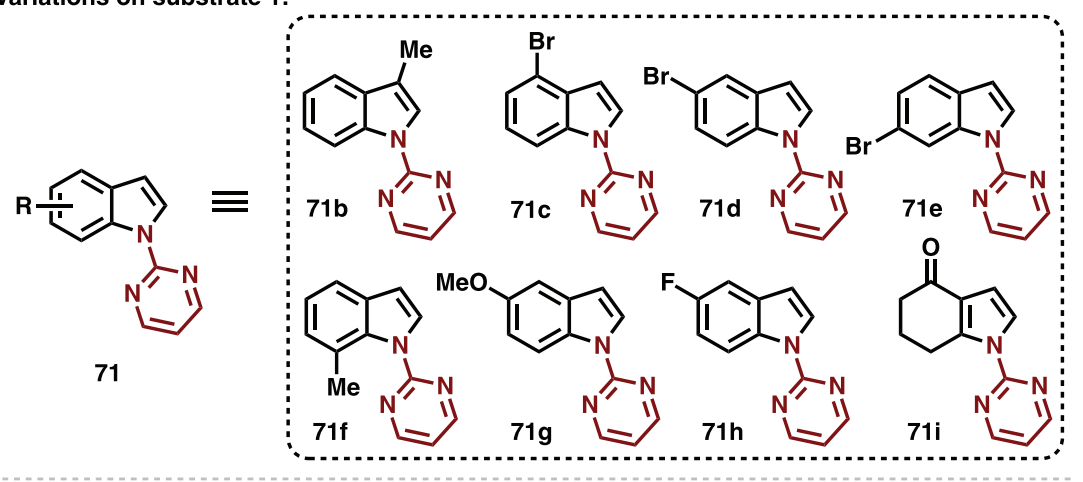

Variations on substrate 2:

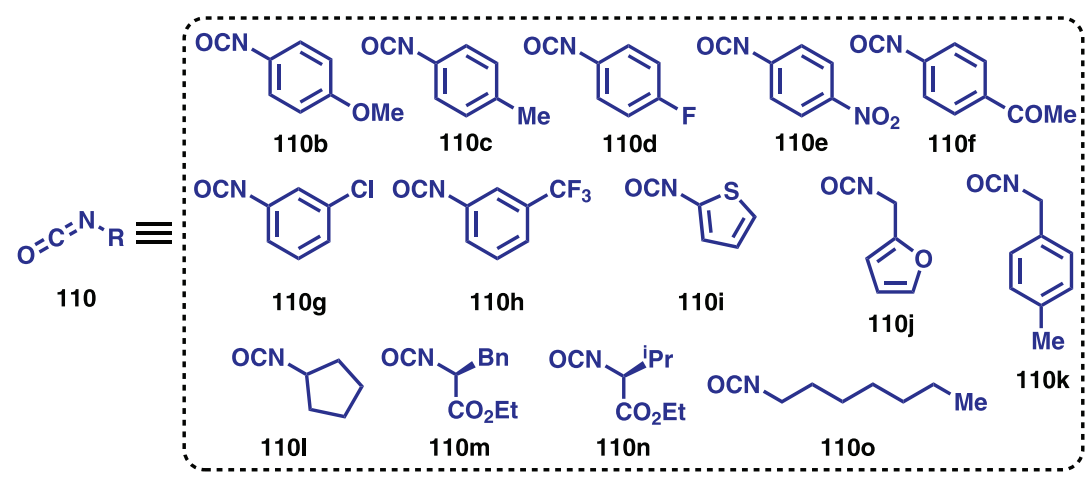

Scheme 20. Scope variations on the $\mathrm{C}-\mathrm{H}$ activation reported by der Eycken and co-workers. ${ }^{172}$ 
The number of products that will compose the final scope table will depend on how appliable the reaction is and how accessible it is to do the modifications. Usually, the publishers choose a number between 10 and 16 examples in each table, ${ }^{173-176}$ considering that this amount can give a great variety from where it may be possible to analyze the effect of the substituents to the reaction. If 12 is the number to be adopted, consider then planning the synthesis of at least the double of it. Sometimes not all the 24 planned reactions need to be performed; sometimes, it is not enough. When planning the synthesis, it is necessary that the variety of substituents covers every important aspect that may interfere or even improve the performance of the reaction, using, for example, electron-withdrawing groups $\left(\mathrm{NO}_{2}, \mathrm{~F}, \mathrm{C}=\mathrm{O}\right)$ and donating groups $(\mathrm{OMe}, \mathrm{SPh}$, alkyl, etc.). ${ }^{173-176}$

It is essential to perform the characterization of every intermediate and every obtained substrate before applying them to the reaction, so there will be no mistake about the expected structure. If the substrate is already known in the literature, it is possible to either explicitly elaborate synthesis and characterization ${ }^{177-179}$ or maybe just citing from where the method was obtained from the literature. ${ }^{180-182}$ Now, if the substrate (or any intermediate) is new, then the full characterization is required to publish the result, which includes NMR spectroscopic analysis, IR spectroscopic analysis, high resolution mass spectrometry (HR-MS) analysis, and melting point. ${ }^{183,184}$ If it is possible to obtain a single-crystal of the product suitable for X-ray analysis can also be an essential tool to corroborate the structure of the compound.

It is also essential to submit the substrate to the optimized methodology as soon as it is synthesized and fully characterized. Do not wait until all planned substrates are achieved, because it is important to consider that not all of them will work. It is strictly important to consider that the substrates that did not work or that did not work so well may require some specific adaptations of the optimized method in order to improve their performance. These adaptations include increasing or decreasing the time of reaction, temperature, modifying the used solvent, increasing or decreasing the catalyst loading, modifying the used additive or the applied stoichiometry. Therefore, it is important to perform a small screening (fine tuning) on these substrates to find the required conditions in which they will offer their best performance.

An aspect that is very important in a publication is the final purpose of the developed research, on other words, what can be the direct social contribution of that new methodology. To cover this aspect, a late-stage study with some more complex molecules can be explored, ${ }^{138,185-189}$ which also improves the layout of the work. Some publishers build a side smaller scope table, with only a few examples, or add these more complex examples in the main table itself, applying the method to a substrate that resembles either a pharmacological compound or a natural compound. A good example published by Ackermann and co-workers ${ }^{138}$ explored a manganesecatalyzed $\mathrm{C}-\mathrm{H}$ alkynylation on several substrates, including a steroid-based compound 112, from which product $\mathbf{1 1 3}$ was obtained in $98 \%$ yield (Scheme 21 ).

Some other publishers increase the scale of the methodology to assure that the method is industrially applicable, making any modification that may be needed. ${ }^{175,190-195}$ The main idea here is to link the published work with other scientific fields, giving a plausible meaning to it. In 2017, Yu and co-workers ${ }^{190}$ reported a notable meta-selective $\mathrm{C}-\mathrm{H}$ arylation on a phenethylamine $\mathbf{1 1 4}$, reaching 116 in $88 \%$ yield on a smaller scale of $0.1 \mathrm{mmol}$ of the substrate. The same reaction was scaled-up to $3.0 \mathrm{mmol}$ of the substrate with no modification at all, other than the stoichiometric scaling, and a yield of $85 \%$ was successfully achieved (Scheme 22).

\section{Mechanistic Studies}

Once the whole methodology is built, it is often necessary to complete the project using a complementary study, such as mechanistic studies, biological assays, or derivatization studies. It is possible to make a plan that includes these studies previously, so they can be developed while the optimization or the scope is also under development. Some groups can count on very sophisticated pieces of equipment to do so, but usually, these side studies are done via collaboration with other groups that have an infrastructure built specifically for this purpose.
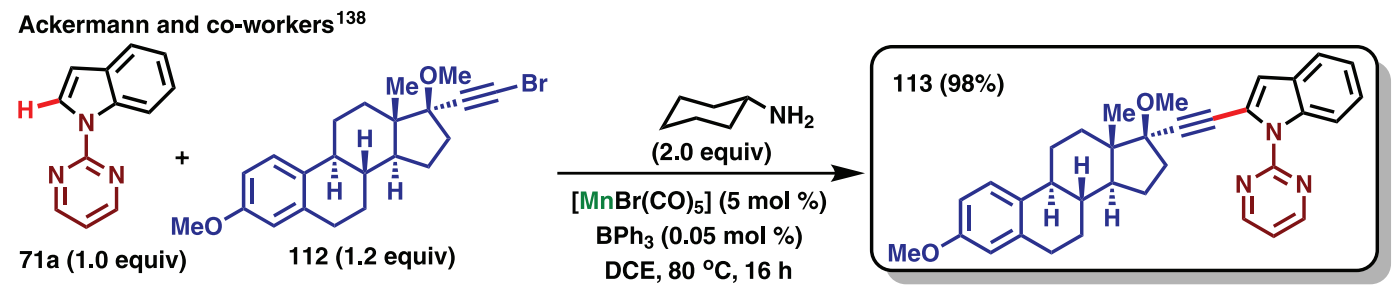

Scheme 21. Late-stage example using a steroid-based substrate. ${ }^{138}$ 


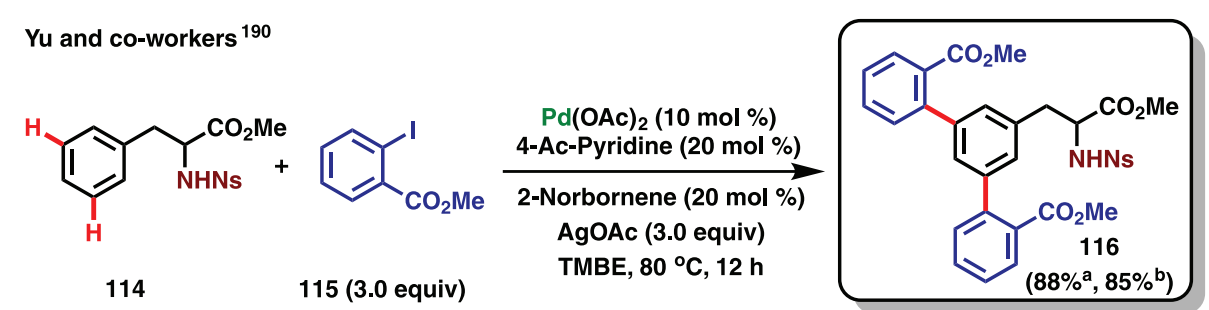

Scheme 22. Comparison of small-scale and large-scale C-H activations. ${ }^{190}$ aNormal-scale reaction: $0.1 \mathrm{mmol}$ of substrate; ${ }^{\mathrm{b}}$ scaled-up reaction: $3.0 \mathrm{mmol}$ of substrate.

There are several ways to understand how the reaction works; the chosen one depends basically on how known that reaction is, and what it is accessible and meaningful to the researcher. The simplest way to propose a mechanism to a reaction is basing on previously published materials similar to the one that is being developed. ${ }^{34,195-197}$ This will assure that the mechanism that is being proposed will be accepted by the chemical society. Like the remarkable work published by Dixneuf and co-workers ${ }^{196}$ about sequential ruthenium-catalyzed $\mathrm{C}-\mathrm{H}$ arylation (Scheme 23), where a plausible mechanism was proposed based on two works previously published by Jutand and co-workers in $2011^{198}$ and $2013 .{ }^{199}$ Since it is a double $\mathrm{C}-\mathrm{H}$ arylation on two chemically-corresponding sites of the molecule 117 ortho-positioned to the directing group, the proposed mechanism covers only the first cycle, indicating that the second cycle happens just like the first one.

If it is a completely new reaction, then this method of mechanistic study may not be enough. Remember that the mechanism must be acceptable to the whole scientific community, not only to the publisher or the referees involved in the manuscript analysis.

Another way to build a mechanism is based on computational studies, with the calculation of the relative Gibbs free energy for all the intermediates and their respective transition states. ${ }^{200-202}$ Even though it is not a "bench experiment", computational studies can offer valuable information about the mechanism and relative stability of the intermediates, including plausible solutions that may help to improve the performance of the reaction. Dong and co-workers ${ }^{203}$ published an important work about a palladium-catalyzed $\mathrm{C}-\mathrm{H}$ arylation of free primary amines (120) via an in situ transient directing-group generations with the ligand quinoline-8-carbaldehyde. Two years later, Chen and co-workers ${ }^{201}$ proposed a mechanism for this reaction based on previously published materials, ${ }^{204-207}$ in which it was perceived that, without the ligand $\mathbf{1 2 1}$, no reaction is observed. The authors also corroborated these proposed data using computational studies, in which the relative energy of the main intermediates was calculated (Scheme 24).

Bench experiments are also possible to either corroborate the computational experiment or/and the literature-based proposal or even to generate a whole new mechanistic proposal. ${ }^{193,208-211}$ The most usual ones include a simple reaction between the reactants and the catalyst. This process is tricky since the obtained material usually cannot be submitted to column chromatography, otherwise, the obtained complex, which is supposed to resemble the most important intermediate, can be destroyed by the free hydroxyl groups and the high contact surface of the silica. Usually, a crystallization of the obtained complex generates a single crystal that can be submitted to crystallographic studies via X-ray diffraction without compromising its structure.

Maiti and co-workers ${ }^{193}$ developed an ortho-directed cobalt-catalyzed $\mathrm{C}-\mathrm{H}$ activation in which biphenyl activated amines (125) were obtained in good yields. In this work, the authors identified a five-membered organometallic cobalt-ring (123-A) via X-ray analysis when reacting the catalyst with the substrate $\mathbf{1 2 3}$, and they also developed kinetic studies to evaluate the behavior of the reaction over time. These combined data led the authors to propose a plausible mechanism for discovering $\mathrm{C}-\mathrm{H}$ activation (Scheme 25).

High-resolution mass spectrometry is another powerful tool for mechanistic studies. ${ }^{212-216}$ In this field, once the general reaction is set, a sample of it is taken every once in a fixed and constant time frame and submitted to the HRMS equipment. With the spectra in hands, it is possible to identify some peculiar signals that are neither the reactants nor the expected products. The intermediates usually present a mass that is near the sum of the masses of the catalyst plus one of the reactants (or even both reactants) and also show the profile of the isotopic abundance of the metal ion used in the catalyst. Every metal has a specific profile of isotopic abundance that can be considered a fingerprint of it. ${ }^{217}$ The correct interpretation of the collected data starts from a proper database, from which it is possible to compare the obtained signals with the expected ones from the literature or computational data. The fact that the reaction happens in solvent media and the HR-MS experiments happen under vacuum must be considered as well, since the solvent can be part of the mechanism, and this correlation will not be shown in the spectra. 

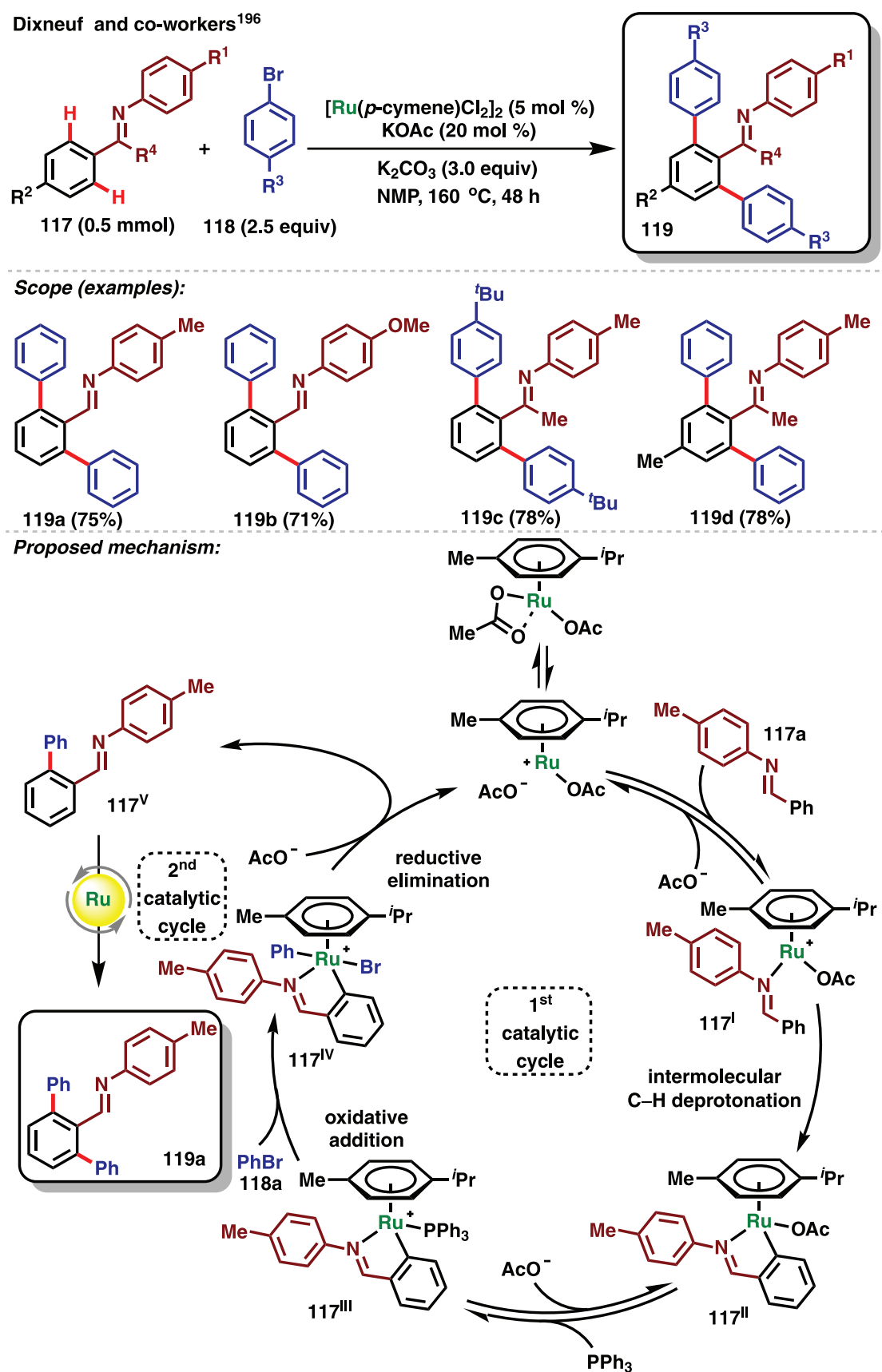

Scheme 23. Sequential ruthenium catalyzed C-H arylation and its proposed mechanism. ${ }^{196}$

A notable example can be extracted from the work published by Cooks and co-workers ${ }^{214}$ in which the authors adapted an interesting system to directly analyze the progress of the reaction in a real-time fashion via a purge of inert gas on the system, generating a manufactured electro-spray that is directly faced to the skimmer of the mass-spectrometer (Scheme 26). This system made the identification of three intermediates of a palladium-catalyzed Negishi crosscoupling reaction possible. Even though this is not a $\mathrm{C}-\mathrm{H}$ activation reaction, it is worth citing here due to its valuable contribution to the chemical society.

\section{Biological Assays}

Several compounds are known for their high biological activities to treat diseases like cancer, ${ }^{218}$ malaria, ${ }^{219}$ Chagas disease, ${ }^{220}$ human immunodeficiency virus (HIV), ${ }^{221}$ and even more recently, COVID-19 (coronavirus disease). ${ }^{222}$ It is important to know in advance the biological contribution that can be expected from the novel compound and to have a good collaboration for these biological assays. Try to understand how the biological experiments works so it may be possible to contribute appropriately to this side of the research. 

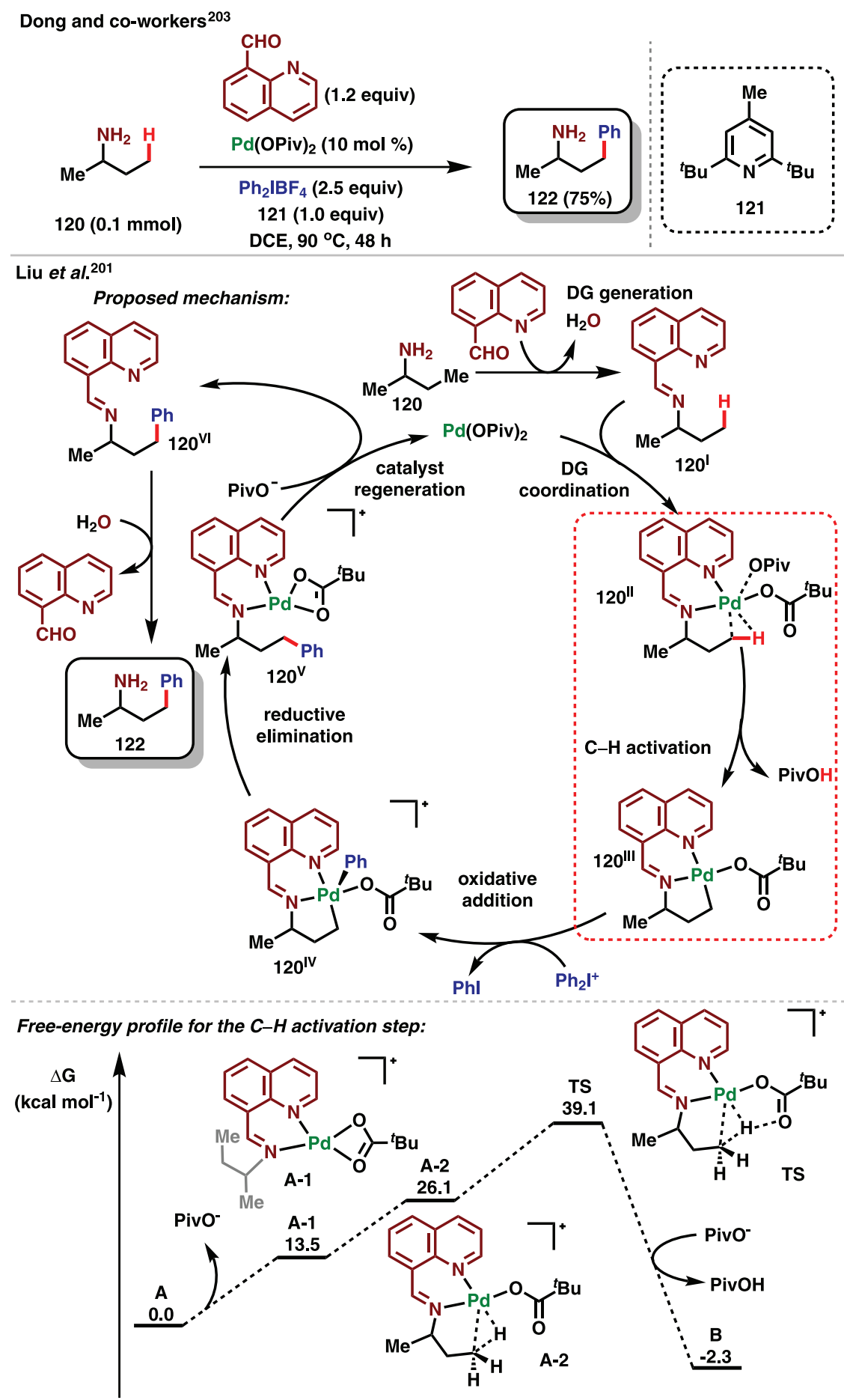

Scheme 24. Palladium-catalyzed C-H arylation of a free primary amine ${ }^{203}$ and its mechanistic studies by computational analysis. ${ }^{201}$

Nowadays, Chagas disease is a dangerous disease that is an issue in tropical countries like Brazil. ${ }^{223-226}$ Having this in mind, in $2018^{220}$ and $2019,{ }^{227}$ we reported a ruthenium-catalyzed $\mathrm{C}-\mathrm{H}$ oxygenation and alkenylation reactions, respectively, of quinones $\mathbf{2 6}$ in which quinones modified at the C-8 position (128 and $\mathbf{1 2 9}$ ), that were obtained in good yields. These quinones were submitted to trypanocidal analysis and nine molecules presented a good half maximal inhibitory concentration $\left(\mathrm{IC}_{50}\right)$ against the Trypanosoma cruzi (Scheme 27). More specifically, two of these nine compounds are more than 3.0 times active compared to benznidazole, which is the most common drug employed to treat Chagas disease.

Strategy: even if the achieved product may not present a valuable activity against a specific disease, it can present 

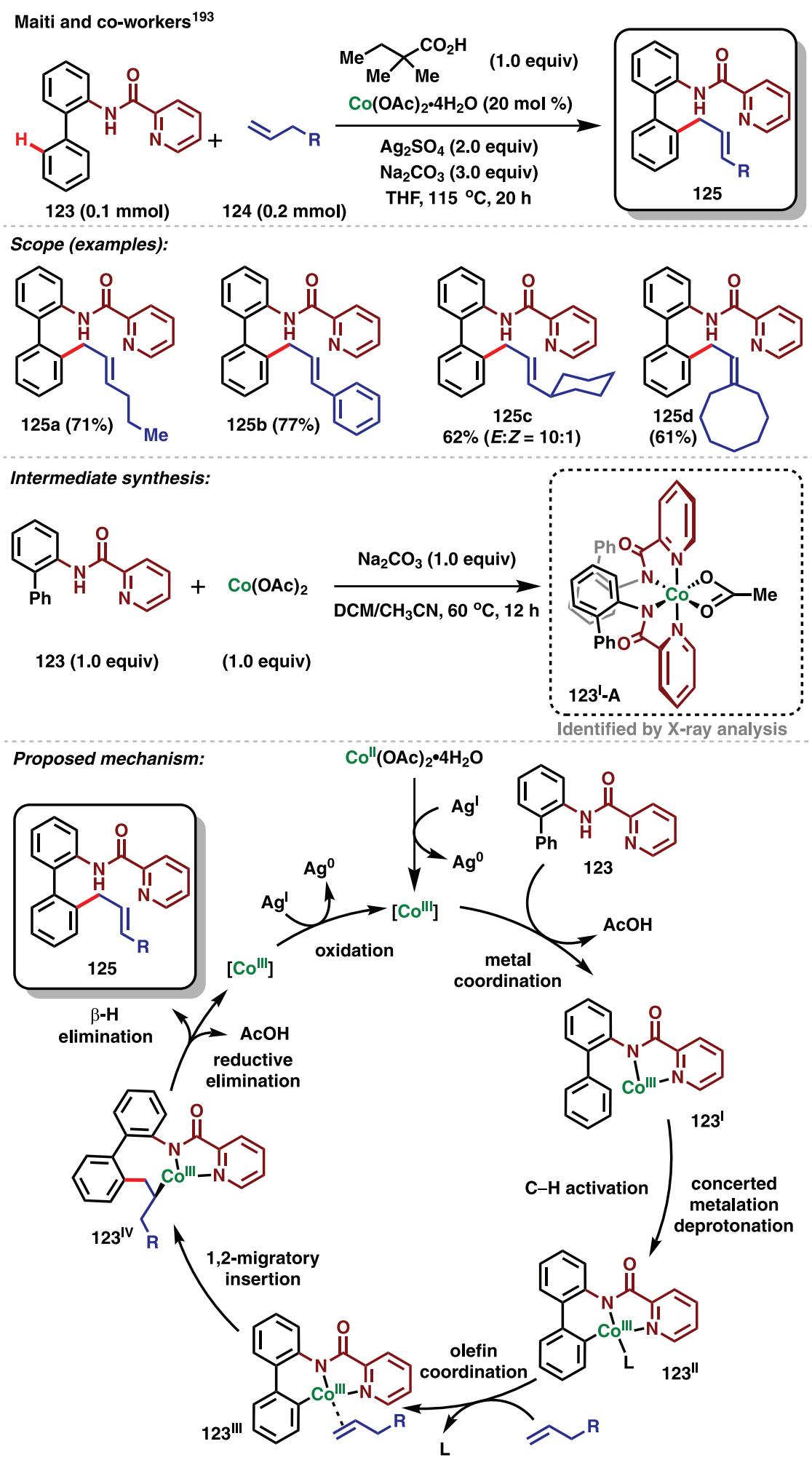

Scheme 25. Cobalt-catalyzed $\mathrm{C}-\mathrm{H}$ activation and its respective mechanistic studies. ${ }^{193}$

important activities against others. A good planning at the beginning of a project can save time if the desired structure matches with other known molecules that presented good activities.

\section{Derivatization}

The derivatization of a method means to find a plausible and useful sequence for that reaction to obtain a natural, pharmaceutical or any compound of interest. ${ }^{34,173,193,228-231}$ 


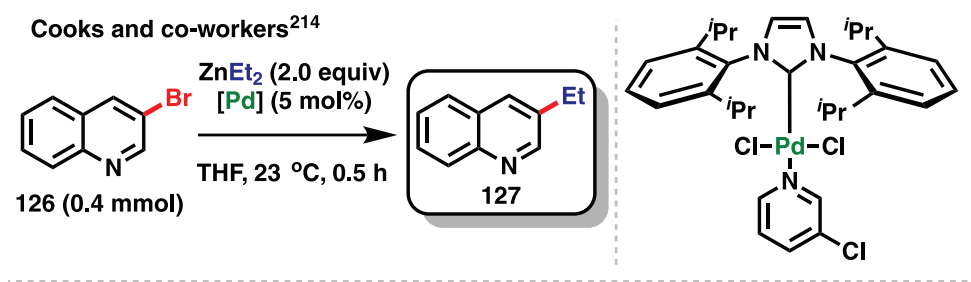

Identified intermediates by mass-spectrometry:

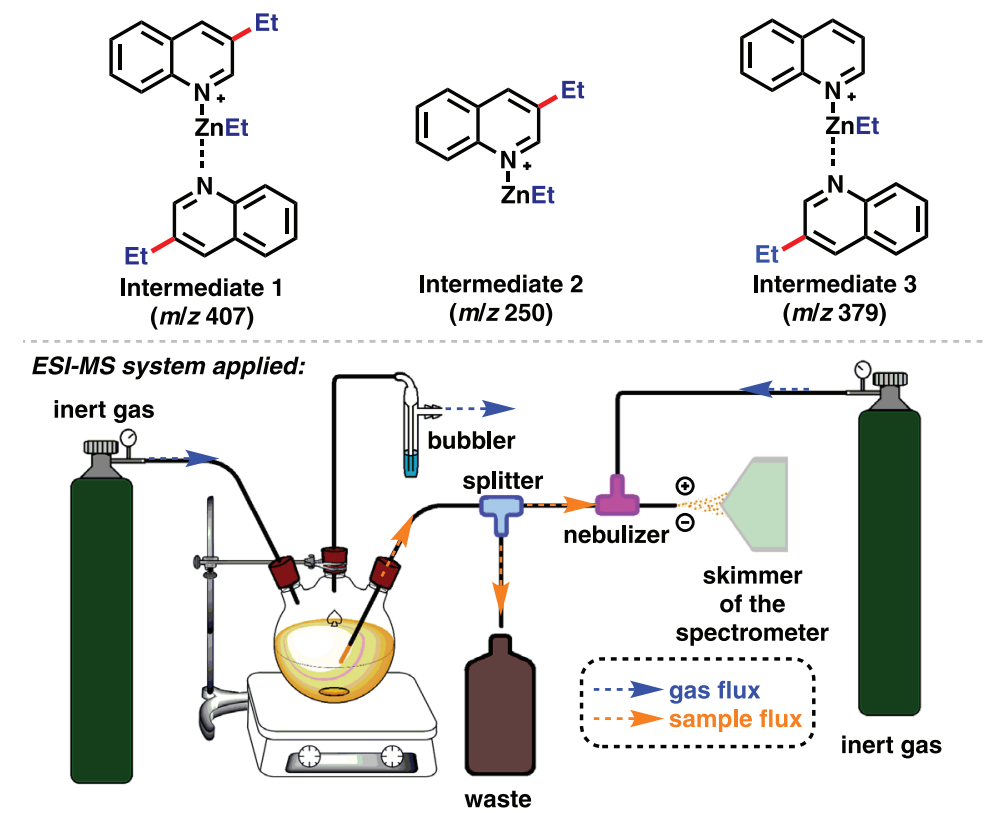

Scheme 26. Palladium-catalyzed Negishi cross-coupling reaction and electrospray ionization-mass spectrometry (ESI-MS) mechanistic studies. ${ }^{214}$

da Silva Júnior and co-workers ${ }^{220,227}$
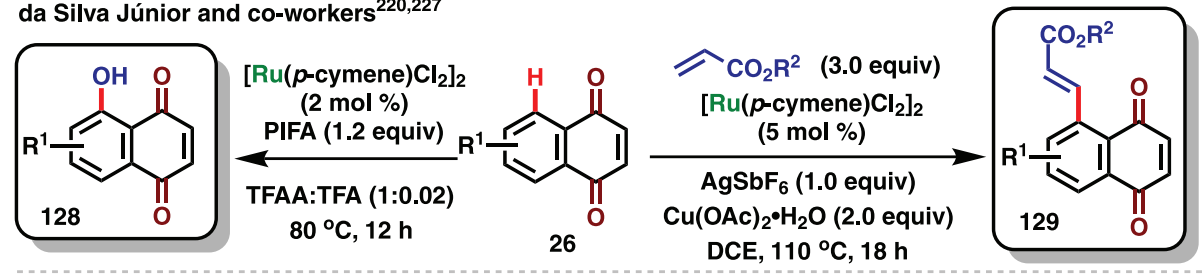

Scope (examples) and $I C_{50} / 24 h(\mu M)$ in parentesis:<smiles>Cc1cc2c(c(O)c1C)C(=O)C=CC2=O</smiles>

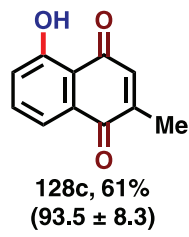<smiles>O=C1C(Cl)=CC(=O)c2c(O)cccc21</smiles><smiles>COC1=C(Cl)C(=O)c2c(O)cccc2C1=O</smiles>

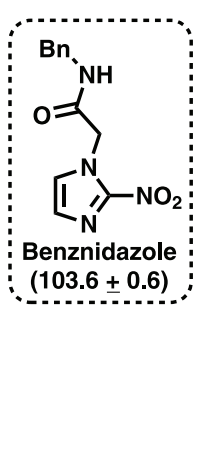

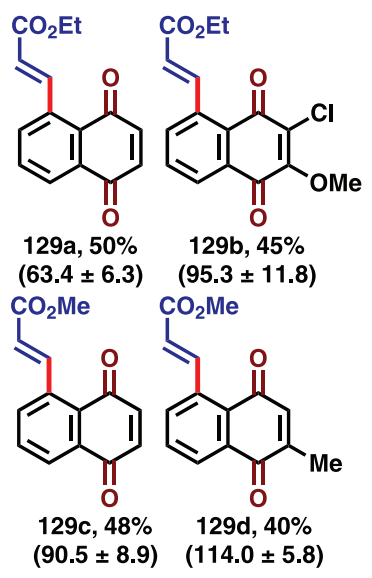

Scheme 27. Ruthenium-catalyzed C-H oxygenation ${ }^{220}$ and alkenylation ${ }^{227}$ of quinones and $\mathrm{IC}_{50} / 24 \mathrm{~h}$ against the T. cruzi.

Some products are only a precursor for a more complex and more important compound, and the methodology that is being published on the current work may only be a small building block of a more remarkable synthesis. For that, subsequent modifications can be tested, and, for obvious reasons, these modifications will depend basically on 
the structure and the amount of the product that will be obtained. For instance, Yu and co-workers ${ }^{228}$ described a palladium-catalyzed cyclization generating a succinimide that, afterward, could be submitted to two successful ringopening methods from which compounds 132 and $\mathbf{1 3 3}$ were obtained in good yields (Scheme 28).

Our group has presented two remarkable works ${ }^{232,233}$ providing examples of late-stage derivatization that can be applied once the $\mathrm{C}-\mathrm{H}$ activation. Separated works can collaborate on each other's importance as well. In the first one, in collaboration with Bower, ${ }^{232}$ a rhodium-catalyzed $\mathrm{C}-\mathrm{H}$ iodination was performed on naphthoquinoidal compounds 26, in which the carbonyl groups from the quinone itself work as an innate directing group. Once the iodination is completed, the second other work was published two years later. ${ }^{233}$ It showed a reasonable substitution in the presence of silver(I) salts, in which C-8 substituted naphthoquinoidal compounds 135 were achieved in moderate to excellent yields (Scheme 29). These two works together represent the crucial link that can happen when a whole idea of a large project is explored even in different opportunities.

\section{Conclusion}

In conclusion, these hints will help to develop an optimized condition for an innovative catalyzed $\mathrm{C}-\mathrm{H}$ activation, with desirable results. The recommendations described in this contribution are general and well-studied, which should be adopted by researchers working on natural product synthesis, pharmaceuticals synthesis, feedstocks, or methodology development in synthetic chemistry to discover new step- and atom-economical synthetic routes. The process of planning, executing and analyzing obtained data are essential for monitoring the $\mathrm{C}-\mathrm{H}$ activation step carefully to achieve well-characterized intermediates along with precise evidence. Likely, this review article can provide complete guidance and further insights through the $\mathrm{C}-\mathrm{H}$ activation step from catalyst loading to characterizations along with the mechanistic studies.

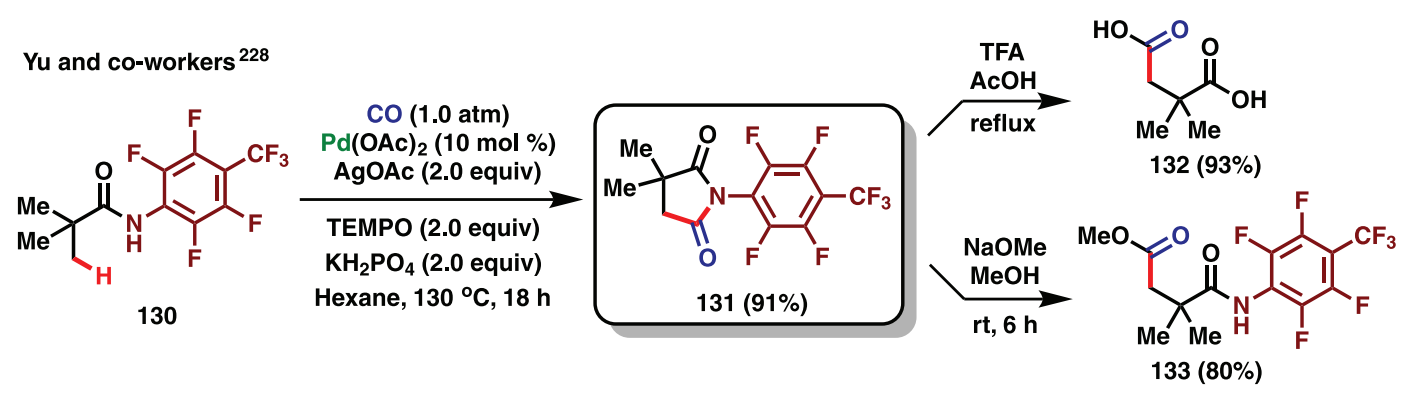

Scheme 28. Example of derivatization after a C-H activation reaction. ${ }^{228}$

da Silva Júnior and co-workers ${ }^{232,233}$

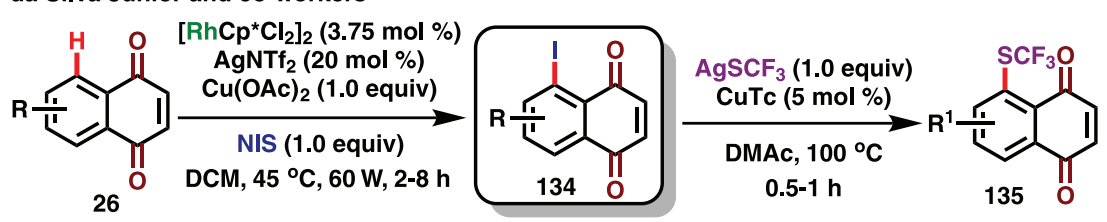

Scope (examples):
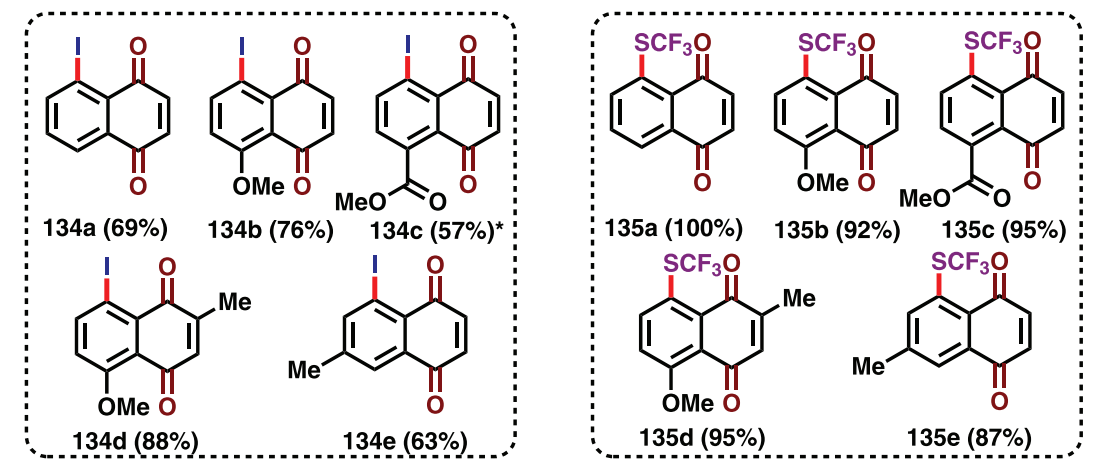

Scheme 29. Rhodium-catalyzed C-H iodination and its respective derivatization. ${ }^{232,233} *\left[\mathrm{RhCp}^{*} \mathrm{Cl}_{2}\right]_{2}(5.0 \mathrm{~mol} \%), \mathrm{AgNTf}_{2}(27.0 \mathrm{~mol} \%)$. 


\section{Acknowledgments}

E. N. da Silva Júnior acknowledges funding from CNPq (PQ 305741/2017-9), FAPEMIG (PPM-00638-16 and PPM-00635-18), INCT-Catálise/CNPq/FAPESC, Return Fellowship of the Alexander von Humboldt Foundation $(\mathrm{AvH})$ and the Royal Society of Chemistry for the research fund grant (R19-9781). C. L. M. Pereira thanks CNPq (PQ 309687/2018-7 and 405199/2016-3) and FAPEMIG (PPM-00630-18). P. Ghosh is thankful to IIT Bombay and PMRF India for instrumental and financial supports. D. Maiti is thankful to BRNS-India (RD/0118-BRNS000-002) for financial support. A special thanks to CAPES and DAAD for the PROBRAL exchange program (99999.008126/2015-01) and scholarships in Germany for R. L. Carvalho and G. G. Dias. We would like to thank Prof Marcelo S. Valle from Federal University of São João del Rei for the preparation of the graphical abstract image.

\section{Author Contributions}

Renato L. Carvalho, Gleiston G. Dias, Cynthia L. M. Pereira and Pintu Ghosh were responsible for preparation of the article, schemes, figures, selection of references and use of the material in the preparation of the article, revision of the material, preparation of graphical abstract and organization of the material to achieve the final result obtained. Debabrata Maiti and Eufrânio N. da Silva Júnior are group leaders and were responsible for designed the paper and prepared the manuscript, writing review and editing, supervision and funding acquisition.

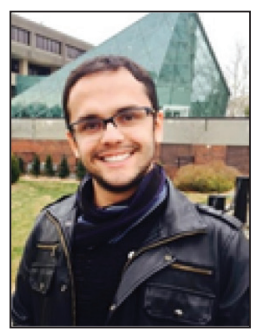

Renato L. de Carvalho received his bachelor's degree in Chemistry in 2017. In 2018 he concluded his MSc at Federal University of Minas Gerais under the supervision of Prof Dr Eufrânio N. da Silva Júnior and in the same year he started his PhD studies in the da Silva Júnior group working on development new methods involving $\mathrm{C}-\mathrm{H}$ annulation for achievement new quinoidal bioactive compounds. His research interests are focused on $\mathrm{C}-\mathrm{H}$ bond activation reactions. He is also interested on Medicinal Chemistry aiming at the synthesis of bioactive compounds.

Gleiston G. Dias received his bachelor's degree in Chemistry in 2014. In 2017 he concluded his MSc at Federal

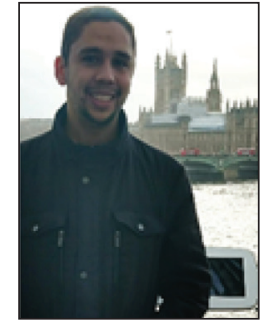

University of Minas Gerais under the supervision of Prof Dr Eufrânio N. da Silva Júnior and in the same year he started his PhD studies in the da Silva Júnior group working with catalysis and $\mathrm{C}-\mathrm{H}$ functionalization methods for achievement of new quinoidal bioactive compounds and fluorescence. His expertise involves development of fluorescent compounds for bioimaging and organic synthesis of new potential pharmacological quinones.

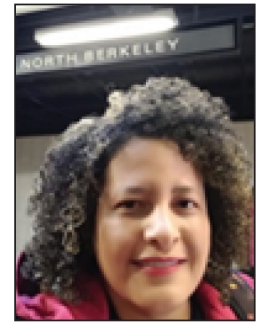

Cynthia L. M. Pereira received her PhD in Sciences (Chemistry) at Universidade Federal de Minas Gerais (UFMG) in 2003. She was a postdoctoral fellow at Université Pierre et Marie Curie, France (2004-2005). In 2005, she started her career as Professor at the Universidade Federal de Juiz de Fora, moving to UFMG in 2009. Recently, she worked as a Visiting Scholar at the University of California, Berkeley, USA (2019-2020). Her research interests are focused on the synthesis of coordination compounds, supramolecular chemistry and multifunctional materials.

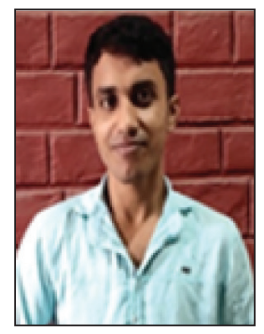

Pintu Ghosh was born and brought up in West Bengal, India. He has concluded his bachelor's studies from R. K. M Vivekananda Centenary College, West Bengal State University in 2018. After receiving his $M S c$ degree from IIT Kharagpur in 2020, he moved to IIT Bombay to start his PhD in the catalysis lab under the supervision of Prof Debabrata Maiti. His research interests are focused on $\mathrm{C}-\mathrm{H}$ bond functionalization reactions using metal or non-metal for the sustainable synthesis of important molecules.

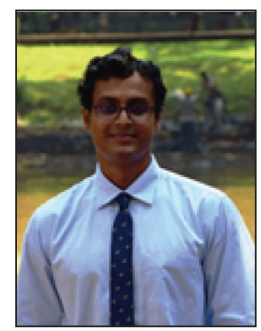

Debabrata Maiti received his PhD from John Hopkins University (USA) in 2008 under the supervision of Prof Kenneth D. Karlin. After postdoctoral studies at the Massachusetts Institute of Technology (MIT) with Prof Stephen L. Buchwald (2008-2010), he joined the Department of Chemistry at IIT Bombay in 2011. His research interests are focused on the development of new and sustainable synthetic and catalytic methods. 


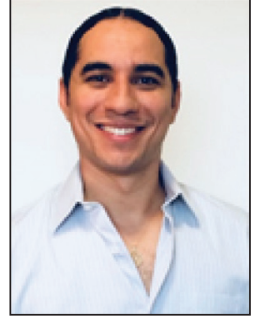

Eufrânio N. da Silva Júnior received his $P h D$ from University of Brasília (UnB) in 2009. In 2010, he started his independent career as Professor at the Federal University of Minas Gerais (UFMG). He is a member of the Brazilian Chemical Society and the Royal Society of Chemistry (RSC). He has received the RSC/BMOS Young Investigator Award (2015), Jones Travelling Fellowship (2016) and Capes-Humboldt Research Fellowship for experienced researchers (2018). His research interests are focused on $\mathrm{C}-\mathrm{H}$ bond activation reactions, organocatalysis, mechanistic investigations, and synthesis of heterocyclic and naphthoquinoidal bioactive and fluorescent compounds.

\section{References}

1. Dong, Z.; Wang, J.; Dong, G.; J. Am. Chem. Soc. 2015, 137, 5887.

2. Lu, Q.; Cembellín, S.; Greßies, S.; Singha, S.; Daniliuc, C. G.; Glorius, F.; Angew. Chem., Int. Ed. 2018, 57, 1399.

3. Li, S.; Ji, H.; Yang, L.; Li, G.; Nat. Commun. 2016, 7, 10443.

4. Shao, Q.; He, J.; Wu, Q.-F.; Yu, J.-Q.; ACS Catal. 2017, 7, 7777.

5. Ang, N. W. J.; Oliveira, J. C. A.; Ackermann, L.; Angew. Chem., Int. Ed. 2020, 59, 12842.

6. Yang, L.; Steinbock, R.; Scheremetjew, A.; Kuniyil, R.; Finger, L. H.; Messinis, A. M.; Ackermann, L.; Angew. Chem., Int. Ed. 2020, 59, 11130.

7. Caiuby, C. A. D.; Jesus, M. P.; Burtoloso, A. C. B.; J. Org. Chem. 2020, 85, 7433.

8. Zhang, L.; Wang, Y.; Zhang, L.; Chi, Z.; Yang, Y.; Zhang, Z.; Zhang, B.; Lin, J.; Wan, S.; Ind. Eng. Chem. Res. 2020, 59, 17357.

9. Wagh, G. D.; Autade, S. B.; Kulkarni, R. V.; Akamanchi, K. G.; New J. Chem. 2020, 44, 10554.

10. Kosri, C.; Kiatphuengporn, S.; Butburee, T.; Youngjun, S.; Thongratkaew, S.; Faungnawakij, K.; Yimsukanan, C.; Chanlek, N.; Kidkhunthod, P.; Wittayakun, J.; Khemthong, P.; Catal. Today, in press, DOI: 10.1016/j.cattod.2020.04.061.

11. Naikwadi, D. R.; Ravi, K.; Singh, A. S.; Advani, J. H.; Biradar, A. V.; ACS Omega 2020, 5, 14291.

12. Liu, N.; Qiao, N.; Liu, F.-S.; Wang, S.; Liang, Y.; J. Mol. Struct. 2020, 1218, 128537.

13. Rafique, J.; Saba, S.; Frizon, T. E. A.; Braga, A. L.; ChemistrySelect 2018, 3, 328.

14. Cherif, M.; Horchani, M.; Al-Ghamdi, Y. O.; Almalki, S. G.; Alqurashi, Y. E.; Jannet, H. N.; Romdhane, A.; J. Mol. Struct. 2020, 1220, 128685.

15. Ding, M.; Miao, Z.; Zhang, F.; Liu, J.; Shuai, X.; Zha, Z.; Cao, Z.; Biomater. Sci. 2020, 8, 4157.
16. Fakhree, A. A.; Ghasemi, Z.; Rahimi, M.; Shahrisa, A.; Appl. Organomet. Chem. 2020, 34, e5773.

17. Wang, N.; Saidhareddy, P.; Jiang, X.; Nat. Prod. Rep. 2020, 37, 246.

18. Kawamoto, Y.; Ozone, D.; Kobayashi, T.; Ito, H.; Eur. J. Org. Chem. 2020, 2020, 4050.

19. Miró, J.; Gensch, T.; Ellwart, M.; Han, S.-J.; Lin, H.-H.; Sigman, S.; Toste, F. D.; J. Am. Chem. Soc. 2020, 142, 6390.

20. Zhang, Z.; Smal, V.; Retailleau, P.; Voituriez, A.; Frison, G.; Marinetti, A.; Guinchard, X.; J. Am. Chem. Soc. 2020, 142, 3797.

21. Meng, Y.; Kong, Z.; Morken, J. P.; Angew. Chem., Int. Ed. 2020, 59,8456 .

22. Ellman, J. A.; Ackermann, L.; Shi, B.-F.; J. Org. Chem. 2019, 84, 12701.

23. Porey, S.; Zhang, X.; Bhowmick, S.; Singh, V. K.; Guin, S.; Paton, R. S.; Maiti, D.; J. Am. Chem. Soc. 2020, 142, 3762.

24. Mousseau, J. J.; Bull, J. A.; Charette, A. B.; Angew. Chem., Int. Ed. 2010, 49, 1115.

25. Rochette, É.; Courtemanche, M.-A.; Fontaine, F.-G.; Chem.-Eur. J. 2017, 23, 3567.

26. Azambuja, F.; Correia, C. R. D.; Quim. Nova 2011, 34, 1779.

27. Dimroth, O.; Ber. Dtsch. Chem. Ges. 1902, 35, 2032.

28. Janowicz, A. H.; Bergman, R. G.; J. Am. Chem. Soc. 1982, 104, 352.

29. Bailey, B. C.; Fan, H.; Baum, E. W.; Huffman, J. C.; Baik, M.H.; Mindiola, D. J.; J. Am. Chem. Soc. 2005, 127, 16016.

30. van der Boom, M. E.; Liou, S.-Y.; Shimon, L. J. W.; Ben-David, Y.; Milstein, D.; Inorg. Chim. Acta 2004, 357, 4015.

31. van der Donk, W. A.; Krebs, C.; Bollinger Jr., J. M.; Curr. Opin. Struct. Biol. 2010, 20, 673.

32. Nishikata, T.; Abela, A. R.; Huang, S.; Lipshutz, B. H.; J. Am. Chem. Soc. 2010, 132, 4978.

33. Kidwai, M.; Bansal, V.; Mishra, N. K.; Kumar, A.; Mozumdar, S.; Synlett 2007, 10, 1581.

34. Grohmann, C.; Wang, H.; Glorius, F.; Org. Lett. 2012, 14, 656.

35. Ma, W.; Dong, H.; Wang, D.; Ackermann, L.; Adv. Synth. Catal. 2017, 359, 966.

36. Brochetta, M.; Borsari, T.; Bag, S.; Jana, S.; Maiti, S.; Porta, A.; Werz, D. B.; Zanoni, G.; Maiti, D.; Chem.-Eur. J. 2019, 25, 10323.

37. Wang, P.; Farmer, M. E.; Yu, J.-Q.; Angew. Chem., Int. Ed. 2017, $56,5125$.

38. Lee, W.-C.; Chen, C.-H.; Liu, C.-Y.; Yu, M.-S.; Lin, Y.-H.; Ong, T.-G.; Chem. Commun. 2015, 51, 17104.

39. Dutta, U.; Maiti, S.; Pimparkar, S.; Maiti, S.; Gahan, L. R.; Krenske, E. H.; Lupton, D. W.; Maiti, D.; Chem. Sci. 2019, 10, 7426.

40. Shilov, A. E.; Shul'pin, G. B.; Chem. Rev. 1997, 97, 2879.

41. Ess, D. H.; Goddard III, W. A.; Periana, R. A.; Organometallics 2010, 29, 6459. 
42. Lin, Z.; Coord. Chem. Rev. 2007, 251, 2280.

43. Balcells, D.; Clot, E.; Eisenstein, O.; Chem. Rev. 2010, 110, 749.

44. Lersch, M.; Tilset, M.; Chem. Rev. 2005, 105, 2471.

45. Ritleng, V.; Sirlin, C.; Pfeffer, M.; Chem. Rev. 2002, 102, 1731.

46. Cundari, T. R.; Klinckman, T. R.; Wolczanski, P. T.; J. Am. Chem. Soc. 2002, 124, 1481.

47. Bennett, J. L.; Wolczanski, P. T.; J. Am. Chem. Soc. 1997, 119 , 10696.

48. Oxgaard, J.; Tenn, W. J.; Nielsen, R. J.; Periana, R. A.; Goddard, W. A.; Organometallics 2007, 26, 1565.

49. Lapointe, D.; Fagnou, K.; Chem. Lett. 2010, 39, 1118.

50. Boutadla, Y.; Davies, D. L.; Macgregor, S. A.; PobladorBahamonde, A. I.; Dalton Trans. 2009, 30, 5820.

51. Wang, H.; Moselage, M.; González, M. J.; Ackermann, L.; ACS Catal. 2016, 6, 2705.

52. Mei, R.; Loup, J.; Ackermann, L.; ACS Catal. 2016, 6, 793.

53. Ma, W.; Mei, R.; Tenti, G.; Ackermann, L.; Chem.-Eur. J. 2014, $20,15248$.

54. Brückl, T.; Baxter, R. D.; Ishihara, Y.; Baran, P. S.; Acc. Chem. Res. 2012, 45, 826.

55. Rosario, A. R.; Casola, K. K.; Oliveira, C. E. S.; Zeni, G.; Adv. Synth. Catal. 2013, 355, 2960.

56. Lyons, T. W.; Sanford, M. S.; Chem. Rev. 2010, 110, 1147.

57. Guerrero, I.; Correa, A.; Eur. J. Org. Chem. 2018, 44, 6034.

58. Arockiam, P. B.; Fischmeister, C.; Bruneau, C.; Dixneuf, P. H.; Green Chem. 2011, 13, 3075.

59. Patureau, F. W.; Glorius, F.; J. Am. Chem. Soc. 2010, 132, 9982.

60. Xiao, B.; Fu, Y.; Xu, J.; Gong, T.; Dai, J.; Yi, J.; Liu, L.; J. Am. Chem. Soc. 2010, 132, 468.

61. Drapeau, M. P.; Gooßen, L. J.; Chem.-Eur. J. 2016, 22, 18654.

62. Huang, Z.; Lim, H. N.; Mo, F.; Young, M. C.; Dong, G.; Chem. Soc. Rev. 2015, 44, 7764

63. Liu, X.; Park, H.; Hu, J.; Hu, Y.; Zhang, Q.; Wang, B.; Sun, B.; Yeung, K.; Zhang, F.; Yu, J-Q.; J. Am. Chem. Soc. 2017, 139, 888.

64. Chen, Z.; Wang, B.; Zhang, J.; Yu, W.; Liu, Z.; Zhang, Y.; Org. Chem. Front. 2015, 2, 1107.

65. Zhang, F.; Spring, D. R.; Chem. Soc. Rev. 2014, 43, 6906.

66. Rousseau, G.; Breit, B.; Angew. Chem., Int. Ed. 2011, 50, 2450.

67. Jardim, G. A. M.; Bower, J. F.; da Silva Júnior, E. N.; Org. Lett. 2016, 18, 4454.

68. Rej, S.; Ano, Y.; Chatani, N.; Chem. Rev. 2020, 120, 1788.

69. Leow, D.; Li, G.; Mei, T. S.; Yu, J. Q.; Nature 2012, 486, 518.

70. Bag, S.; Patra, T.; Modak, A.; Deb, A.; Maity, S.; Dutta, U.; Dey, A.; Kancherla, R.; Maji, A.; Hazra, A.; Bera, M.; Maiti, D.; J. Am. Chem. Soc. 2015, 137, 11888.

71. Dey, A.; Sinha, S. K.; Achar, T. K.; Maiti, D.; Angew. Chem., Int. Ed. 2019, 58, 10820.

72. Sharma, R.; Thakur, K.; Kumar, R.; Kumar, I.; Sharma, U.; Catal. Rev.: Sci. Eng. 2015, 57, 345.
73. Sinha, S. K.; Sasmal, S.; Lahiri, G. K.; Maiti, D.; J. Indian Chem. Soc. 2018, 95, 743.

74. Ackermann, L.; Vicente, R.; Kapdi, A. R.; Angew. Chem., Int. Ed. 2009, 48, 9792.

75. Hussaina, I.; Singh, T.; Adv. Synth. Catal. 2014, 356, 1661.

76. Das, R.; Kapur, M.; Asian J. Org. Chem. 2018, 7, 1524.

77. Park, Y.; Kim, Y.; Chang, S.; Chem. Rev. 2017, 117, 9247.

78. Dong, Z.; Ren, Z.; Thompson, S. J.; Xu, Y.; Dong, G.; Chem. Rev. 2017, 117, 9333.

79. Das, P.; Saha, D.; Guin, J.; ACS Catal. 2016, 6, 6050.

80. Perumgani, P. C.; Parvathaneni, S. P.; Babu, G. V. S.; Srinivas, K.; Mandapati, M. R.; Catal. Lett. 2018, 148, 1067.

81. Li, J.; Ackermann, L.; Angew. Chem., Int. Ed. 2015, 54, 3635.

82. Zhang, H.; Yang, Z.; Liu, J.; Yu, X.; Wang, Q.; Wu, Y.; Org. Chem. Front. 2019, 6, 967.

83. Wan, T.; Du, S.; Pi, C.; Wang, Y.; Li, R.; Wu, Y.; Cui, X.; ChemCatChem 2019, 11, 3791.

84. Su, L.; Guo, D.-D.; Li, B.; Guo, S.-H.; Pan, G.-F.; Gao, Y.-R.; Wang, Y.-Q.; ChemCatChem 2017, 9, 2001.

85. Xiao, Y.; Wang, S.; Liu, J.; Zhang, H.; Xu, Y.; Tetrahedron Lett. 2019, 60, 1317.

86. Zhou, C.; Zhao, J.; Guo, W.; Jiang, J.; Wang, J.; Org. Lett. 2019 , 21,9315 .

87. Cheng, K.; Yao, B.; Zhao, J.; Zhang, Y.; Org. Lett. 2008, 10, 5309.

88. Peng, J.; Chen, M.; Xie, Z.; Luo, S.; Zhu, Q.; Org. Chem. Front. 2014, 1, 777 .

89. Jiang, X.; Zeng, Z.; Hua, Y.; Xu, B.; Shen, Y.; Xiong, J.; Qiu, H.; Wu, Y.; Hu, T.; Zhang, Y.; J. Am. Chem. Soc. 2020, 142, 15585.

90. Reddy, V. P.; Qiu, R.; Iwasaki, T.; Kambe, N.; Org. Lett. 2013, 15, 1290.

91. Clennan, M. M.; Clennan, E. L.; J. Chem. Educ. 2005, 82, 1676.

92. Franz, J. F.; Kraus, W. B.; Zeitler, K.; Chem. Commun. 2015, 51,8280 .

93. McBride, E. M.; Keller, R. E.; Verbeck, G. F.; Int. J. Mass Spectrom. 2018, 428, 55.

94. Richter, G.; Schober, C.; Süß, R.; Fuchs, B.; Müller, M.; Schiller, J.; J. Chromatogr. B 2008, 867, 233.

95. Andrade, A. P. S.; Arantes, L. M.; Kadooca, J. Y.; Carvalho, R. L.; de Fátima, Â.; Sabino, A. A.; ChemistrySelect 2016, 1, 886.

96. Feriante, C. H.; Jhulki, S.; Evans, A. M.; Dasari, R. R.; Slicker, K.; Dichtel, W. R.; Marder, S. R.; Adv. Mater. 2020, 32, 1905776.

97. Matsidik, R.; Luzio, A.; Hameury, S.; Komber, H.; McNeill, C. R.; Caironi, M.; Sommer, M.; J. Mater. Chem. C 2016, 4, 10371.

98. Malik, A. A.; Dangroo, N. A.; Ara, T.; ChemistrySelect 2020, 5,12965 .

99. Questell-Santiago, Y. M.; Yeap, J. H.; Amiri, M. T.; le Monier, B. P.; Luterbacher, J. S.; ACS Sustainable Chem. Eng. 2020, 8, 1709. 
100. Grobelny, A. L.; Verdu, F. A.; Groeneman, R. H.; CrystEngComm 2017, 19, 3562.

101. Das, D.; Poddar, P.; Maity, S.; Samanta, R.; J. Org. Chem. 2017, $82,3612$.

102. McAteer, D. C.; Javed, E.; Huo, L.; Huo, S.; Org. Lett. 2017, 19, 1606.

103. Zhou, X.; Luo, Y.; Kong, L.; Xu, Y.; Zheng, G.; Lan, Y.; Li, X.; ACS. Catal. 2017, 7, 7296.

104. Still, W. C.; Kahn, M.; Mitra, A.; J. Org. Chem. 1978, 43, 2923.

105. Skorupa, A.; Gierak, A.; J. Planar Chromatogr---Mod. TLC 2011, 24, 274.

106. Jamil, M. A. R.; Touchy, A. S.; Poly, S. S.; Rashed, M. N.; Siddiki, S. M. A. H.; Toyao, T.; Maeno, Z.; Shimizu, K.-i.; Fuel Process. Technol. 2020, 197, 106204.

107. Zhu, Z.; Bai, S.; Shang, H.; Tian, Q.; Sun, J.; Wu, X.; Liu, J.; Microporous Mesoporous Mater. 2020, 293, 109768.

108. Bahia, S. B. B. B.; Vargas, C. A. A.; Denadai, Â. M. L.; Araujo, M. H.; Moraes, A. H.; Brandão, T. A. S.; J. Phys. Chem. C 2020, 124,17111

109. Gocan, S.; J. Liq. Chromatogr. Relat. Technol. 2004, 27, 1105.

110. Zhang, J.; Shi, D.; Zhang, H.; Xu, Z.; Bao, H.; Jin, H.; Liu, Y.; Tetrahedron 2017, 73, 154.

111. Tang, S.; Zhou, D.; Deng, Y.; Li, Z.; Yang, Y.; He, J.; Wang, Y.; Sci. China: Chem. 2015, 58, 684.

112. Botero, W. B.; de Amorim, M. R.; Carlos, I. Z.; Polesi, M. C.; dos Santos, L. C.; J. Braz. Chem. Soc. 2020, 31, 364.

113. Tomassini, L.; Frezza, C.; Ventrone, A.; Serafini, M.; Nicoletti, M.; Piovano, M.; Biochem. Syst. Ecol. 2020, 91, 104073.

114. Cusano, E.; Cagliani, L. R.; Consonni, R.; Simonato, B.; Zapparoli, G.; LWT--Food Sci. Technol. 2020, 118, 108771.

115. Labrado, D.; Ferrero, S.; Caballero, I.; Alvarez, C. M.; Villafañe, F.; Blanco, C. A.; J. Sci. Food Agric. 2020, 100, 3971.

116. Lee, S.; Lee, H.; Tan, K. L.; J. Am. Chem. Soc. 2013, 135, 18778.

117. Silva Júnior, E. N.; Carvalho, R. L.; Almeida, R. G.; Rosa, L. G.; Fantuzzi, F.; Rogge, T.; Costa, P. M. S.; Pessoa, C.; Jacob, C.; Ackermann, L.; Chem.-Eur. J. 2020, 26, 10981.

118. Roman, D. S.; Charette, A. B.; Org. Lett. 2013, 15, 4394.

119. Miura, W.; Hirano, K.; Miura, M.; Org. Lett. 2016, 18, 3742.

120. Fan, Z.; Li, J.; Lu, H.; Wang, D.-Y.; Wang, C.; Uchiyama, M.; Zhang, A.; Org. Lett. 2017, 19, 3199.

121. Grosheva, D.; Cramer, N.; Angew. Chem., Int. Ed. 2018, 57, 13644.

122. Singh, K. S.; Catalysts 2019, 9, 173.

123. Kanchupalli, V.; Shukla, R. K.; Singh, A.; Volla, C. M. R.; Eur. J. Org. Chem. 2020, 2020, 4494.

124. Song, L.; Ni, D.; Jia, S.; Pi, R.; Dong, S.; Yang, F.; Tang, J.; Liu, S.; Org. Lett. 2020, 22, 1846.

125. Zhang, Q.-W.; An, K.; Liu, L.-C.; Guo, S.; Jiang, C.; Guo, H.; He, W.; Angew. Chem., Int. Ed. 2016, 55, 6319.
126. Esteruelas, M. A.; Martínez, A.; Oliván, M.; Oñate, E.; Chem.Eur. J. 2020, 26, 12632.

127. Boebel, T. A.; Hartwig, J. F.; J. Am. Chem. Soc. 2008, 130, 7534.

128. Cui, X.-F.; Qiao, X.; Wang, H.-S.; Huang, G.-S.; J. Org. Chem. 2020, 85, 13157.

129. Hennessy, E. J.; Buchwald, S. L.; J. Am. Chem. Soc. 2003, 125, 12084.

130. Gu, S.; Chen, C.; Chen, W.; J. Org. Chem. 2009, 74, 7203.

131. Neufeldt, S. R.; Sanford, M. S.; Acc. Chem. Res. 2012, 45, 936.

132. Liu, P. M.; Frost, C. G.; Org. Lett. 2013, 15, 5862.

133. Ackermann, L.; Fenner, S.; Org. Lett. 2011, 13, 6548.

134. Kozhushkov, S. I.; Ackermann, L.; Chem. Sci. 2013, 4, 886.

135. Gallego, D.; Baquero, E. A.; Open Chem. 2018, 16, 1001.

136. Tzouras, N. V.; Stamatopoulos, I. K.; Papastavrou, A. T.; Liori, A. A.; Vougioukalakis, G. C.; Coord. Chem. Rev. 2017, 343, 25.

137. Ding, Z.; Yoshikai, N.; Angew. Chem., Int. Ed. 2012, 51, 4698.

138. Ruan, Z.; Sauermann, N.; Manoni, E.; Ackermann, L.; Angew. Chem., Int. Ed. 2017, 56, 3172.

139. Kimura, N.; Kochi, T.; Kakiuchi, F.; J. Am. Chem. Soc. 2017, $139,14849$.

140. Chen, X.; Hao, X.-S.; Goodhue, C. E.; Yu, J.-Q.; J. Am. Chem. Soc. 2006, 128, 6790.

141. Yoshida, Y.; Kurahashi, T.; Matsubara, S.; Chem. Lett. 2011, 40, 1140.

142. Hazra, S.; Hirano, K.; Miura, M.; Asian J. Org. Chem. 2019, 8, 1097.

143. Armarego, W. L. F.; Purification of Laboratory Chemicals, $8^{\text {th }}$ ed.; Butterworth-Heinemann: Oxford, 2017.

144. Budnikova, Y. H.; Dudkina, Y. B.; Khrizanforov, M. N.; Inorganics 2017, 5, 70.

145. Campbell, A. N.; Stahl, S. S.; Acc. Chem. Res. 2012, 45, 851.

146. Shi, Z.; Zhang, C.; Tanga, C.; Jiao, N.; Chem. Soc. Rev. 2012 , 41, 3381 .

147. Feng, W.; Wang, T.; Liu, D.; Wang, X.; Dang, Y.; ACS Catal. 2019, 9, 6672.

148. Bhaskararao, B.; Singh, S.; Anand, M.; Verma, P.; Prakash, P.; Malakar, A. C. S.; Schaefer, H. F.; Sunoj, R. B.; Chem. Sci. 2020, 11, 208.

149. Chen, X.-R.; Zhang, S.-Q.; Meyer, T. H.; Yang, C.-H.; Zhang, Q.-H.; Liu, J.-R.; Xu, H.-J.; Cao, F.-H.; Ackermann, L.; Hong, X.; Chem. Sci. 2020, 11, 5790.

150. Sherikar, M. S.; Kapanaiah, R.; Lanke, V.; Prabhu, K. R.; Chem. Commun. 2018, 54, 11200.

151. Lai, R.; Wu, X.; Lv, S.; Zhang, C.; He, M.; Chen, Y.; Wang, Q.; Hai, L.; Wu, Y.; Chem. Commun. 2019, 55, 4039.

152. Muniraj, N.; Kumar, A.; Prabhu, K. R.; Adv. Synth. Catal. 2020, 362,152 .

153. Yu, Y.; Chakraborty, P.; Song, J.; Zhu, L.; Li, C.; Huang, X.; Nat. Commun. 2020, 11, 461. 
154. Hunter, C. J.; Boyd, M. J.; May, G. D.; Fimognari, R.; J. Org. Chem. 2020, 85, 8732.

155. Oliveira, J. A. C.; Kiala, G.; Siopa, F.; Bernard, A.; Gontard, G.; Oble, J.; Afonso, C. A. M.; Poli, G.; Tetrahedron 2020, 76, 131182.

156. Patil, V. V.; Shankarling, G. S.; J. Org. Chem. 2015, 80, 7876.

157. Han, X.; Kong, L.; Feng, J.; Li, X.; Chem. Commun. 2020, 56, 5528.

158. Bierschenk, S. M.; Bergman, R. G.; Raymond, K. N.; Toste, F. D.; J. Am. Chem. Soc. 2020, 142, 733.

159. Yang, J.; Yang. T.; Luo, Y.; He, J.; Shi, J.; Peng, A.; Lett. Org. Chem. 2011, 8, 258.

160. Zhang, J.; Li, S.; Deng, G.-J.; Gong, H.; ChemCatChem 2018 , 10, 376 .

161. Maiti, S.; Mal, P.; Synth. Commun. 2014, 44, 3461.

162. Chassaing, S.; Isorez-Mahler, G.; Kueny-Stotz, M.; Brouillard, R.; Tetrahedron 2015, 71, 3066.

163. Boehm, P.; Roediger, S.; Bismuto, A.; Morandi, B.; Angew. Chem., Int. Ed. 2020, 59, 17887.

164. Purohit, G.; Rawat, D. S.; Reiser, O.; ChemCatChem 2020, 12 , 569.

165. Pattanaik, S.; Gunanathan, C.; Chem. Commun. 2020, 56, 7345.

166. Rodriguez, J.; Adet, N.; Saffon-Merceron, N.; Bourissou, D.; Chem. Commun. 2020, 56, 94.

167. Liu, S.; Li, S.; Shen, X.; Wang, Y.; Du, J.; Chen, B.; Han, B.; Liu, H.; Chem. Commun. 2020, 56, 2638.

168. Toniolo, D.; Bobbink, F. D.; Dyson, P. J.; Mazzanti, M.; Helvetica 2020, 103, e1900258.

169. Schlagbauer, M.; Kallmeier, F.; Irrgang, T.; Kempe, R.; Angew. Chem., Int. Ed. 2020, 132, 1501.

170. Shi, L.; Wang, B.; Org. Lett. 2016, 18, 2820.

171. Zhang, L.; Zhao, C.; Liu, Y.; Xu, J.; Xu, X.; Jin, Z.; Angew. Chem., Int. Ed. 2017, 56, 12245.

172. Xu, J.; Sharma, N.; Sharma, U. K.; Li, Z.; Song, G.; der Eycken, E. V. V.; Adv. Synth. Catal. 2015, 357, 2615.

173. Wang, S.-G.; Liu, Y.; Cramer, N.; Angew. Chem., Int. Ed. 2019 , $58,18136$.

174. Yang, G.; Zhu, D.; Wang, P.; Tang, R.-Y.; Yu, J.-Q.; Chem.-Eur. J. 2018, 24, 3434.

175. Tran, A. T.; Yu, J.-Q.; Angew. Chem., Int. Ed. 2017, 56, 10530.

176. Ye, M.; Edmunds, A. J. F.; Morris, J. A.; Sale, D.; Zhang, Y.; Yu, J.-Q.; Chem. Sci. 2013, 4, 2374.

177. Modak, A.; Mondal, A.; Watile, R.; Mukherjee, S.; Maiti, D.; Chem. Commun. 2016, 52, 13916.

178. Guin, S.; Deb, A.; Dolui, P.; Chakraborty, S.; Singh, V. K.; Maiti, D.; ACS Catal. 2018, 8, 2664.

179. Wang, H.; Li, G.; Engle, K. M.; Yu, J.-Q.; Davies, H. M. L.; J. Am. Chem. Soc. 2013, 135, 6774.

180. Choi, I.; Messinis, A. M.; Ackermann, L.; Angew. Chem., Int. Ed. 2020, 59, 12534.
181. Messinis, A. M.; Finger, L. H.; Hu, L.; Ackermann, L.; J. Am. Chem. Soc. 2020, 142, 13102.

182. Korvorapun, K.; Struwe, J.; Zangarelli, A.; Kuniyil, R.; Casnati, A.; Waeterschoot, M.; Ackermann, L.; Angew. Chem., Int. Ed. 2020, 59, 18103.

183. Liang, Y.-F.; Müller, V.; Liu, W.; Münch, A.; Stalke, D.; Ackermann, L.; Angew. Chem., Int. Ed. 2017, 56, 9415.

184. Garlets, Z. J.; Hicks, E. F.; Fu, J.; Voight, E. A.; Davies, H. M. L.; Org. Lett. 2019, 21, 4910.

185. Pham, M. V.; Ye, B.; Cramer, N.; Angew. Chem., Int. Ed. 2012, 51,10610 .

186. Zhou, X.; Yu, S.; Kong, L.; Li, X.; ACS Catal. 2016, 6, 647.

187. Liu, Y.-J.; Liu, Y.-H.; Zhang, Z.-Z.; Yan, S.-Y.; Chen, K.; Shi, B.-F.; Angew. Chem., Int. Ed. 2016, 55, 13859.

188. Chen, K.; Li, X.; Zhang, S.-Q.; Shi, B.-F.; Chem. Commun. 2016, 52, 1915.

189. Chen, K.; Li, X.; Zhang, S.-Q.; Shi, B.-F.; Org. Chem. Front. 2016, 3, 204.

190. Ding, Q.; Ye, S.; Cheng, G.; Wang, P.; Farmer, M. E.; Yu, J.-Q.; J. Am. Chem. Soc. 2017, 139, 417.

191. Yu, C.-B.; Li, X.; Zhou, Y.-G.; Asian J. Org. Chem. 2019, 8, 1118.

192. Yu, C.-B.; Wang, J.; Zhou, Y.-G.; Org. Chem. Front. 2018, 5, 2805.

193. Baccalini, A.; Vergura, S.; Dolui, P.; Maiti, S.; Dutta, S.; Maity, S.; Khan, F. F.; Lahiri, G. K.; Zanoni, G.; Maiti, D.; Org. Lett. 2019, $21,8842$.

194. Chu, L.; Wang, X.-C.; Moore, C. E.; Rheingold, A. L.; Yu, J.-Q.; J. Am. Chem. Soc. 2013, 135, 16344.

195. Zhu, D.; Yang, G.; He, J.; Chu, L.; Chen, G.; Gong, W.; Chen, K.; Eastgate, M. D.; Yu, J.-Q.; Angew. Chem., Int. Ed. 2015, 54, 2497.

196. Li, B.; Bheeter, C. B.; Darcel, C.; Dixneuf, P. H.; Top. Catal. 2014, 57, 833.

197. Chan, K. S. L.; Fu, H.-Y.; Yu, J.-Q.; J. Am. Chem. Soc. 2015, 137, 2042.

198. Flegeau, E. F.; Bruneau, C.; Dixneuf, P. H.; Jutand, A.; J. Am. Chem. Soc. 2011, 133, 10161.

199. Fabre, I.; von Wolff, N.; le Duc, G.; Flegeau, E. F.; Bruneau, C.; Dixneuf, P. H.; Jutand, A.; Chem.-Eur. J. 2013, 19, 7595.

200. Newton, C. G.; Braconi, E.; Kuziola, J.; Wodrich, M. D.; Cramer, N.; Angew. Chem., Int. Ed. 2018, 57, 11040.

201. Hu, X.-X.; Liu, J.-B.; Wang, L.-L.; Huang, F.; Sun, C.-Z.; Chen, D.-Z.; Org. Chem. Front. 2018, 5, 1670.

202. Mei, R.; Wang, H.; Warratz, S.; Macgregor, S. A.; Ackermann, L.; Chem.-Eur. J. 2016, 22, 6759.

203. Xu, Y.; Young, M. C.; Wang, C.; Magness, D. M.; Dong, G.; Angew. Chem., Int. Ed. 2016, 55, 9084.

204. He, C.; Gaunt, M. J.; Chem. Sci. 2017, 8, 3586.

205. Dang, Y.; Qu, S.; Wang, Z.-X.; Wang, X.; J. Am. Chem. Soc. 2014, 136, 986. 
206. Dang, Y.; Qu, S.; Nelson, J. W.; Pham, H. D.; Wang, Z.-X.; Wang, X.; J. Am. Chem. Soc. 2015, 137, 2006.

207. Yang, Y.-F.; Chen, G.; Hong, X.; Yu, J.-Q.; Houk, K. N.; J. Am. Chem. Soc. 2017, 139, 8514.

208. Maity, S.; Kancherla, R.; Dhawa, U.; Hoque, E.; Pimparkar, S.; Maiti, D.; ACS Catal. 2016, 6, 5493.

209. Das, D.; Biswas, A.; Karmakar, U.; Chand, S.; Samanta, R.; J. Org. Chem. 2016, 81, 842.

210. Li, Y.; Xie, F.; Li, X.; J. Org. Chem. 2016, 81, 715.

211. Yang, X.-F.; Hu, X.-H.; Feng, C.; Loh, T.-P.; Chem. Commun. 2015, 51, 2532.

212. Adlhart, C.; Hinderling, C.; Baumann, H.; Chen, P.; J. Am. Chem. Soc. 2000, 122, 8204.

213. Schröder, D.; Acc. Chem. Res. 2012, 45, 1521.

214. Yan, X.; Sokol, E.; Li, X.; Li, G.; Xu, S.; Cooks, R. G.; Angew. Chem., Int. Ed. 2014, 53, 5931.

215. Smith, G.; Leary, J. A.; J. Am. Chem. Soc. 1998, 120, 13046.

216. Hoffmann, T.; Hofmann, D.; Klumpp, E.; Küppers, S.; Anal. Bioanal. Chem. 2011, 399, 1859.

217. Tsednee, M.; Huang, Y.-C.; Chen, Y.-R.; Yeh, K.-C.; Sci. Rep. 2016, 6, 26785.

218. Jardim, G. A. M.; da Cruz, E. H. G.; Valença, W. O.; Lima, D. J. B.; Cavalcanti, B. C.; Pessoa, C.; Rafique, J.; Braga, A. L.; Jacob, C.; da Silva Júnior, E. N.; Molecules 2018, 23, 83.

219. Mahajan, P. S.; Humne, V. T.; Tanpure, S. D.; Mhaske, S. B.; Org. Lett. 2016, 18, 3450.

220. Dias, G. G.; Rogge, T.; Kuniyil, R.; Jacob, C.; Menna-Barreto, R. F. S.; da Silva Júnior, E. N.; Ackermann, L.; Chem. Commun. 2018, 54, 12840.
221. da Silva, F. C.; de Souza, M. C. B. V.; Frugulhetti, I. I. P.; Castro, H. C.; Souza, S. L. O.; Souza, T. M. L.; Rodrigues, D. Q.; Souza, A. M. T.; Abreu, P. A.; Passamani, F.; Rodrigues, C. R.; Ferreira, V. F.; Eur. J. Med. Chem. 2009, 44, 373.

222. McKee, D. L.; Sternberg, A.; Stange, U.; Laufer, S.; Naujokat, C.; Pharm. Res. 2020, 157, 104859.

223. Schmunis, G. A.; Yadon, Z. E.; Acta Trop. 2010, 115, 14.

224. Jackson, Y.; Herrera, V. M.; Gascon, J.; Bull. W. H. O. 2014, 92,771 .

225. Conteh, L.; Engels, T.; Molyneux, D. H.; Lancet 2010, 375, 239.

226. Rassi, A.; Marin-Neto, J. A.; Lancet 2010, 375, 1388.

227. Dias, G. G.; do Nascimento, T. A.; de Almeida, A. K. A.; Bombaça, A. C. S.; Menna-Barreto, R. F. S.; Jacob, C.; Warratz, S.; da Silva Júnior, E. N.; Ackermann, L.; Eur. J. Org. Chem. 2019, 2019, 2344.

228. Yoo, E. J.; Wasa, M.; Yu, J.-Q.; J. Am. Chem. Soc. 2010, 132, 17378.

229. Saget, T.; Perez, D.; Cramer, N.; Org. Lett. 2013, 15, 1354.

230. Wang, D.-H.; Engle, K. M.; Shi, B.-F.; Yu, J.-Q.; Science 2010 , 327,315 .

231. Yamaguchi, J.; Yamaguchi, A. D.; Itami, K.; Angew. Chem., Int. Ed. 2012, 51, 8960.

232. Jardim, G. A. M.; da Silva Júnior, E. N.; Bower, J. F.; Chem. Sci. 2016, 7, 3780

233. Jardim, G. A. M.; Oliveira, W. X. C.; Freitas, R. P.; MennaBarreto, R. F. S.; Silva, T. L.; Goulart, M. O. F.; da Silva Júnior, E. N.; Org. Biomol. Chem. 2018, 16, 1686.

Submitted: November 24, 2020 Published online: February 19, 2021 